Aus der Abteilung Primatengenetik

(Prof. Dr. rer. nat. L. Walter)

im Deutschen Primatenzentrum

in Göttingen

\title{
Untersuchungen zur Funktion des tripartite-motif-22 (TRIM22)-Proteins
}

\author{
INAUGURAL-DISSERTATION \\ zur Erlangung des Doktorgrades \\ der Medizinischen Fakultät \\ der Georg-August-Universität zu Göttingen
}

vorgelegt von

Cornelius Simon Deuschl

aus

Freiburg im Breisgau

Göttingen 2013 
Dekan:

1. Berichterstatter:

2. Berichterstatter/in:
Prof. Dr. rer. nat. H. K. Kroemer

Prof. Dr. rer. nat. L. Walter

Prof. Dr. rer. nat. M. Bohnsack

Tag der mündlichen Prüfung: 21. Oktober 2013 
Meiner Familie. 


\section{Inhaltsverzeichnis}

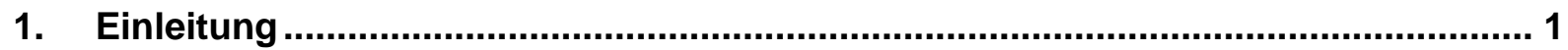

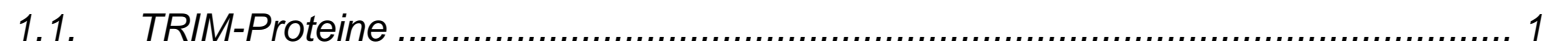

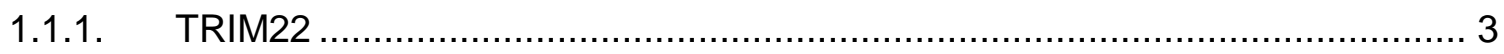

1.2. Der eukaryotische Zellzyklus.................................................................... 7

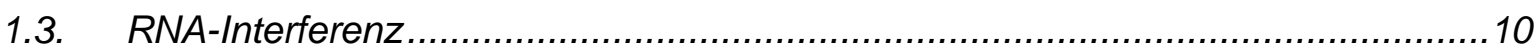

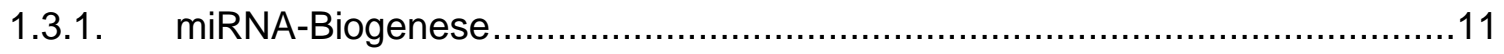

1.3.2. Die RNAi als innovative Therapieform ...................................................... 14

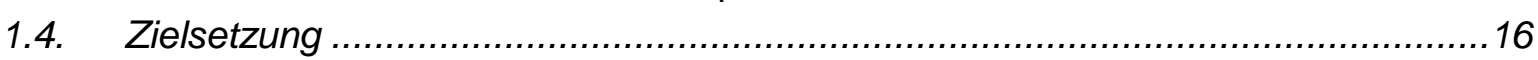

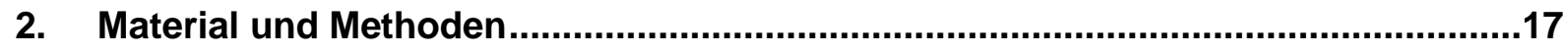

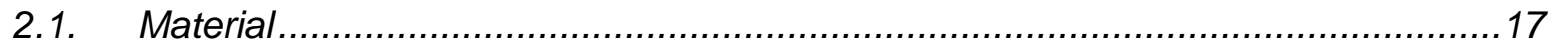

2.1.1. Verwendete Geräte ...................................................................... 17

2.1.2. Zelllinien und Kulturmedien ................................................................ 18

2.1.3. Standardchemikalien und Verbrauchsmaterialien....................................... 19

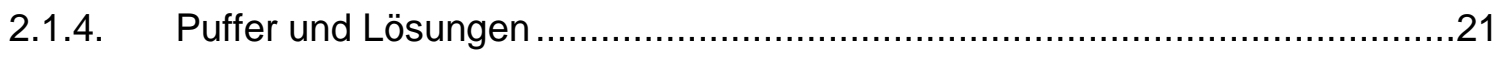

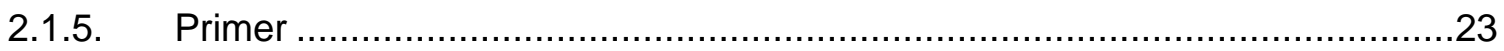

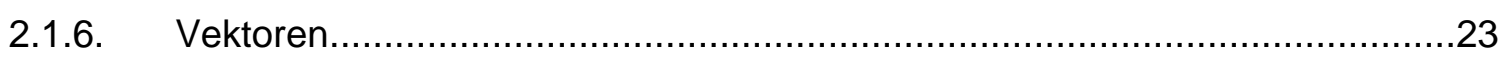

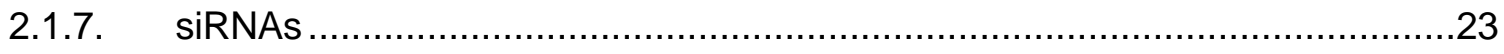

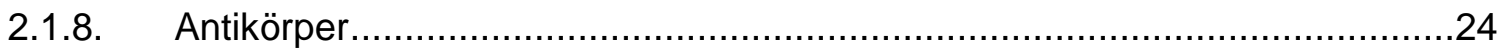

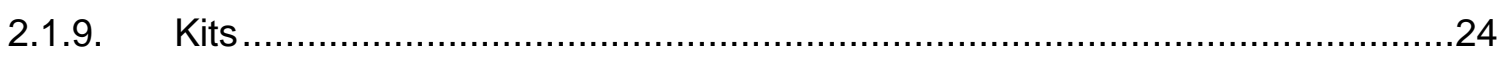

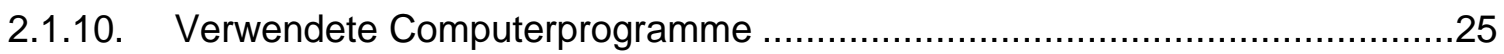

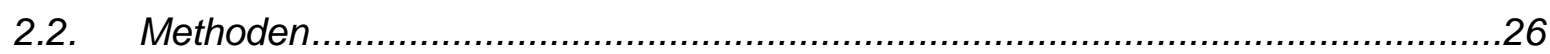

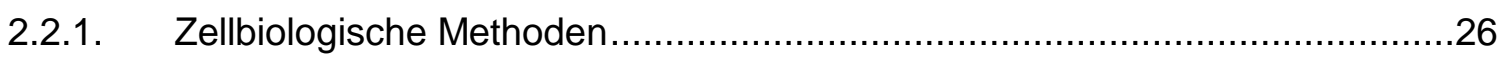

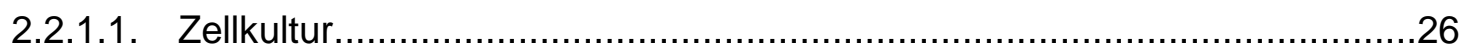

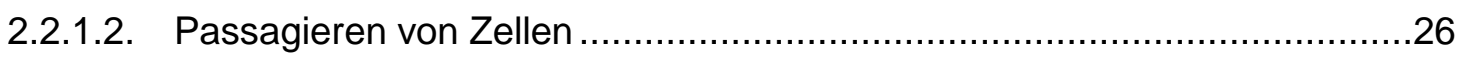

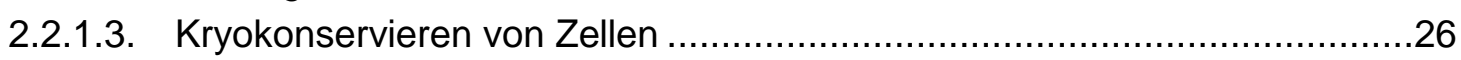

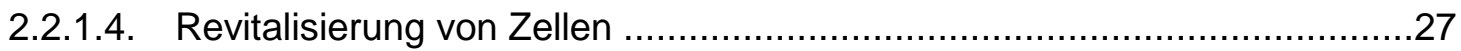

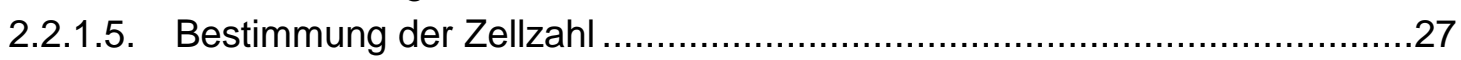

2.2.1.6. Apoptosenachweis durch den TUNEL-Test ..........................................27

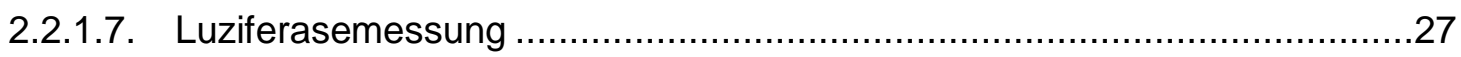

2.2.1.8. Transiente Transfektion eukaryotischer Zellen .....................................29

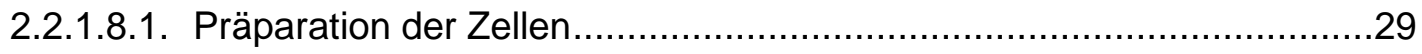

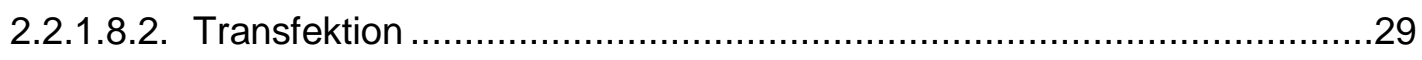

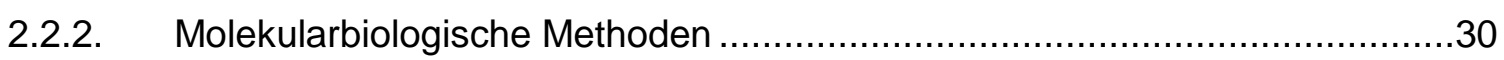

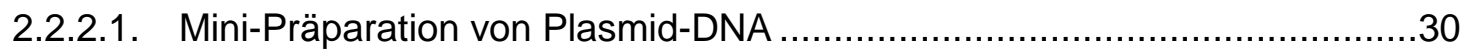

2.2.2.2. Midi-Präparation von Plasmid-DNA ..................................................... 30

2.2.2.3. Transformation kompetenter Bakterien mittels Elektroporation ..................31

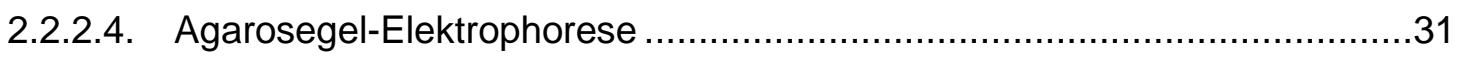

2.2.2.5. DNA-Extraktion aus Agarosegelen ..................................................... 31

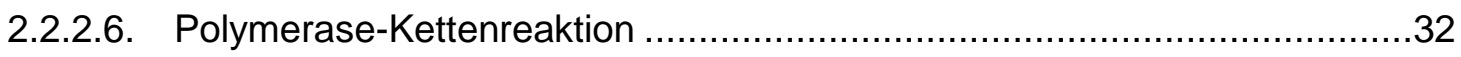

2.2.2.7. RNA-Isolation aus eukaryotischen Zellen ...........................................33

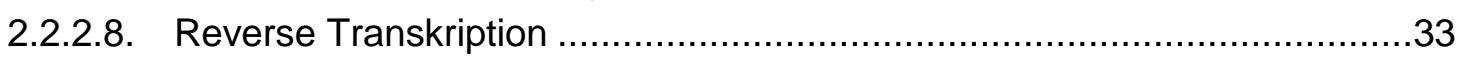

2.2.2.9. Ethanolfällung der DNA aus wässrigen Lösungen .................................34

2.2.2.10. Quantitative Echtzeit-PCR .......................................................... 34 
2.2.2.11. Konzentrationsbestimmung von Nukleinsäuren .................................35

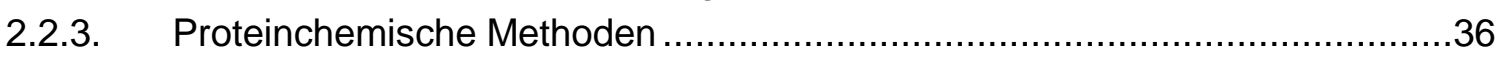

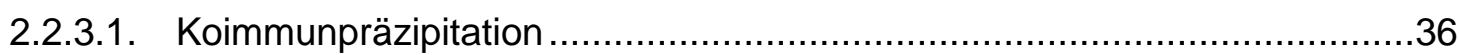

2.2.3.2. Isolation des Gesamtproteins aus Zellkulturen .....................................37

2.2.3.3. SDS-Polyacrylamid-Gelelektrophorese (SDS-PAGE) .............................38

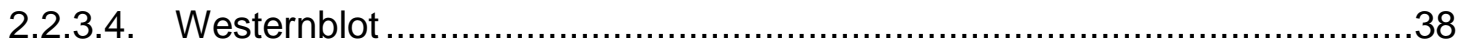

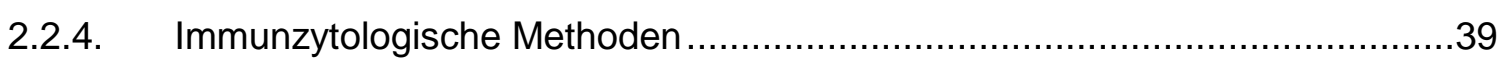

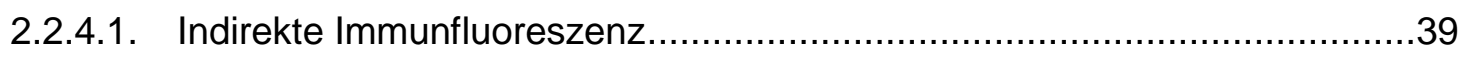

2.2.4.2. Inverse Mikroskopie mit dem AxioObserver...........................................40

2.2.4.3. Konfokale Laserscanning-Mikroskopie mit dem LSM 5 PASCAL...............40

2.2.4.4. Durchflusszytometrie (Fluorescence Activated Cell Scanning) ...................41

2.2.4.4.1. Apoptosenachweis durch die Sub-G1-peak-Methode.........................41

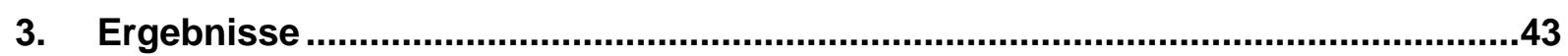

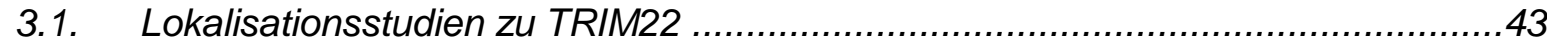

3.1.1. Lokalisation des ektopisch exprimierten TRIM22 in Relation zu den

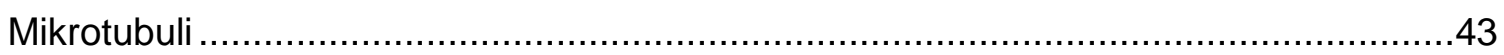

3.1.2. Lokalisation des endogenen TRIM22 in Relation zu den Mikrotubuli .............46

3.1.3. Lokalisation des TRIM22 in Relation zu dem Zentrosom ...............................47

3.1.3.1. Endogenes TRIM22 und das Zentrosom ..........................................47

3.1.3.2. Ektopisch exprimiertes TRIM22 und das Zentrosom...............................48

3.1.4. Überblick über die Lokalisationsstudien.................................................49

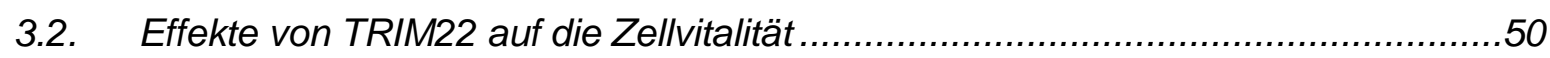

3.2.1. TRIM22-GFP kann die Zellvitalität negativ beeinflussen.............................50

3.2.2. Induktion von RNAi im TRIM22-Gen ................................................... 52

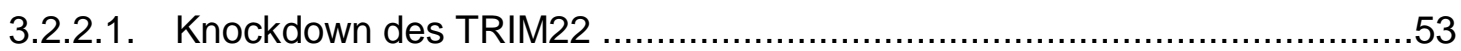

3.2.3. Untersuchungen zum Zellzyklus und zur Zellvitalität mittels Sub-G1-peak-

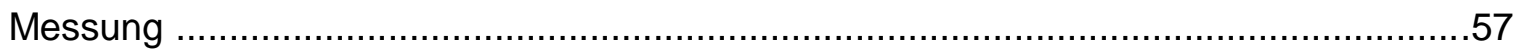

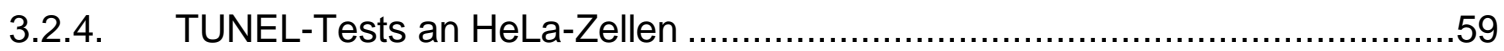

3.2.5. Überblick zu den Ergebnissen der Zusammenhänge von TRIM22 und der

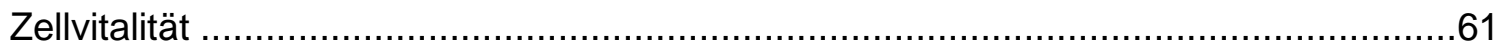

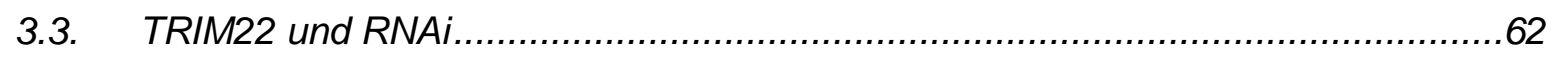

3.3.1. TRIM22 komplexiert mit Komponenten der Silencing-Maschinerie .................62

3.3.2. Funktioneller Nachweis von TRIM22 in der RNAi ......................................65

3.3.3. Überblick zu den Ergebnissen von TRIM22 und RNAi...............................68

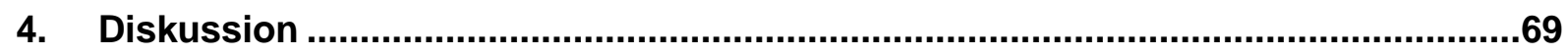

4.1. Visualisierung der subzellulären Lokalisation des TRIM22 ..............................69

4.2. Kolokalisation mit den Zentrosomen ............................................................ 70

4.3. Zellproliferative Aspekte........................................................................ 71

4.3.1. Ektopisch exprimiertes TRIM22-GFP zeigt andere Eigenschaften als endogenes TRIM22 …...........................................................................

4.3.2. Zellzyklusanalyse spricht gegen Apoptoseinduktion bei TRIM22-

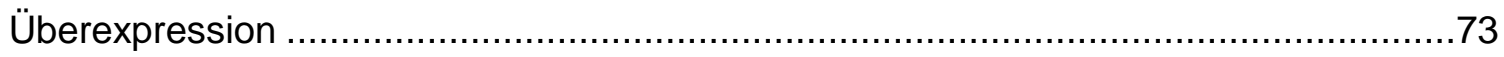

4.3.3. Apoptose bei Knockdown ........................................................................ 74

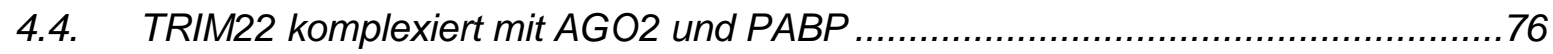

4.5. Luziferasemessung zeigt TRIM22-Beteiligung an der miRNA-Prozessierung .......78 


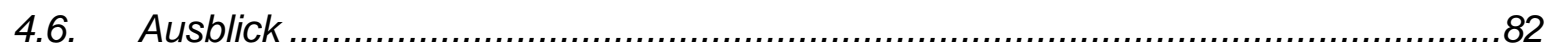

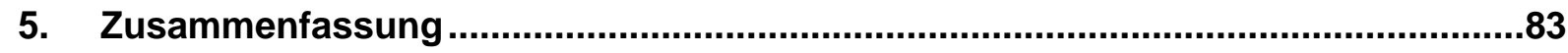

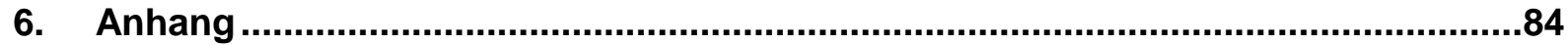

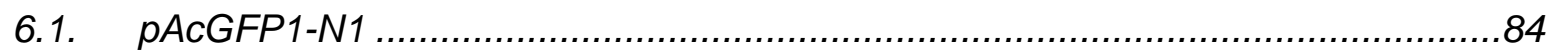

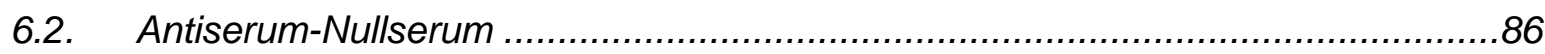

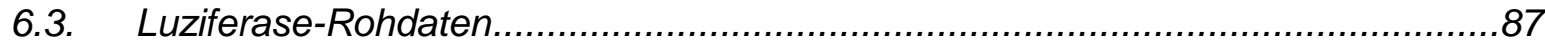

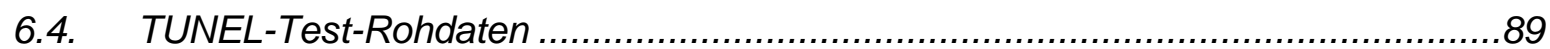

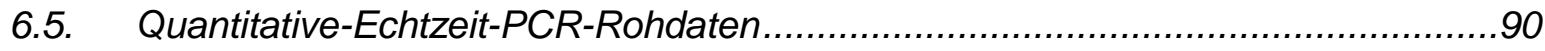

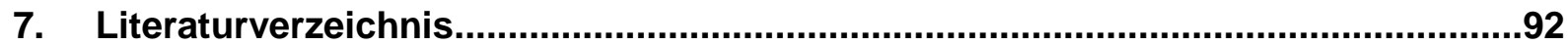

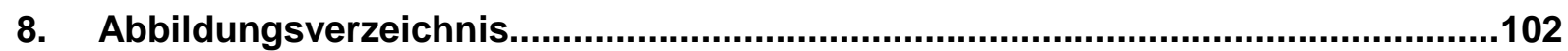

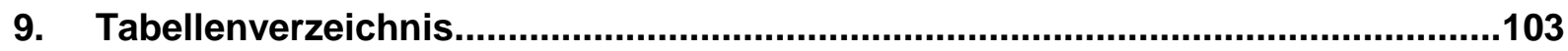




\section{Abkürzungsverzeichnis}

\begin{tabular}{|c|c|}
\hline Abkürzung & Bedeutung \\
\hline$\%$ & Prozent \\
\hline Abb. & Abbildung \\
\hline AGO2 & Argonautprotein 2 \\
\hline agRNA & antigene Ribonukleinsäure \\
\hline $\mathrm{AK}$ & Antikörper \\
\hline ARF & ADP-Ribosylation-Factors \\
\hline ATP & Adenosintriphosphat \\
\hline $\mathrm{bp}$ & Basenpaare \\
\hline BSA & Rinderserumalbumin \\
\hline bzw. & Beziehungsweise \\
\hline${ }^{\circ} \mathrm{C}$ & Grad Celsius \\
\hline ca. & Circa \\
\hline cDNA & komplementäre Desoxyribonukleinsäure \\
\hline CENP-E & zentrosomales Protein E \\
\hline CMV & Zytomegalie-Virus \\
\hline Co-IP & Koimmunpräzipitation \\
\hline CT-Wert & Cycle-treshold-Wert \\
\hline dATP & Desoxyadenosin-5'-Triphosphat \\
\hline dCTP & Desoxycytosin-5'-Triphosphat \\
\hline DGCR8 & DiGeorge-Critical-Region-8 \\
\hline dGTP & Desoxyguanin-5'-Triphosphat \\
\hline DICER & zytoplasmatische Ribonuklease Typ III (engl. to dice: in Würfel schneiden) \\
\hline DNA & Desoxyribonukleinsäure \\
\hline dNTP & Desoxyribonukleosid-5'-Triphosphat \\
\hline DSMZ & Deutsche Sammlung von Mikroorganismen und Zellkulturen GmbH \\
\hline dsRNA & doppelsträngige Ribonukleinsäure \\
\hline dTTP & Desoxythymidin-5`-Triphosphat \\
\hline E. coli & Escherichia coli \\
\hline EBV & Epstein-Barr-Virus \\
\hline ECL-Lösung & enhanced-chemiluminescence-Lösung \\
\hline EDTA & Ethylendiamintetraessigsäure \\
\hline EIAV & equine-infectious-anemia-Virus \\
\hline elF4E & eukaryotischer Translations-Initiations-Faktor 4E \\
\hline et al. & und andere (lat.: et alii) \\
\hline FACS & Durchflusszytometrie (engl.: Fluorescence Activated Cell Scanning) \\
\hline FITC & Fluoreszeinisothiozyanat \\
\hline $\mathrm{fw}$ & vorwärts (engl. forward) \\
\hline $\mathrm{g}$ & Gramm \\
\hline${ }^{*} \mathrm{~g}$ & -fache Erdbeschleunigung \\
\hline GAG-Protein & group-specific antigen (Strukturprotein des HIV) \\
\hline GFP & grün fluoreszierendes Protein \\
\hline GW182 & glycine-tryptophan protein of 182 Kilodalton \\
\hline $\mathrm{h}$ & Stunde (lat.: hora) \\
\hline HBV & Hepatitis-B-Virus \\
\hline HeLA & Gebärmutterhalskrebszellen, zurückführbar auf Patientin Henrietta Lacks \\
\hline HIV & humanes Immundefizienz-Virus \\
\hline HRP & Horse-radish-peroxidase \\
\hline HSV & Herpes-simplex-Virus \\
\hline IF & Immunfluoreszenz \\
\hline Inf- $\beta$ & Interferon- $\beta$ \\
\hline kDa & Kilodalton \\
\hline 1 & Liter \\
\hline LSM & Laserscanning Mikroskop \\
\hline$\mu$ & Mikro \\
\hline $\mathrm{m}$ & Milli \\
\hline $\mathrm{M}$ & Mol \\
\hline $\mathrm{mA}$ & Milli-Ampere \\
\hline MCS & Multiple Klonierungsstelle \\
\hline $\min$ & Minute $(\mathrm{n})$ \\
\hline
\end{tabular}




\begin{tabular}{|c|c|}
\hline miRNA & mikro-Ribonukleinsäure \\
\hline MLV & murine-leukemia-Virus \\
\hline M-MLV-Transkriptase & moloney-murine-leukemia-Virus-Transkriptase \\
\hline MOZ & Mikrotubulusorganisationszentrum \\
\hline mRNA & messenger-Ribonukleinsäure \\
\hline $\mathrm{n}$ & Nano \\
\hline $\mathrm{nm}$ & Nanometer \\
\hline nt & Nukleotide \\
\hline PABP & Poly $(\mathrm{A})$-binding-Protein \\
\hline p-Bodies & processing-Bodies \\
\hline PCR & Polymerase-Kettenreaktion \\
\hline $\mathrm{pH}$ & $\begin{array}{l}\text { Pondus hydrogenii (negativ dekadischer Logarithmus der } \\
\text { Protonenkonzentration) }\end{array}$ \\
\hline $\mathrm{PI}$ & Propidiumiodid \\
\hline Poly-A-Schwanz & Poly-Adenosin-Schwanz \\
\hline preRISC & precursor ribonucleic acid-containing ribonucleic acid-induced silencing \\
\hline pri-miRNA & primordial-mikro-Ribonukleinsäure \\
\hline RBCC-Motiv & really-interesting-new-gene-, B-box-, coiled-coil-Motiv \\
\hline rev & rückwärts (engl.: reverse) \\
\hline RING-Domäne & really-interesting-new-gene-Domäne \\
\hline RISC & ribonucleic acid-induced silencing complex \\
\hline RNA & Ribonukleinsäure \\
\hline RNAi & Ribonukleinsäure-Interferenz \\
\hline RNAP-II & Ribonukleinsäure-Polymerase-II \\
\hline RNase & Ribonuklease \\
\hline RT & Raumtemperatur \\
\hline SDS-PAGE & Natriumdodecylsulfat-Polyacrylamidgelelektrophorese \\
\hline $\mathrm{sec}$ & Sekunden \\
\hline shRNA & short-hairpin-Ribonukleinsäure \\
\hline SIM & small ubiquitin like modifier interacting motif \\
\hline siRNA & small-interfering-Ribonukleinsäure \\
\hline SIVmac & simian-immunodeficiency-Virus \\
\hline sno-RNA & small-nucleolar-Ribonukleinsäure \\
\hline SUMO & small ubiquitin like modifier \\
\hline Tab. & Tabelle \\
\hline TdT & terminale Desoxyribosyl-Transferase \\
\hline tiRNA & transcription-initiation-Ribonukleinsäure \\
\hline TMR & Tetramethylrhodamin \\
\hline TRBP & Trans-Activation-Response-RNA-Binding-Protein \\
\hline TRIM & tripartite-motif-Proteinfamilie \\
\hline TRIM22 & tripartite-motif-Protein-22 (synonym: RNF94, STAF50, GPSTAF50) \\
\hline TRIM22-GFP & tripartite-motif-Protein-22-grün-fluoreszierendes-Protein \\
\hline TRITC & Tetramethylrhodamin-Isothiozyanat \\
\hline TUNEL-Test & terminal deoxynucleotidyl transferase dUTP nick end labeling test \\
\hline $\mathrm{U}$ & Einheit (engl.: unit) \\
\hline u.a. & unter anderem \\
\hline ü.N. & über Nacht \\
\hline UV-Licht & ultraviolettes Licht \\
\hline UZ & Ultrazentrifuge \\
\hline $\mathrm{V}$ & Volt \\
\hline $\mathrm{V} / \mathrm{cm}$ & Volt/Zentimeter \\
\hline $\mathrm{v} / \mathrm{v}$ & Volumen zu Volumen \\
\hline VEGF & vascular endothelial growth factor \\
\hline VSIV & vesicular-stomatitis-Indiana-Virus \\
\hline WT-Zellen & Wildtyp-Zellen \\
\hline z. B. & zum Beispiel \\
\hline
\end{tabular}




\section{Einleitung}

Die Charakterisierung eines Proteins hinsichtlich seiner physiologischen Funktion dient nicht nur dem biochemischen und zytologischen Grundverständnis, sondern nutzt auch der Medizin. Erst mit dem Erkennen und Verstehen der Aufgaben eines Proteins innerhalb eines Organismus ist es möglich, eine zielgerichtete Therapie zu erstellen.

Diese Arbeit beschäftigt sich mit der Analyse des tripartite-motif-Proteins-22 (TRIM22), einem Mitglied der TRIM-Proteinfamilie, deren zytologische und physiologische Aufgaben bisher unzureichend beschrieben sind.

In der Einleitung soll zuerst die TRIM-Proteinfamilie vorgestellt werden und anschließend der heutige Stand der Wissenschaft in Bezug auf TRIM22 präsentiert werden. Im weiteren Verlauf der Einleitung werden der Zellzyklus und die Ribonukleinsäure-Interferenz (RNAi) als zwei mögliche Funktionsbereiche des TRIM22 vorgestellt.

\subsection{TRIM-Proteine}

TRIM-Proteine stellen eine große Familie mit bisher über 70 beschriebenen Mitgliedern dar, die in ihrer Funktion heterogen sind. Die verschiedenen Funktionen umfassen Zelldifferenzierung, Transkriptionsregulation, Apoptoseinduktion und weitere zelluläre Prozesse (Meroni und Diez-Roux 2005; Reymond et al. 2001). Die Zugehörigkeit zu der TRIM-Familie erhält ein Protein aufgrund seiner Struktur: Diese ist über das stark konservierte, dreiteilige $\underline{R}$ ING-, $\underline{B}$-box-, coiled-coil- (RBCC-) Motiv definiert.

Die really-interesting-ñew-gene-(RING-) Domäne enthält eine Zinkfinger-Struktur (Saurin et al. 1996) und besitzt E3-Ubiquitin-Ligase-Aktivität (Freemont 2000). Zinkfingerproteine besitzen in ihrer Polypeptidkette ein Zinkatom, durch das eine schleifenförmige Struktur entsteht, die nicht nur mit Desoxyribonukleinsäure (Blumberg et al. 1987; Fabian et al. 2009), sondern auch mit Ribonukleinsäure spezifisch interagieren kann (Brown 2005; Hall 2005). Zinkfingerproteine können auch an Protein- oder Lipidinteraktionen beteiligt sein (Gamsjaeger et al. 2007). Des Weiteren konnte diesem Motiv E3-Ubiquitin-Ligase-Aktivität zugeordnet werden, 
wodurch Proteine für die Degradation in Proteasomen markiert werden können (Gack et al. 2007; Horn et al. 2004; Trockenbacher et al. 2001; Urano et al. 2002).

Die B-Box stellt das spezifische Element der TRIM-Proteine dar. Diese kann anhand der Aminosäuresequenz wiederum in verschiedene Gruppen, beispielsweise in die B-Box-1 und B-Box-2 unterteilt werden. Diese besitzen ebenfalls eine Zinkfingerdomäne und agieren beispielsweise als Transkriptionsfaktoren oder Ribonukleoproteine (Massiah et al. 2006; Nisole et al. 2005; Short und Cox 2006).

Die coiled-coil-Domäne besteht aus zwei bis sieben verschlungenen $\alpha$-Helices (Crick 1952; Liu et al. 2006) und ist in eine Vielzahl von Funktionen eingebunden. Hierzu gehören unter anderem Proteinhomo- und Heteromultimerisierungen (Reymond et al. 2001).

Etwa 60\% der TRIM-Proteine enthalten neben dem RBCC-Motiv zudem eine variable C-terminale Domäne, wie beispielsweise die ARF/SAR-, Fibronectin III-, NHL-, Filamin-, WD40-, Bromo- oder MATH-Domänen (Nisole et al. 2005). Eine weitere Cterminale Domäne ist die B30.2-Domäne, die an Proteinmultimerisierungen und an RNA-Interaktionen beteiligt ist (Hilton et al. 1998; Ponting et al. 1997). Die B30.2Domäne und das RBCC-Motiv sind beim Menschen auf dem Chromosom 11p15 lokalisiert und bilden hier ein Gencluster, zu dem neben TRIM5, TRIM6, TRIM21 und TRIM34 auch TRIM22 gehört. Abbildung (Abb. 1) gibt den strukturellen Aufbau der TRIM-Proteine wieder.

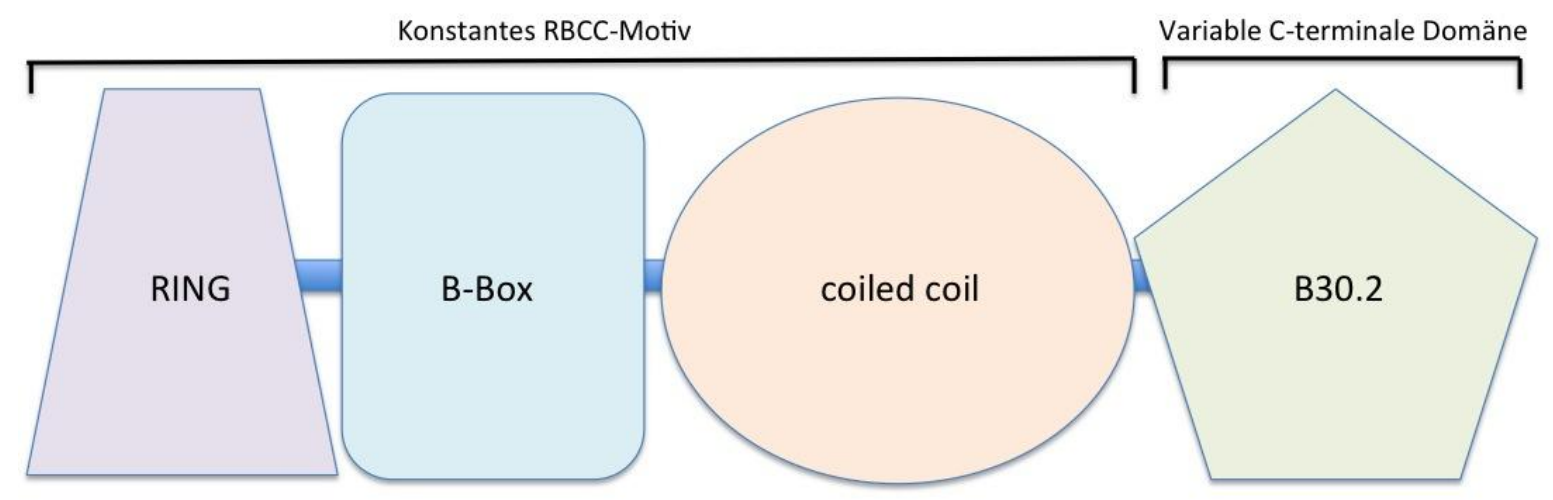

Abb. 1: Struktureller Aufbau der TRIM-Proteine des 11p15-Genclusters.

TRIM-Proteine sind durch das RBCC-Motiv charakterisiert, welches aus RINGDomäne, B-box und coiled-coil-Domäne besteht. Der Großteil der TRIM-Proteine besitzt zusätzlich eine variable C-terminale Domäne, die beispielsweise durch die B30.2-Domäne besetzt sein kann. 
In den letzten Jahren konnte gezeigt werden, dass einige TRIM-Proteine, vor allem Vertreter des 11p15-Genclusters, Teil des angeborenen antiviralen Immunsystems sind.

TRIM5a ist der populärste Familienvertreter der TRIM-Familie. Indem es das Kapsid des humanen Immundefizienz-Virus (HIV) (Kaminskyy und Zhivotovsky 2010) nach dessen Eintritt in die Zelle bindet, verhindert TRIM5a eine weitere Infektion der CD4+T-Lymphozyten (Grutter und Luban 2012; Neagu et al. 2009; Stremlau et al. 2004). Das TRIM5a-Protein des Rhesusaffen besitzt eine deutlich stärkere Potenz der HIV1-Bindung als sein humanes Äquivalent (Neagu et al. 2009). TRIM5a spielt sein antivirales Potential unter anderem (u.a.) über small-ubiquitin-like-modifier (SUMO) (Brocker et al. 2010) und SUMO-interacting-motifs (SIMs) aus (Arriagada et al. 2011). Bisher konnte in vivo jedoch keine Beeinflussung einer simianimmunodeficiency-Virus- (SIVmac-) Infektion nachgewiesen werden (Fenizia et al. 2011).

Auch weitere TRIM-Proteine zeigen antivirale Funktionen. TRIM19 zum Beispiel besitzt antivirale Aktivität gegen Herpes-simplex-Virus-Typ-1 (HSV-1), vesicularstomatitis-Indiana-Virus (VSIV), Influenza-A-Virus und Zytomegalie-Virus (CMV) (Nisole et al. 2005; Towers et al. 2003). TRIM34 weist bei Überexpression antiretrovirale Aktivität gegen HIV-2, SIVmac und equine-infectious-anemia-Virus (EIAV) auf (Li et al. 2007). TRIM1 kann die Infektion durch das murine-leukemiaVirus (MLV) verhindern (Hatziioannou et al. 2004; Keckesova et al. 2004; Perron et al. 2004). TRIM21 besitzt eine E3-Ubiquitin-Protein-Ligase-Aktivität und kann durch Ubiquitinierung von Antikörper- (AK-) Viren-Komplexen deren Abbau im Proteasom induzieren (Massiah et al. 2006).

\subsubsection{TRIM22}

Auch für TRIM22 (synonym: RNF94, STAF50, GPSTAF50) konnten bereits antivirale Eigenschaften nachgewiesen werden. So konnte gezeigt werden, dass TRIM22 die Genexpression des Hepatitis-B-Virus (HBV) signifikant reduzieren kann (Gao et al. 2009), sowie antivirale Eigenschaften gegen das Epstein-Barr-Virus (EBV) besitzt (Zhang et al. 2004). Des Weiteren ist eine antiretrovirale Potenz gegen HIV-1 bekannt. Besonders bei Überexpression durch Zytokine wie Interferon- (Inf-) $\beta$ kann TRIM22 eine HIV-1-Infektion um 50 bis $90 \%$ unterdrücken (Bouazzaoui et al. 2006). Es bindet am HIV-group-specific-Antigen- (GAG-) Protein nach der Invagination (Barr 
et al. 2008). Die RING-Domäne supprimiert den HIV-1-Promotor und verhindert somit die HIV-1-Replikation (Bouazzaoui et al. 2006; Tissot und Mechti 1995). Dies ist wahrscheinlich bedingt durch die Zinkfingereigenschaften von TRIM22. Des Weiteren besitzt TRIM22 Aufgaben in der Zelldifferenzierung und Zellproliferation von Leukämiezellen, wobei es direkt von p53 aktiviert wird (Obad et al. 2004). TRIM22 ist ein durch Typ-I-Interferon induzierbares Protein (Barr et al. 2008; Karpov 2001). TypI-Interferone sind immunmodulierende Proteine, die zu den Zytokinen und hier zu der Familie der Interleukine gezählt werden (Brocker et al. 2010). Sie können von verschiedenen Zellen sezerniert werden und entfalten durch Rezeptorbindungen unter anderem antiproliferative oder immunmodulatorische Wirkungen (AsselinPaturel et al. 2001; Biron et al. 1999; Reiter 1993).

Frau Dr. Herr konnte im Rahmen ihrer Dissertation (2008) am Deutschen Primatenzentrum erste Anhaltspunkte einer apoptotischen Wirkung des transfizierten TRIM22-grün-fluoreszierendes-Proteins (GFP) mithilfe eines Annexin-V-Tests zeigen (Abb. 2). Sie stellte die These auf, dass überexprimiertes TRIM22 die Zentrosomen blockieren und dadurch einen Zellzyklusarrest bewirken kann, der zur Apoptose führt. 

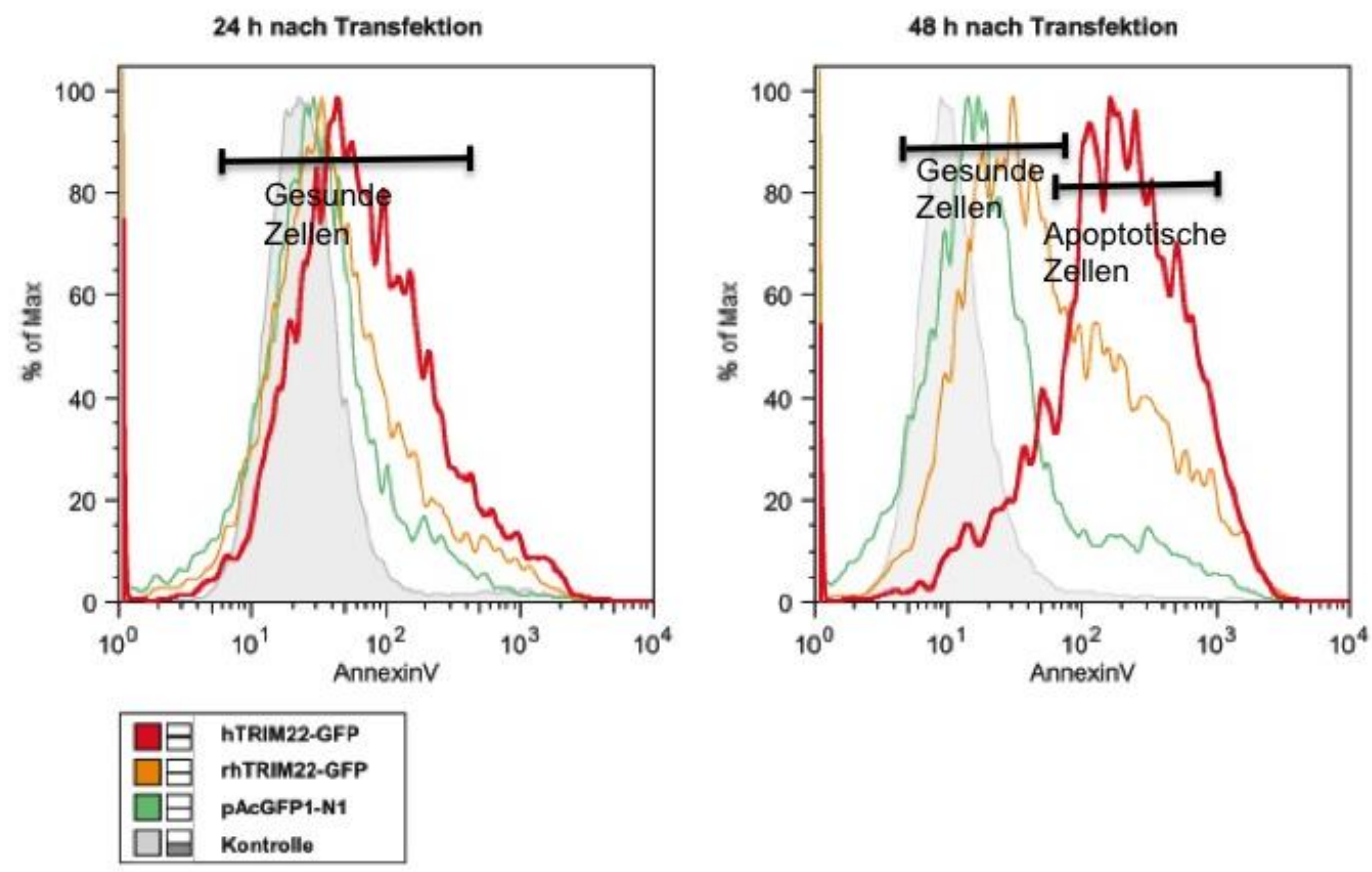

Abb. 2: FACS-Messung nach Annexin-V-Test

HeLa-Zellen wurden je mit humanemTRIM22-GFP, rhesusTRIM22-GFP und dem pAcGFP1-N1-Vektor transfiziert. HeLa-Zellen wurden dem Annexin-V-Test, einem Apoptose-Assay, unterzogen. Nach 48h Inkubationszeit zeigen die mit humanemTRIM22-GFP transfizierten Zellen die stärkste Apoptosetendenz. Der Annexin-V-Test weist Phosphatidylserin auf der extrazellulären Seite der Plasmamembran nach, das während der Apoptose dorthin verlagert wird. Bei gesunden Zellen ist Phosphatidylserin nur auf der intrazellulären Seite der Plasmamembran nachweisbar (modifiziert nach Herr (2008, S. 107)).

Bisherige Arbeiten zur Lokalisationsbestimmung von TRIM22 zeigten ein Vorkommen im Zytosol (Herr et al. 2009) und im Nukleus (Gao et al. 2009). Weitere Arbeiten beschrieben eine Verteilung vorwiegend im Nukleus und im Nukleolus (Sivaramakrishnan et al. 2009), sowie eine Kolokalisation mit dem Zentrosom (Petersson et al. 2009).

Weiterhin wird TRIM22 eine Rolle in der hämatopoetischen Differenzierung zugeschrieben. So scheint die TRIM22-Expression invers mit dem Differenzierungsgrad der Hämatopoese zu korrelieren (Obad et al. 2007a). Zudem wurde erst kürzlich entdeckt, dass TRIM22 durch Bindung des eukaryotischen Translations-Initiations-Faktors-4E (elF4E) die Translation inhibieren kann (Petersson et al. 2012).

TRIM22 ist in eine Vielzahl zellulärer Prozesse involviert. Unter anderem wird eine direkte Interaktion mit p53 vermutet, die sich auf die Zellproliferation auswirken kann. 
Da diese Prozesse aber bislang ungenau beschrieben sind, bedarf es weiterer Untersuchungen zur genaueren Beschreibung des Proteins. 


\subsection{Der eukaryotische Zellzyklus}

Im Rahmen dieser Arbeit zeigte sich eine Assoziation zwischen Zellvitalität und TRIM22-Expression. Weiterhin wurde das Protein mehrfach mit der Zellproliferation in Zusammenhang gebracht (Obad et al. 2004; Obad et al. 2007a). Aus diesem Grund werden im Folgenden die Grundzüge des Zellzyklus dargestellt.

Das Leben einer Zelle beginnt mit der Teilung der Mutterzelle in die beiden Tochterzellen. Diese Schwesterzellen durchlaufen den Zellzyklus, der sich in Interphase und Mitose gliedert (Abb.3). Im nächsten Zellzyklus bilden diese beiden Zellen die neuen Mutterzellen, aus denen wiederum je zwei Tochterzellen hervorgehen.

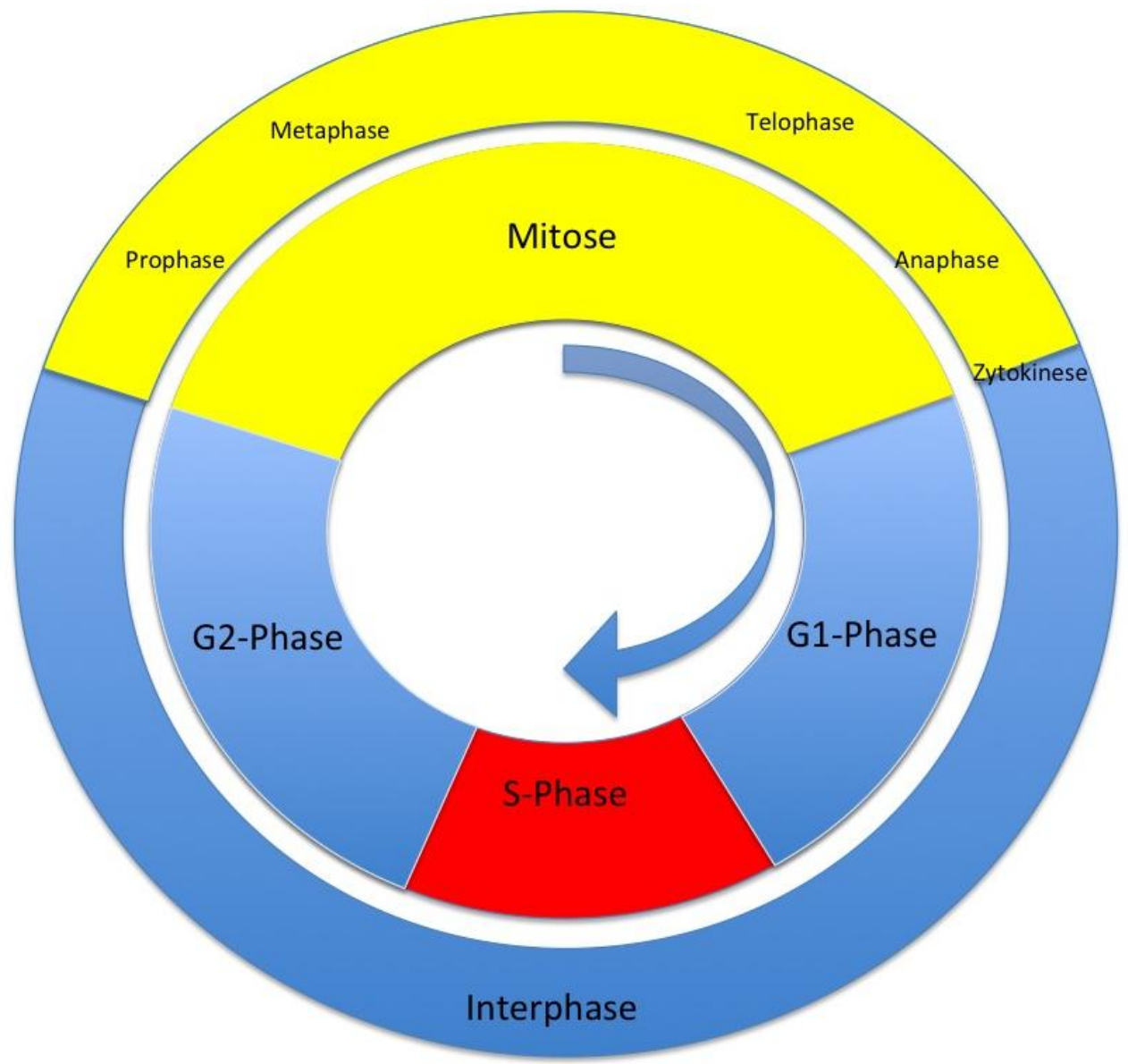

Abb. 3: Schematische Darstellung des Zellzyklus

Die Kreise werden im Uhrzeigersinn verfolgt, um die chronologische Reihenfolge korrekt wiederzugeben. Im äußeren Kreis stellt der größere blaue Abschnitt die Interphase dar, welche in G1-, S- und G2-Phase unterteilt wird (innerer Kreis). Der gelbe Abschnitt stellt die Mitose dar (innerer Kreis), die sich in Pro-, Meta-, Telound Anaphase unterteilt (äußerer Kreis). Die Zytokinese markiert den Übergang von Mitose zur Interphase. 
Die Interphase wird in G1-, S- und G2-Phase unterteilt (Abb.3). In der G1-Phase erfült die Zelle ihre Aufgaben im Organismus und reichert unter anderem wichtige Proteine an (Smith und Martin 1973). Aus dieser Phase kann eine Zelle in Abhängigkeit von Wachstumsfaktoren und Adhäsionsmolekülen den üblichen Zellzyklus verlassen und in die sogenannte G0-Phase wechseln. Sie nimmt somit nicht mehr am aktiven Zellzyklus teil. Ein Wiedereintritt in die G1-Phase mit normalem Zellzyklus ist möglich. In der S-Phase findet die DNA-Replikation statt, sodass die Zelle nun diploid ist (Cameron und Greulich 1963; Wu und Bonner 1981). In der darauf folgenden G2-Phase wird das Ergebnis der DNA-Replikation auf Fehler überprüft und eventuell korrigiert.

Während der Mitose werden die Chromosomen gleichmäßig auf beide Tochterzellen verteilt. Die Mitose gliedert sich in Pro-, Meta-, Ana- und Telophase.

In der Prophase findet eine maximale Kondensation der Chromosomen und eine Wanderung der beiden Zentriolen zu den Zellpolen statt. Am Ende der Prophase löst sich die Kernhülle auf. In der Metaphase wachsen Mikrotubuli, röhrenförmige Proteinkomplexe, von beiden Zellpolen in die Äquatorialebene ein, um hier an den Zentromeren der Chromosomen anzudocken und somit die Kinetochore auszubilden. Mikrotubuli sind essenziell für den korrekten Ablauf der Mitose (Compton 2000). Sie bestehen aus zwei globulären Proteinen, $\alpha$ - und $\beta$-Tubulin, die sich in Form gemeinsamer Heterodimere zu fadenförmigen Protofilamenten zusammenlagern. Dreizehn dieser Protofilamente bilden einen ringförmigen Proteinkomplex, der durch weitere Polymerisation zu einem Mikrotubulus heranwächst. Mikrotubuli sind dynamische und polare Strukturen, deren Minus-Ende am Zentrosom verankert ist und deren Plus-Ende sich in der Zellperipherie befindet. Durch die assoziierten Motorproteine Kinesin und Dynein findet der Transport von Zellorganellen und Zellprodukten statt (Hirokawa et al. 1998; Kim AJ und Endow 2000). Das Andocken der Mikrotubuli an die Zentromere wird durch die Kinetochoren vermittelt, welche hochkomplexe heterogene Proteinkomplexe sind. Am Ende der Metaphase liegen die Chromosomen in der Äquatorialebene und die Tubulinpolymere beginnen mit der Auflösung der Zentromere.

Während der Anaphase sammeln sich die Chromosomen an den gegenüberliegenden Zellpolen. In der Telophase wird die Kernmembran wiederhergestellt, die Chromosomen dekondensieren und Nukleoli bilden sich aus. 
Die Zytokinese ist ein eigenständiger Prozess zwischen Mitose und G1-Phase (McIntosh und Koonce 1989). Auf Höhe der früheren Äquatorialebene schnürt ein Actin-Myosinring die einzige Verbindung der beiden nun eigenständigen Tochterzellen ab (Glotzer 2005).

Der Zellzyklus ist ein in einem hohen Maße regulierter Prozess. Es existieren sogenannte Checkpoints, die integraler Bestandteil des physiologischen Zellzyklusablaufs sind. Beispielsweise überprüft der Spindle-assembly-Checkpoint als hochkomplexer Mechanismus den korrekten Ablauf der Mitose und führt bei defizienten Prozessen zu einem Zellzyklusarrest und anschließend entweder zur Apoptose (Musacchio 2011) oder zur Entstehung polyploider Zellen. Letztere sind durch einen erhöhten Chromosomensatz gekennzeichnet. Diese Zellen besitzen also mehr als zwei Sätze homologer Chromosomen und können durch drei verschiedene Mechanismen entstehen: durch Zellfusionen, durch Fehler in der Zytokinese oder durch Fehler in der Mitose (Storchova und Kuffer 2008). Die geplante Polyploidie ist ein in der Natur häufig vorkommendes Phänomen, welches beispielsweise bei lachsund forellenartigen Fischen, den Salmonidae (de Boer et al. 2007), oder auch im Pflanzenreich beobachtet werden kann (Rieseberg und Willis 2007). Beim Menschen kann Polyploidie natürlicherweise im Rahmen der Differenzierung eines Gewebes vorliegen. Myelozyten des Muskelgewebes und Osteoklasten des Knochengewebes gehören beispielsweise zu typisch polyploiden Zellen. Polyploidie ist aber auch häufig in tumorösen Geweben zu finden (Barrett et al. 2003; Olaharski et al. 2006).

Der Zellzyklus wird durch verschiedene Steuerungselemente reguliert. Hierzu zählt neben diversen Proteinen und Ribonukleinsäuren (RNAs) auch die Chromatinorganisation. Eine Beteiligung des TRIM22 an diesem System wäre in Anbetracht der zentrosomalen Kolokalisation ebenfalls denkbar (Petersson et al. 2009). Zudem werden zellproliferative Eigenschaften mit TRIM22 in Verbindung gebracht (Obad et al. 2004). 


\subsection{RNA-Interferenz}

Im Rahmen dieser Arbeit wurde ein möglicher Zusammenhang zwischen TRIM22 und mikro-Ribonukleinsäuren- (miRNA-) Prozessierung beobachtet. Aus diesem Grund werden nun die RNA-Interferenz (RNAi) und die miRNA-Prozessierung vorgestellt.

Die RNAi ist eine zelluläres Steuerungselement zur transkriptionellen und posttranskriptionellen Regulation der Genexpression durch kleine doppelsträngige RNA-Moleküle (Elbashir et al. 2001; Kim DH et al. 2008; Morris 2009). Erstmals wurde dieses Phänomen 1998 von Andrew Fire und Craig Mello entdeckt und anschließend angewendet, um in dem Fadenwurm Caenorhabditis elegans eine Suppression der Genexpression herbeizuführen. Für diese Erkenntnisse erhielten die beiden Wissenschaftler 2006 den Nobelpreis für Physiologie und Medizin. Hamilton und Baulcombe erkannten 1999, dass der Mechanismus dieser Genregulation auf eine Interaktion zwischen einer messenger-Ribonukleinsäure (mRNA) und einer komplementären, etwa 25 Nukleotid (nt)-langen RNA zurückzuführen ist (Hamilton und Baulcombe 1999). Thomas Tuschl konnte schließlich mit seiner Arbeitsgruppe 21 nt-lange RNA-Moleküle als Effektormoleküle der RNAi beschreiben, die für die Regulation verantwortlich sind (Elbashir et al. 2001).

Im Zuge der genannten Arbeiten wurden endogene RNA-Moleküle, sogenannte mikro-RNAs (miRNAs), beschrieben. Diese kodieren nicht für Proteine, sondern sind durch Homologie zu bestimmten mRNA-Bereichen verantwortlich für Genregulationen (Lagos-Quintana et al. 2001; Martin und Caplen 2007). Der Organismus kann somit zu bestimmten Zeitpunkten gezielt unterschiedliche biologische Prozesse steuern. Dazu gehören unter anderem Metabolismus, Entwicklung, Apoptose und Differenzierung (Bartel und Chen 2004; Boehm und Slack 2006). Außerdem hat die RNAi eine entscheidende Rolle in der antiviralen Abwehr (Haasnoot et al. 2007; Umbach und Cullen 2009). Aktuell wird postuliert, dass die Mehrzahl aller menschlichen Gene sowohl auf transkriptioneller als auch auf translationeller Ebene ein Ziel für regulatorische RNAs darstellen (Kawamata und Tomari 2010; Lewis et al. 2003). 


\subsection{1. miRNA-Biogenese}

Den initialen Schritt der miRNA-Biogenese stellt die Transkription der miRNA-Gene durch die RNA-Polymerase-II (RNAP-II) dar. Hierbei entsteht eine schleifenförmige Haarnadelstruktur, die primordial-mikro-RNA (pri-miRNA) (Abb. 4) (Kim VN und Nam 2006; Tomari und Zamore 2005). Anschließend prozessiert die Ribonuklease (RNase) Typ III DROSHA mit ihrem Kofaktor DiGeorge-Critical-Region-8 (DGCR8) die pri-miRNA zu einer etwa 70 nt-langen Haarnadelstruktur. Es entsteht die precursor-mikro-RNA (pre-miRNA) mit spezifischen 2 nt-langen 3'-Überhängen (Lee et al. 2003; Lee et al. 2002), die daraufhin durch eine direkte Interaktion mit Exportin 5 aktiv aus dem Nukleus transportiert wird. Hierbei ist eine basengepaarte Region im Bereich der Haarnadelschleife (stem-Struktur) für den effektiven Export verantwortlich (Zeng und Cullen 2005). Im Zytoplasma schneidet die RNase Typ III DICER anhand des zugehörigen RNA-Bindungsproteins Trans-Activation-ResponseRNA-Binding-Protein (TRBP) die Haarnadelschleife der pre-miRNA auf (Bernstein et al. 2001; Hutvagner et al. 2001). Es entstehen kurze, doppelsträngige RNAs (dsRNA) einer Länge von etwa 20 bis 25 Nukleotiden (Lund et al. 2004; Yi et al. 2003). Die dsRNA-Moleküle sind komplementär zueinander und haben an den 3'Enden Nukleotidüberhänge von meist zwei Basen (Siomi und Siomi 2009; Vermeulen et al. 2005; Zamore et al. 2000). Diese dsRNAs bestehen aus der reifen miRNA (Guide) und dem komplementären Gegenstrang (Passenger). Im weiteren Verlauf wird die reife miRNA in den Effektorkomplex, den precursor ribonucleic acidcontaining ribonucleic acid-induced silencing complex (preRISC), eingebaut, und der Passenger-Strang wird abgebaut (Meister und Tuschl 2004; Schwarz et al. 2004).

Der Guide-Strang der miRNA liegt dem Argonautprotein 2 (AGO2) an, welches die Hauptnuklease des ribonucleic acid-induced silencing complex (RISC) darstellt (Meister et al. 2004). Argonaut-Proteine sind evolutionär stark konserviert und bilden das katalytische Zentrum des RISC. Sie binden die Zielsequenz der gesuchten mRNA, um die Translation durch Zerstörung der mRNA zu verhindern (Ahlquist 2002). Die mRNA wird an ihrem Poly-A-Schwanz durch das RNA-Bindungsprotein Poly(A)-binding-Protein (PABP) am RISC fixiert (Kahvejian et al. 2005). Die weitere Prozessierung findet innerhalb der processing-Bodies ( $p$-Bodies) statt, die als zytoplasmatische Strukturen das Kernstück der mRNA-Repression durch GenSilencing darstellen (Liu et al. 2005; Parker und Sheth 2007). Am Gen-Silencing in den $p$-Bodies sind miRNA, mRNA und RISC-Effektorproteine beteiligt, zu denen 
unter anderem AGO2, GW-182 und PABP gezählt werden (Liu et al. 2005; Pillai 2005; Sen und Blau 2005).

Über das weitere Procedere entscheidet nun die Sequenzkomplementarität zwischen mRNA und miRNA. Liegt eine vollständige Komplementarität vor, schneidet die Endonuklease AGO2 die mRNA im zentralen Bereich des Guide-Strangs (Schwarz et al. 2004), wodurch die mRNA abgebaut und die Translation verhindert wird. Liegt nur eine partielle Komplementarität vor, kommt es zu einer posttranskriptionellen Inhibition der Translation, welche initial durch einen Translationsstop gekennzeichnet ist. Ausschlaggebend ist hierbei eine Komplementarität im Bereich der Nukleotidpositionen 2 bis 8 am 5'-Ende der miRNA, dem sogenannten Seed-Bereich (Lewis et al. 2003). Meist erfolgt im Anschluss eine Deadenylation, also die Entfernung des Poly-Adenosin-(Poly-A) Schwanzes am 3`-Ende der mRNA (Coller und Parker 2004). Dieser schützt die mRNA vor Exonukleasen und terminiert die Translation. Zusätzlich wird ein Decapping, also ein Entfernen des Caps am 5'-Ende der mRNA, durchgeführt. Das 5'-Cap ist ein an Position 7 methyliertes GuanosinNukleotid, das über eine 5'-5'-Phosphodiesterbindung an die mRNA gebunden ist. Es ist essentiell für die Erkennung der mRNA, die Bindung der Ribosomen und den Schutz vor Nukleasen (Muthukrishnan et al. 1975; Visa et al. 1996; Walther et al. 1998). Durch die genannten destabilisierenden Prozesse kommt es bei unvollständiger Komplementarität zwischen miRNA und mRNA letztendlich ebenfalls zu einem Abbau der mRNA. Hier liegt jedoch eine langsamere Kinetik vor als bei vollständiger Komplementarität. Interessanterweise erfolgt in Pflanzenzellen überwiegend die mRNA-Degradation (Rhoades et al. 2002), wohingegen in Säugetierzellen meist die Translationsinhibition stattfindet (Lewis et al. 2003).

Die RNAi wird mittlerweile unverzichtbar als wissenschaftliches Untersuchungswerkzeug eingesetzt, insbesondere bei funktionalen Untersuchungen mittels reverser Genetik. So findet in vielen molekulargenetischen Studien entweder mit synthetisierten 21 bis 23 Basenpaar (bp)-langen small-interfering-RNAs (siRNAs) oder mit sogenannten short-hairpin-RNAs (shRNAs) eine gezielte Herunterregulation eines Gens statt (Elbashir et al. 2001). Hierbei ahmt die siRNA die reife miRNA nach, wohingegen die shRNA die pre-miRNA imitiert. 


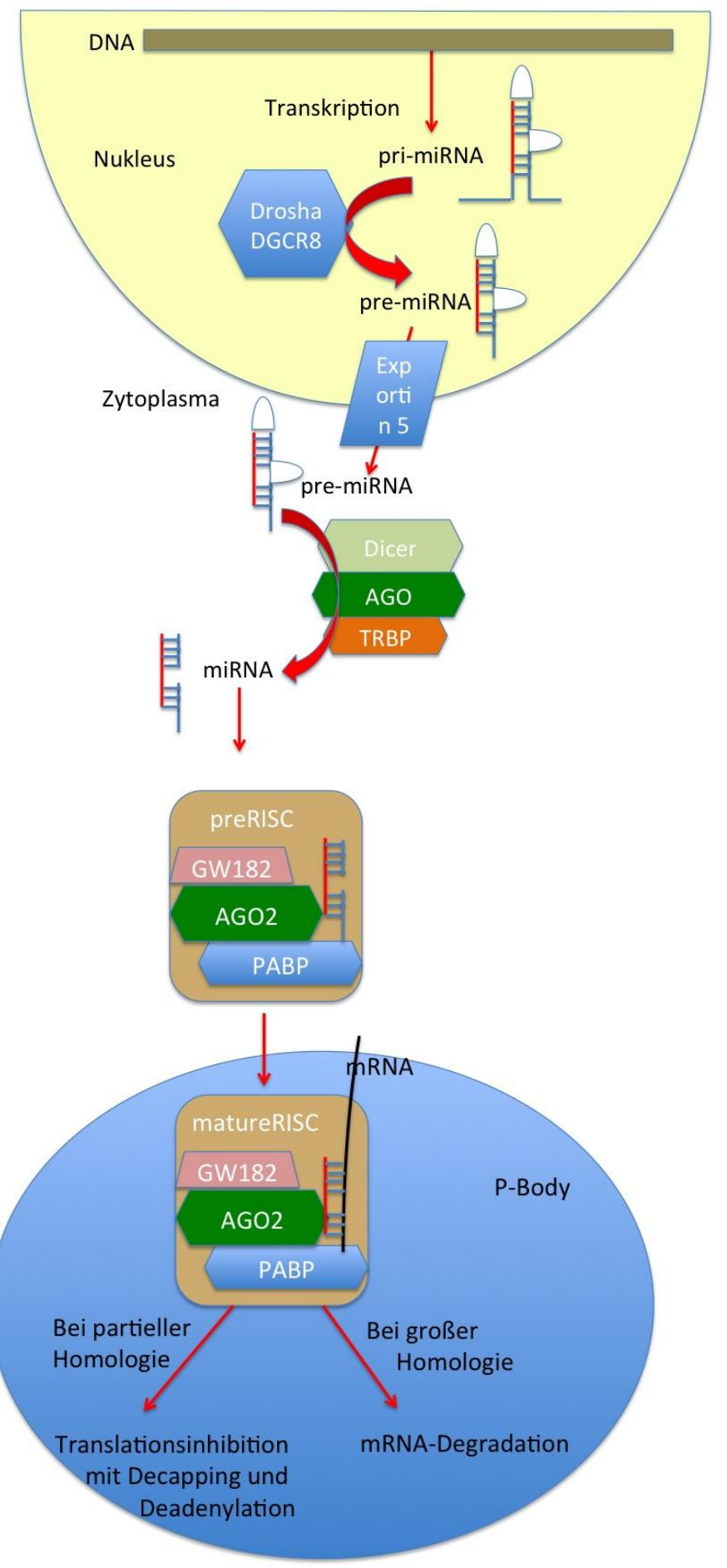

Abb. 4: Schematische Darstellung der RNAi

Die pri-miRNA ist das Primärtranskript der Transkription und besitzt den üblichen Poly-A-Schwanz am 3`-Ende und das Methylguanosin am 5`-Ende. Intrazellulär prozessiert DROSHA mithilfe des Kofaktors DGCR8 die pri-miRNA zur pre-miRNA mit ihrer typischen Haarnadelstruktur. Diese wird über Exportin 5 nach extranukleär transportiert. DICER schneidet im Zytoplasma aus der pre-miRNA die typische 21 bis 25 nt-lange ds-miRNA, welche anschließend in den preRISC integriert wird. Nach der Abspaltung des Passengers und der Bindung der mRNA entsteht der reife RISC im p-Body. Der RISC besteht unter anderem aus AGO2, PABP und glycinetryptophan protein of 182 Kilodalton ( $\mathrm{kDa}$ ) (GW182) und den RNAs. Je nach Komplementarität von miRNA und mRNA wird die mRNA zerstört oder es kommt zu einer Translationsinhibition. 
Die RNAi selbst ist auch Gegenstand intensiver Forschung. Mittlerweile liegen in diesem Bereich mehr als 38.000 Publikationen in der wissenschaftlichen Onlinebibliothek PubMed vor. Kontinuierlich werden bei bekannten und neu beschriebenen Proteinen, beispielsweise bei AGO-Proteinen oder PABP (Cenik und Zamore 2011; Kahvejian et al. 2005), direkte oder indirekte Beteiligungen an der RNAi nachgewiesen. Des Weiteren können der RNAi immer mehr Funktionen, wie Beteiligungen an der DNA-Methylierung, an epigenetischen Regulationen und Chromatinmodifikationen (Gonzalez und Li 2012), zugeordnet werden.

Immer weitere Effektoren der RNAi werden beschrieben. Beispielsweise konnte erst kürzlich die small-nucleolar-Ribonukleinsäure (sno-RNAs) in der Primatengenetik des Deutschen-Primatenzentrums näher beschrieben werden, wo auch diese Dissertation angefertigt wurde (Brameier et al. 2011). Weitere neu entdeckte RNAiEffektoren sind u.a. die transcription-initiation-Ribonukleinsäuren (tiRNAs) oder antigene RNAs (agRNAs) ( Janowski und Corey 2010; Taft et al. 2011).

\subsubsection{Die RNAi als innovative Therapieform}

Der medizinisch-therapeutische Einsatz der RNAi zeigt Erfolg versprechende Ansätze. Aktuell befinden sich mehrere Therapeutika in klinischen Studien der Phase I bis III. Beispielsweise gibt es bezüglich der feuchten altersbedingten Makuladegeneration mehrere Versuche, dieses System zu nutzen. Bei dieser Erkrankung entstehen am Augenhintergrund neue, instabile Gefäße durch eine vaskuläre Hyperproliferation induziert durch das Protein Vascular-EndothelialGrowth-Factor (VEGF). Gegen die mRNA dieses Faktors wurde die siRNA Bevasiranib (Acuity Pharmaceuticals) entwickelt, die einen Abbau der VEGF induziert. Im Mausmodell zeigte Bevasiranib vielversprechende Ergebnisse und konnte bereits in ersten klinischen Studien zu einer Stabilisierung des Zustands bis hin zu einer Verbesserung der visuellen Fähigkeiten führen (Shen et al. 2006). Derzeit befindet sich das Therapeutikum in einer klinischen Studie der Phase III.

Die siRNA QPI-1002 (Quark Pharmaceuticals) soll das akute Nierenversagen verhindern, welches bei etwa $2 \%$ der Bypassoperationen auftritt. QPI-1002 ist gegen die mRNA des Transkriptionsfaktors p53 gerichtet, der bei Zellschädigungen, beispielsweise durch Ischämien bei Bypassoperationen, hochreguliert wird. Dadurch werden initial diverse DNA-Reparaturmechanismen aktiviert und schließlich die Apoptose in der betroffenen Zelle eingeleitet. Durch QPI-1002 soll die p53- 
Expression während und nach Bypassoperationen reduziert werden. Die entsprechenden Studien befinden sich bereits in der klinischen Phase Ila.

Trotz vieler Erfolg versprechender Ansätze in der klinischen Nutzung der RNAi sind einige Probleme dieser neuen Therapieform noch nicht zufriedenstellend gelöst. Oft stellt sich das Einbringen der therapeutischen RNA als Problem dar oder es kommt neben dem gewünschten Effekt zu einer Beeinflussung anderer RNAs, zu sogenannten Off-Target-Effekten (Jackson et al. 2003). Des Weiteren kann es zu einer Aktivierung des angeborenen Immunsystems kommen.

$\mathrm{Ob}$ die RNAi als neue Therapieoption ihren hohen Erwartungen gerecht werden kann, muss sich noch zeigen. Das grundlegende Verständnis der RNAi ist für ihren klinischen Einsatz jedenfalls essentiell. Es bedarf weiterhin umfangreicher Forschung, um weitere Komponenten der RNAi zu erfassen. TRIM22 soll in dieser Arbeit auf eine Funktion in der RNAi untersucht werden. 


\subsection{Zielsetzung}

Bisherige Arbeiten an TRIM22 weisen auf diverse Funktionen des TRIM22 im Bereich der zellulären Immunabwehr und im Zellzyklus hin. Diese Arbeit gliedert sich in zwei Hauptfelder. Dazu sollen einerseits Lokalisationsstudien und andererseits Untersuchungen zur Funktionsbeschreibung durchgeführt werden.

Die intrazelluläre Verteilung von endogenem und ektopisch exprimiertem TRIM22 soll aufgrund widersprüchlicher Angaben in früheren Publikationen überprüft werden. Hierzu soll durch Immunfluoreszenzstudien die subzelluläre Lokalisation des TRIM22 näher beschrieben werden.

Des Weiteren soll durch RNAi der Effekt eines TRIM22-Knockdowns auf die Zellvitalität untersucht werden, da vorangegangene Experimente einen Zusammenhang zwischen veränderter TRIM22-Expression und Apoptose herstellen konnten.

Zusätzlich soll TRIM22 hinsichtlich seiner Funktion näher analysiert werden. 


\section{Material und Methoden}

\subsection{Material}

\subsubsection{Verwendete Geräte}

Tabelle 1: Verwendete Geräte

\begin{tabular}{|c|c|c|}
\hline Gerätetyp & Bezeichnung & Hersteller \\
\hline Autoklav & Varioklav® 400E & $\mathrm{H}+\mathrm{P}$ Labortechnik, Oberschleissheim \\
\hline Autoradiographiekassette & Cronex-Kassette & DuPont, Nemours \\
\hline Blotter, Semi-Dry & V20-SDB & Roth, Karlsruhe \\
\hline Brutschränke & B12 (Bakterien) & Heraeus, Osterode \\
\hline Brutschränke & B6220 (Säugetierzellen) & Heraeus, Osterode \\
\hline Brutschränke & B6060 (Säugetierzellen) & Heraeus, Osterode \\
\hline Durchflusszytometer & BD LSR II BD & Biosciences, Franklin Lakes, NJ USA \\
\hline Einfrierkammer für eukar. Zellen & Mr. Frosty Freezing Container & $\begin{array}{l}\text { Thermo-Scientific, Waltham, MA, } \\
\text { USA }\end{array}$ \\
\hline Elektrophoresekammer & Horizon 58 & Gibco, Life Technology, Darmstadt \\
\hline Elektroporationsgerät & Gene Pulser II & Bio Rad, München \\
\hline Elektroporator & GENE-PULSER II & BIO-RAD, München \\
\hline Entwicklermaschine & Kodak M35 X-Omat Processor & Kodak,Stuttgart \\
\hline Feinwaage & BP $310 \mathrm{~S}$ & Sartorius, Göttingen \\
\hline Gel-Dokumentation (Agarosegele) & Gel Jet Imager 2000 & Intas, Göttingen \\
\hline Gel-Dokumentation (SDS-PAGE) & L 600 & Reflecta, Rottenburg \\
\hline Hamiltonspritze & Mikroliter Syringes & Hamilton, Martinsried \\
\hline Heizblock & M32 & GLW, Würzburg \\
\hline Kühlschränke & Superöko Energiesparer & Privileg, Münster \\
\hline Luminometer & Victor $^{2} 1420$ Medilab Counter & PerkinElmer, Waltham, MA, USA \\
\hline Magnetrührer & M32 & GLW, Würzburg \\
\hline Mikroskope & AxioObserver & Zeiss, Jena \\
\hline Mikroskope & LSM 5 PASCAL & Zeiss, Jena \\
\hline Mikrowellengeräte & Mikromat & AEG, Nürnberg \\
\hline Mikrowellengeräte & NN-K458W & Panasonic, Hamburg \\
\hline Netzteile & Power Pack P25 & Biometra, Göttingen \\
\hline Netzteile & Etron-S & Etron, Neckargerach \\
\hline Netzteile & PP3000 & Biometra, Göttingen \\
\hline pH-Meter & pH 535 Multi CalB & WTW, Weilheim \\
\hline pH-Meter & Komet & Variomag, Darmstadt \\
\hline Fotometer & Gene Quant II & Pharmacia Biotech, Uppsala, Se \\
\hline Pipetten & Research 0.1-2.5 $\mu \mathrm{l}$ & Eppendorf, Hamburg \\
\hline Pipetten & Reference $10 \mu \mathrm{l}$ & Eppendorf, Hamburg \\
\hline Pipetten & Research $10 \mu \mathrm{l}$ & Eppendorf, Hamburg \\
\hline Pipetten & Research $100 \mu \mathrm{l}$ & Eppendorf, Hamburg \\
\hline Pipetten & Research 20-200 $\mu \mathrm{l}$ & Eppendorf, Hamburg \\
\hline Pipetten & Research $1000 \mu \mathrm{l}$ & Eppendorf, Hamburg \\
\hline $\begin{array}{l}\text { Quantitative-Echtzeit-PCR- } \\
\text { System }\end{array}$ & $\begin{array}{l}\text { Relative Quantification ABI } \\
7500\end{array}$ & Invitrogen, Karlsruhe \\
\hline Quantitative-Echtzeit-PCR-Gerät & Rel. Quantification ABI 7500 & Applied Biosystem, Darmstadt \\
\hline Rundschüttler & 3033 & GFL, Burgwedel \\
\hline Rundschüttler & Unimax 1010 & Heidolph, Schwabach \\
\hline Schüttelinkubator & \begin{tabular}{|l|} 
Thermomixer comfort \\
\end{tabular} & Eppendorf, Hamburg \\
\hline Schüttelinkubator & SGD 2000 & Heidolph, Schwabach \\
\hline SDS-PAGE Kammer & EPH-1010-V & Bridge, London, Engl. \\
\hline
\end{tabular}




\begin{tabular}{|l|l|l|} 
Sequenziergerät & ABI3100avant & Applied Biosystem, Darmstadt \\
\hline Spektrofotometer & NanoDrop® ND1000 & PeqLab, Erlangen \\
\hline Sterilbank & K-Safety-KR & Kojair, Rielasingen-Worblingen \\
\hline Thermocycler & GeneAmp PCR System 2700 & Applied Biosystem, Darmstadt \\
\hline Thermocycler & PTC-200 & Bio-Rad, Dreieich \\
\hline Thermocycler & Labcycler & Sensoquest, Göttingen \\
\hline Thermoheizblock & 50126101 & Liebisch, Bielefeld \\
\hline Tiefkühlschrank $\left(-20^{\circ} \mathrm{C}\right)$ & Premium & Liebherr, Biberach an der Riss \\
\hline Tiefkühlschrank $\left(-80^{\circ} \mathrm{C}\right)$ & U 725 & Scientific NB, Hamburg \\
\hline Trockengerät für SDS-PAGE & Titramax 1000 & H. Saur, Reutlingen \\
\hline Vakuumzentrifuge & Speedvac & H. Saur, Reutlingen \\
\hline Vortexer & L46 & GLW, Würzburg \\
\hline Wasserbad & 1003 & GFL, Burgwedel \\
\hline Wasserbad & 1083 & GFL, Burgwedel \\
\hline Zählkammer für eukar. Zellen & Neubauer improved & Marienfeld superior, L. Königshofen \\
\hline Zentrifugen & Centrifuge 5415 R & Eppendorf, Hamburg \\
\hline Zentrifugen & Centrifuge 5415 D & Eppendorf, Hamburg \\
\hline Zentrifugen & Minispin & Eppendorf, Hamburg \\
\hline Zentrifugen & Biofuge Pico & Heraeus, Osterode \\
\hline Zentrifugen & Fresco 21 & Heraeus, Osterode \\
\hline Zentrifugen & Pico 21 & Heraeus, Osterode \\
\hline Zentrifugen & 113 & Sigma, Osterode \\
\hline
\end{tabular}

\subsubsection{Zelllinien und Kulturmedien}

Tabelle 2: Zelllinien und Kulturmedien

\begin{tabular}{|l|l|l|l|}
\hline Zelltyp & Ursprung & Zellkulturmedium & Zusammensetzung \\
\hline HeLa & Humanes Zervixkarzinom; & DMEM-Medium & $1 \times$ DMEM (High \\
& Gebärmutterhalskrebszellen; & & Glucose) \\
& adhärente Zellen. & $10 \%$ FKS Gold (45 min \\
& Ursprünglich zurückführbar & & bei $65^{\circ} \mathrm{C}$ hitzeinaktiviert) \\
& auf die Patientin Henrietta & & $1 \%$ Pen/Strep \\
& Lacks (DSMZ, & & \\
& Braunschweig) & & $1 \times$ RPMI \\
\hline HEK 293 & Human Embryonic Kidney; & RPMI-Medium & $10 \%$ FKSGold (45 min \\
& adhärente Zellen. & & bei $65^{\circ} \mathrm{C}$ hitzeinaktiviert) \\
& (DSMZ, Braunschweig) & & $1 \%$ Pen/Strep \\
\hline
\end{tabular}




\subsubsection{Standardchemikalien und Verbrauchsmaterialien}

Tabelle 3: Standardchemikalien und Verbrauchsmaterialien

\begin{tabular}{|c|c|}
\hline Chemikalien und Verbrauchsmaterialien & Firma \\
\hline 96-, 24-, 12-, 6-Well-Schalen (beschichtet) & Sarstedt, Nümbrecht \\
\hline Acrylamid & Roth, Karlsruhe \\
\hline Adeninsulfat & Sigma-Aldrich, Deisenhofen \\
\hline Agar & Roth, Karlsruhe \\
\hline Agarose & Invitrogen, Karlsruhe \\
\hline Aminosäuren & Biomol, Hamburg \\
\hline Ammoniumperoxodisulfat (APS) & Sigma-Aldrich, Deisenhofen \\
\hline Ammoniumsulfat & Roth, Karlsruhe \\
\hline Ampicillin & Sigma-Aldrich, Deisenhofen \\
\hline Ampuwa & Fresenius AG, Bad Homburg \\
\hline Bacto-Tryptone & Roth, Karlsruhe \\
\hline Bovines Serumalbumin (Bouazzaoui et al.) & Sigma-Aldrich, Deisenhofen \\
\hline Chloroform & Baker, Deventer, NL \\
\hline Coomassie-Brilliant Blau R250 & Fluka, Deisenhofen \\
\hline DAPI & Sigma-Aldrich, Deisenhofen \\
\hline Deckgläschen & Menzel-Gläser, Braunschweig \\
\hline Dextransulfat & Amersham Biosciences, Freiburg \\
\hline Diethylpyrocarbonat (DEPC) & Sigma-Aldrich, Deisenhofen \\
\hline Difco $^{\mathrm{TM}}$ Yeast Nitrogen Base & Becton Dickinson, Heidelberg \\
\hline Dimethylsulfoxid (DMSO) & Roth, Karlsruhe \\
\hline dNTPs (100 mM) & Boehringer, Mannheim \\
\hline DTT & Biomol, Hamburg \\
\hline Elektroporationsküvetten $(0,2 \mathrm{~mm}, 0,4 \mathrm{~mm})$ & Biozym, Hessisch Oldendorf \\
\hline Entwickler & Kodak, Darmstadt \\
\hline Ethanol & Roth, Karlsruhe \\
\hline Ethanol (EtOH) & Roth, Karlsruhe \\
\hline Ethidiumbromid & Sigma-Aldrich, Deisenhofen \\
\hline Ethylendiamintetraessigsäure (EDTA) & Roth, Karlsruhe \\
\hline Falcon Röhrchen 50 mL & Greiner Bio-One, Frickenhausen \\
\hline Falcon-Röhrchen $15 \mathrm{~mL}$ & Greiner Bio-One, Frickenhausen \\
\hline Faltenfilter & Sartorius, Göttingen \\
\hline Filter Top Zellkulturflaschen 50 ml & Greiner Bio-One, Frickenhausen \\
\hline Fixierer & Kodak, Darmstadt \\
\hline Fluorescent-Mounting-Medium & Dako, Hamburg \\
\hline Glycerol & Roth, Karlsruhe \\
\hline Glycylglycin & Roth, Karlsruhe \\
\hline Hamiltonspritze, Mikroliter Syringes & Hamilton, Reno, USA \\
\hline IPTG & Biomol, Hamburg \\
\hline Isopropanol & Roth, Karlsruhe \\
\hline Kaliumacetat & Roth, Karlsruhe \\
\hline Kryokonservierungsröhrchen & Sarstedt, Nümbrecht \\
\hline Leupeptin & Sigma-Aldrich, Deisenhofen \\
\hline Luminol-Fluka & Sigma-Aldrich, Deisenhofen \\
\hline Metafectene & Biontex, Martinsried \\
\hline Methanol & Roth, Karlsruhe \\
\hline Mikro-Schraubröhrchen (2 ml), PP & Sarstedt, Nümbrecht \\
\hline Natriumchlorid & Roth, Karlsruhe \\
\hline Natriumdodecylsulfat (SDS) & Serva, Heidelberg \\
\hline
\end{tabular}




\begin{tabular}{|c|c|}
\hline Nitrocellulose Transfermembran & Schleicher \& Schuell, Dassel \\
\hline NuPAGE TM LDS Sample buffer (4x) & Invitrogen, Karlsruhe \\
\hline NuPAGE TM MES Running buffer (20x) & Invitrogen, Karlsruhe \\
\hline OligoFectamine & Invitrogen, Karlsruhe \\
\hline Orange-G & Sigma-Aldrich, Deisenhofen \\
\hline Petrischalen & Greiner Bio-One, Frickenhausen \\
\hline PfuTurbo-DNA Polymerase & Stratagene, La Jolla, USA \\
\hline Phenol & Invitrogen, Karlsruhe \\
\hline Pipettenspitzen $100 \mu \mathrm{L}$ & Sarstedt, Nümbrecht \\
\hline Pipettenspitzen $1000 \mu \mathrm{L}$ & Sarstedt, Nümbrecht \\
\hline Pipettenspitzen $2,5 \mu \mathrm{L}$ & Biozym, Hessisch Oldendorf \\
\hline Pipettenspitzen $20 \mu \mathrm{L}$ & Biozym, Hessisch Oldendorf \\
\hline Platinum-Taq-DNA-Polymerase & Invitrogen, Karlsruhe \\
\hline PNP- $\alpha-G A L$ & MP Biomedicals, Eschwege \\
\hline Polyacrylamid (PAA) $30 \%$ & Roth, Karlsruhe \\
\hline Propidiumiodid (PI) & Sigma-Aldrich, Deisenhofen \\
\hline Proteinase $\mathrm{K}$ & Amersham Biosciences, Freiburg \\
\hline Reaktionsgefäß 0,2 mL & Sarstedt, Nümbrecht \\
\hline Reaktionsgefäß $0,5 \mathrm{~mL}$ & Sarstedt, Nümbrecht \\
\hline Reaktionsgefäß $1 \mathrm{~mL}$ & Sarstedt, Nümbrecht \\
\hline Reaktionsgefäß $2 \mathrm{~mL}$ & Eppendorf, Hamburg \\
\hline Rediprime $^{\Upsilon M} \|$ II & Amersham Biosciences, Freiburg \\
\hline Restriktionsenzyme & Invitrogen, Karlsruhe \\
\hline Reverse Transkriptase SuperScript II & Invitrogen, Karlsruhe \\
\hline RNA-Längenstandard & Invitrogen, Karlsruhe \\
\hline RNase A & Invitrogen, Karlsruhe \\
\hline RNase-Inhibitor & MBI, St. Leon-Rot \\
\hline Röhrchen für Durchflusszytometrie & Becton Dickinson, Heidelberg \\
\hline Roti®Fect & Roth, Karlsruhe \\
\hline Simply Blue Safe Stain & Invitrogen, Karlsruhe \\
\hline B-Mercaptoethanol & Serva, Heidelberg \\
\hline SYBR®Green-Lösung (50x) & Bioline, Luckenwalde \\
\hline T4-DNA-Ligase & Promega, Mannheim \\
\hline Taq-DNA-Polymerase & Amersham Biosciences, Freiburg \\
\hline TEMED & Sigma-Aldrich, Deisenhofen \\
\hline Tris & Roth, Karlsruhe \\
\hline Triton X-100 & Fluka, Deisenhofen \\
\hline TRIZOL & Invitrogen, Karlsruhe \\
\hline Trypton & Becton Dickinson, Heidelberg \\
\hline Tween 20 & Merck, Darmstadt \\
\hline Vecta Shield mit DAPI & VectorLab, Burlingame, USA \\
\hline Wachskugeln & Wachskugeln \\
\hline Wasser (HPLC- $\left.\mathrm{H}_{2} \mathrm{O}\right)$ & Merck, Darmstadt \\
\hline Whatman-Papier GB 002, GB 005 & Schleicher \& Schuell, Dassel \\
\hline X-Gal & Biomol, Hamburg \\
\hline Zellkulturmedien & PAN, Nürnberg \\
\hline a-Gal & MP Biomedicals, Eschwege \\
\hline
\end{tabular}




\subsubsection{Puffer und Lösungen}

Tabelle 4: Puffer und Lösungen

\begin{tabular}{|c|c|}
\hline Name & Zusammensetzung \\
\hline Blocklösung & $\begin{array}{l}5 \% \text { Milchpulver in } 1 \times \text { TBS } \\
0,05 \% \text { Tween } 20\end{array}$ \\
\hline $\mathrm{DEPC}-\mathrm{H}_{2} \mathrm{O}$ & $0,1 \%$ DEPC in $\mathrm{H}_{2} \mathrm{O}$ \\
\hline dNTP-Mix & $\begin{array}{l}25 \text { mM Desoxyadenosin-5'-Triphosphat (dATP) } \\
25 \text { mM Desoxycytosin-5'-Triphosphat (dCTP) } \\
25 \text { mM Desoxyguanin-5'-Triphosphat (dGTP) } \\
25 \text { mM Desoxythymidin-5`-Triphosphat (dTTP) }\end{array}$ \\
\hline ECL-Lösung & $\begin{array}{l}100 \mu \mathrm{l} 250 \mathrm{mM} \text { Luminol } \\
44 \mu \mathrm{l} 90 \mathrm{mM} \text {-CA } \\
1 \mathrm{ml} 1 \mathrm{M} \text { Tris- } \mathrm{HCl} \mathrm{pH} 8,5 \\
8,8 \mathrm{ml} \mathrm{H} \mathrm{H}_{2}\end{array}$ \\
\hline KMT-Puffer (5x) & $\begin{array}{l}2,5 \mathrm{ml} 1 \mathrm{M} \mathrm{TRIS} \\
860 \mu \mathrm{l} 1 \mathrm{M} \mathrm{HCl} \\
5 \mathrm{ml} 2,5 \mathrm{M} \mathrm{KCl} \\
500 \mu \mathrm{l} \mathrm{MgCl}_{2} \\
\text { auf } 50 \mathrm{ml} \mathrm{mit} \mathrm{H}_{2} \mathrm{O} \text { auffüllen } \\
\mathrm{pH} 8,4\end{array}$ \\
\hline Laemmli-Puffer (6x) & $\begin{array}{l}4,53 \mathrm{~g} \text { TRIS } \\
12 \mathrm{~g} \text { SDS } \\
15 \mathrm{~g} \text { Saccharose } \\
\text { mit Wasser auf } 80 \mathrm{ml} \text { auffüllen } \\
\mathrm{pH} 6,8 \text { (mit } 1 \mathrm{M} \mathrm{HCl} \text { ) } \\
90 \mathrm{mg} \text { Bromphenolblau } \\
\text { mit } \mathrm{H}_{2} \mathrm{O} \text { auf } 100 \mathrm{ml} \\
\text { filtrieren }\end{array}$ \\
\hline P1-Lösung & $\begin{array}{l}50 \mathrm{mM} \text { TRIS }(\mathrm{pH} 8,0) \\
10 \mathrm{mM} \text { EDTA }(\mathrm{pH} 8,0) \\
\mathrm{pH}-\text { Wert auf } 8,0 \text { einstellen } \\
\text { vor Gebrauch } 100 \mu \mathrm{g} / \mathrm{ml} \text { RNase A hinzufügen }\end{array}$ \\
\hline $\begin{array}{l}\text { P1-Puffer } \\
\text { (Plasmidpräparation) }\end{array}$ & $\begin{array}{l}2 \% \text { RNase A }(10 \mathrm{mg} / \mathrm{ml}), 50 \mathrm{mM} \text { TRIS, } \\
1 \mathrm{mM} \text { EDTA }(\mathrm{pH} 8,0)\end{array}$ \\
\hline P2-Lösung & $\begin{array}{l}\text { P2a: } 400 \mathrm{mM} \mathrm{NaOH} \\
\text { P2b: } 2 \% \text { PBS } \\
\text { vor Gebrauch 1:1 mischen }\end{array}$ \\
\hline P3-Lösung & $\begin{array}{l}3 \mathrm{M} \mathrm{KAc} \\
\mathrm{pH} 4,8 \\
\text { einstellen mit Essigsäure }\end{array}$ \\
\hline PBS (10x) & $\begin{array}{l}1,37 \mathrm{M} \mathrm{NaCl} \\
27 \mathrm{mM} \mathrm{Kcl} \\
81 \mathrm{mM} \mathrm{Na}_{2} \mathrm{HPO} 4 \\
14,7 \mathrm{mM} \mathrm{KH}_{2} \mathrm{PO} 4\end{array}$ \\
\hline PBS/EDTA & $\begin{array}{l}1 \% \text { PBS (10x) } \\
100 \text { mM EDTA } \\
\text { steril filtrieren }\end{array}$ \\
\hline Probenpuffer & $\begin{array}{l}1 \% \text { SDS } \\
100 \text { mM DTT } \\
50 \text { mM TRIS }(\mathrm{pH} 7,5)\end{array}$ \\
\hline
\end{tabular}




\begin{tabular}{|c|c|}
\hline Sammelgel $4 \%$ & $\begin{array}{l}0,54 \mathrm{ml} 30 \% \text { Polyacrylamid } \\
1 \mathrm{ml} 4 x \text { TRIS/SDS }(\mathrm{pH} 6,8) \\
2,46 \mathrm{ml} \mathrm{H}_{2} \mathrm{O} \\
50 \mu \mathrm{l} 10 \% \text { APS } \\
20 \mu \mathrm{l} \text { TEMED } \\
\end{array}$ \\
\hline SDS-Sammelgel (5\%) & $\begin{array}{l}1,7 \mathrm{ml} \mathrm{PAA}(30 \%) \\
1,25 \mathrm{ml} \mathrm{TRIS} / \mathrm{SDS}(\mathrm{pH} 6,8) \\
6,8 \mathrm{ml} \mathrm{H} \mathrm{O} \\
50 \mu \mathrm{APS}(10 \%) \\
20 \mu \mathrm{l} \text { TEMED }\end{array}$ \\
\hline SDS-Trenngel (8\%/10\%) & $\begin{array}{l}5,3 / 6,7 \mathrm{ml} \mathrm{PAA}(30 \%) \\
5 \mathrm{ml} \text { TRIS/SDS }(\mathrm{pH} 8,8) \\
10,6 / 9,3 / 7,9 \mathrm{ml} \mathrm{H} \mathrm{H}_{2} \mathrm{O} \\
75 \mu \mathrm{I} \text { APS } \\
25 \mu \mathrm{I} \text { TEMED }\end{array}$ \\
\hline $\begin{array}{l}\text { Semi-Dry-Transferpuffer }(\mathrm{pH} \\
8,3)\end{array}$ & $\begin{array}{l}25 \mathrm{mM} \text { Trisbase } \\
150 \mathrm{mM} \text { Glycin } \\
20 \% \text { Methanol } \\
\end{array}$ \\
\hline TBE-Agarosegel (1\%) & $\begin{array}{l}1 \times \mathrm{TBE} \\
1 \% \text { Agarose } \\
\text { aufkochen und auf } 55^{\circ} \mathrm{C} \text { abkühlen lassen } \\
0,5 \mu \mathrm{m} / \mathrm{ml} \text { Ethidiumbromid } \\
\text { hinzufügen } \\
\end{array}$ \\
\hline TBS (10x) & 1,37 M NaCl100 mM TRIS/HCl (pH 7,2) \\
\hline TRIS/SDS $(\mathrm{pH} 6,8) 4 \mathrm{x}$ & $\begin{array}{l}0,5 \mathrm{M} \text { Trisbase } \\
140 \mathrm{mM} \text { SDS } \\
\text { pH-Wert auf } 6,8 \text { einstellen } \\
\text { nach zwei Tagen pH nachjustieren }\end{array}$ \\
\hline TRIS/SDS $(\mathrm{pH} 8,8) 4 \mathrm{x}$ & $\begin{array}{l}1,5 \mathrm{M} \text { TRISbase } \\
14 \mathrm{mM} \text { SDS } \\
\text { pH-Wert auf } 8,8 \text { einstellen } \\
\text { nach zwei Tagen pH nachjustieren }\end{array}$ \\
\hline Trypanblau-Lösung & \begin{tabular}{|l} 
1x PBS \\
$0,5 \%$ Trypanblau \\
\end{tabular} \\
\hline Trypsin-EDTA-Lösung & $\begin{array}{l}\text { 0,05\% Trypsin } \\
0,02 \% \text { EDTA } \\
\end{array}$ \\
\hline SOC-Medium & $\begin{array}{l}\text { pro Liter dest. } \mathrm{H}_{2} \mathrm{O}: \\
20 \mathrm{~g} \text { Trypton / Pepton } \\
5 \mathrm{~g} \text { Hefeextrakt } \\
2 \mathrm{ml} 5 \mathrm{M} \mathrm{NaCl} \\
1 \mathrm{ml} 2,5 \mathrm{M} \mathrm{KCl} \\
10 \mathrm{ml} 1 \mathrm{M} \mathrm{MgCl} \\
2,464 \mathrm{~g} \mathrm{MgSO}_{4} \\
3,604 \mathrm{~g} \text { Glukose } \\
\text { autoklavieren } \\
\end{array}$ \\
\hline Silikamilch (100 mg / ml) & $\begin{array}{l}5 \mathrm{~g} \text { Silika } \\
10 \mathrm{ml} 1 \mathrm{x} \text { PBS } \\
2 \text { x mischen, } 2 \mathrm{~h} \text { stehen lassen, Überstand abnehmen } \\
\text { bei } 2000 \times \mathrm{xg} 2 \mathrm{~min} \text { zentrifugieren und restlichen Überstand abnehmen } \\
50 \mathrm{ml} 3 \mathrm{M} \mathrm{NaJ} \text { zugeben, resuspendieren und aliquotieren } \\
\end{array}$ \\
\hline $6 \mathrm{M}$ Natriumjodid & $\begin{array}{l}224,84 \mathrm{~g} \mathrm{NaJ} \\
\text { ad. } 250 \mathrm{ml} \text { mit Millipore } \\
\mathrm{H}_{2} \mathrm{O} \text { bei } 4{ }^{\circ} \mathrm{C} \text { dunkel lagern } 20 \mathrm{~g}\end{array}$ \\
\hline BSA / Triton-Puffer & $\begin{array}{l}5 \mathrm{ml} \mathrm{BSA} \text {-Stocklösung }(100 \mathrm{mg} / \mathrm{ml}) 350 \mathrm{mg} \text { Triton X } \\
\text { ad. } 50 \mathrm{ml} \text { mit DNase- und RNase-freiem } \mathrm{H}_{2} \mathrm{O} \\
\text { steril filtrieren }\end{array}$ \\
\hline Nonidet-P-40-Puffer & $\begin{array}{l}1 \% \mathrm{NP}-40 \\
150 \mathrm{mM} \mathrm{NaCl} 50 \mathrm{mM} \text { TRIS-HCl pH 8,0 }\end{array}$ \\
\hline
\end{tabular}




\subsubsection{Primer}

Tabelle 5: Primer

\begin{tabular}{|l|l|}
\hline Name & Sequenz $\mathbf{5}^{\prime} \mathbf{- 3}^{\prime}$ \\
\hline TRIM22-fw & AAG CTT GCA ATG GAT TTC TCA GTA AAG \\
\hline TRIM22-rev & AAG CTT GGA AAA CCC CAA TAC GAC AG \\
\hline GAPDH-fw & CCA GCA AGA GCA CAA GAG GAA GAG \\
\hline GAPDH-rev & AGC ACA GGG ATA CTT TAT TAG ATG \\
\hline
\end{tabular}

\subsubsection{Vektoren}

Tabelle 6: Vektoren

\begin{tabular}{|l|l|}
\hline Vektor & Firma \\
\hline psiCHECK-2-Vektor & PromegaMadison, WI USA \\
\hline pAcGFP-N1 & Clontech, Palo Alto, CA, USA \\
\hline
\end{tabular}

\subsection{7. siRNAs}

Tabelle 7: siRNAs

\begin{tabular}{|c|c|c|c|}
\hline Gen & SiRNA & $\begin{array}{l}\text { siRNA-Sequenz oder ID- } \\
\text { Nummer }\end{array}$ & Hersteller \\
\hline TRIM22 & siTRIM22-I & $\begin{array}{l}\text { GCUAAUGCCUUAAUGAAAUU } \\
U\end{array}$ & Thermo Scientific, Waltham, MA, USA \\
\hline TRIM22 & $\begin{array}{l}\text { siTRIM22- } \\
\text { II }\end{array}$ & $\begin{array}{l}\text { UAGCAAAGCAUCAUAGAUUU } \\
U\end{array}$ & Thermo Scientific, Waltham, MA, USA \\
\hline EG-5 & siEG-5 & $\begin{array}{l}\text { AACUGGAUCGUAAGAAGGCA } \\
\text { GUU }\end{array}$ & Thermo Scientific, Waltham, MA, USA \\
\hline DROSHA & $\begin{array}{l}\text { SiDROSH } \\
\mathrm{A}\end{array}$ & sc-44080 & $\begin{array}{l}\text { Santa Cruz Biotech , Heidelberg, } \\
\text { Germany }\end{array}$ \\
\hline DICER & siDICER & \#6576 & $\begin{array}{l}\text { Cell Signaling Technology, Danvers, } \\
\text { MA, USA }\end{array}$ \\
\hline \multicolumn{4}{|c|}{ nicht humanes Ziel: } \\
\hline GL-2 & siGL-2 & $\begin{array}{l}\text { CACGUACGCGGAAUACUUCG } \\
\text { AAA }\end{array}$ & Thermo Scientific, Waltham, MA, USA \\
\hline
\end{tabular}




\subsubsection{Antikörper}

Tabelle 8: Antikörper

\begin{tabular}{|c|c|c|c|c|c|}
\hline $\begin{array}{l}\text { Antikörper } \\
\text { (gegen) }\end{array}$ & Herkunft & $\begin{array}{l}\text { IF- } \\
\text { Verdünnun } \\
\text { g }\end{array}$ & $\begin{array}{l}\text { WB- } \\
\text { Verdünnung }\end{array}$ & Nummer & Hersteller \\
\hline $\begin{array}{l}\text { TRIM22 } \\
\text { Antiserum }\end{array}$ & Maus & $1+500$ & & & eigene Herstellung \\
\hline TRIM22 & Maus & & $2 \mu \mathrm{g} / \mathrm{ml}$ & ab81642 & Abcam, Cambridge, UK \\
\hline$\alpha$-Tubulin-FITC & Maus & $1+20$ & & & $\begin{array}{l}\text { Sigma-Alderich, St. } \\
\text { Louis, MI, USA }\end{array}$ \\
\hline $\mathrm{Y}$-Tubulin & Maus & $1+500$ & & & $\begin{array}{l}\text { Sigma-Alderich, St. } \\
\text { Louis, MI, USA }\end{array}$ \\
\hline Y-Tubulin & Kaninchen & $1+150$ & & & Abcam, Cambridge, UK \\
\hline CENP-E & Maus & $1+100$ & & $\begin{array}{l}\text { Klon } \\
1 \mathrm{H} 12\end{array}$ & $\begin{array}{l}\text { Active Motif, La Hulpe, } \\
\text { Belgien }\end{array}$ \\
\hline DICER & Maus & $1+100$ & $2.5 \mu \mathrm{g} / \mathrm{ml}$ & $a b 14601$ & Abcam, Cambridge, UK \\
\hline DROSHA & Hase & $1+25$ & $1 \mu \mathrm{g} / \mathrm{ml}$ & $a b 12286$ & Abcam, Cambridge, UK \\
\hline AGO2 & Hase & $1+200$ & $2 \mu \mathrm{g} / \mathrm{ml}$ & ab32381 & Abcam, Cambridge, UK \\
\hline PABP & Hase & $1+50$ & $20 \mu \mathrm{g} / \mathrm{ml}$ & ab21060 & Abcam, Cambridge, UK \\
\hline $\begin{array}{l}\text { Anti-M-sek- } \\
\text { FITC }\end{array}$ & Hase & $1+40$ & & & Dako, Deutschland \\
\hline $\begin{array}{l}\text { Anti-M-sek- } \\
\text { TRITC }\end{array}$ & Hase & $1+40$ & & & Dako, Deutschland \\
\hline $\begin{array}{l}\text { Anti-R-sek- } \\
\text { TRITC }\end{array}$ & Schwein & $1+40$ & & & Dako, Deutschland \\
\hline & & \multicolumn{2}{|c|}{$\begin{array}{l}\text { Verdünnung mit } 5 \% \text { BSA } \\
\text { PBS }\end{array}$} & & \\
\hline
\end{tabular}

\subsubsection{Kits}

Tabelle 9: Kits

\begin{tabular}{|l|l|}
\hline Name & Firma \\
\hline BigDye® Terminator v1.1 Cycle Sequencing Kit & Applied Biosystem,Carlsbad, Ca \\
\hline In Situ Cell Death Detection Kit TMR red & Roche, Mannheim \\
\hline QIAquick® Plasmid Midi/Maxi Kit & Qiagen, Hilden \\
\hline RNeasy Mini Kit & Qiagen, Hilden \\
\hline Dual Luciferase Kit & Promega, Madison \\
\hline SteadyGlo Luciferase Kit & Promega, Madison \\
\hline Renilla Luciferase Kit & Promega, Madison \\
\hline Pierce Co-Immunoprecipitation Kit & Pierce, Thermo Scientific, Rockford, IL \\
\hline
\end{tabular}




\subsubsection{Verwendete Computerprogramme}

FACS-Messung: BD FACSDiva Sofware (BD Biosciences)

Auswertung von FACS-Analysen: FlowJo 8.7.1 (Tree Star Inc.)

Literaturprogramm: EndNote X4 (NilesSoftware Inc.)

Textbearbeitung und -erstellung: Word 2011 (Microsoft)

Tabellen und Graphen: Exel 2011 (Microsoft)

Bildbearbeitung: Powerpoint 2011 (Microsoft)

Genbank (http://www.ncbi.nlm.nih.gov):

1. Analyse von DNA- und Protein-Sequenzen mit der Datenbank (http://www.ncbi.nlm.nih.gov/BLAST/Blahcgi)

2. Vergleich von zwei DNA-Sequenzen

(http://www.ncbi.nlm.nih.govgorf/bl2.html/) 


\subsection{Methoden}

\subsubsection{Zellbiologische Methoden}

\subsubsection{Zellkultur}

Alle in 2.1.1 aufgeführten Zelllinien wurden bei $37^{\circ} \mathrm{C}, 95 \%$ Luftfeuchtigkeit und $5 \%$ $\mathrm{CO}_{2}$ im Brutschrank kultiviert. Medien und Lösungen wurden, soweit nicht anders angegeben, in einem Wasserbad auf $37^{\circ} \mathrm{C}$ vorgewärmt, bevor die Behandlung der Zellen erfolgte. Im Allgemeinen wurde die Kultivierung der Zellen mit den oben angegebenen Medien durchgeführt (siehe 2.1.2).

\subsubsection{Passagieren von Zellen}

Adhärent wachsende Zellen wurden mit Erreichen der optischen Konfluenz passagiert, um die Zellen für Versuche in der gewünschten Dichte auszuplattieren. Hierzu wurde das Zellkulturmedium entfernt und die Zellen einmal mit auf $37^{\circ} \mathrm{C}$ vorgewärmtem und sterilem 1x PBS gewaschen. Nach Entfernung des PBS wurden die Zellen für 2 bis 5 min in Trypsin-EDTA-Lösung bei $37^{\circ} \mathrm{C}$ inkubiert. Anschließend wurde unter mikroskopischer Kontrolle auf die vollständige Ablösung der Zellen gewartet. Durch die Zugabe des Zellkulturmediums wurde die Trypsin-Reaktion gestoppt, mögliche Zellklumpen durch gründliches Pipettieren aufgelöst und die Zellzahl in der Neubauer-Zählkammer bestimmt. Die Zellen wurden nun in gewünschter Dichte ausgesät.

\subsubsection{Kryokonservieren von Zellen}

Zur Kryokonservierung wurden Zellen bei einer optischen Konfluenz von über $80 \%$ gewaschen, trypsiniert, in Zellkulturmedium aufgenommen und anschließend 5 min bei $1000^{*} \mathrm{~g}$ zentrifugiert. Danach wurde das Zellkulturmedium entfernt, die Zellen in $4{ }^{\circ} \mathrm{C}$ kaltem Einfriermedium (8\% (v/v) DMSO in Zellkulturmedium) resuspendiert und jeweils $1 \mathrm{ml}$ dieser Lösung in Einfrierröhrchen überführt. Diese wurden anschließend im mit Isopropanol befüllten Mr. Frosty gelagert und durch eine definierte Kühlungsrate von etwa $-1^{\circ} \mathrm{C} / \mathrm{min}$ auf $-80^{\circ} \mathrm{C}$ gekühlt. Anschließend wurden die Einfrierröhrchen in flüssigen Stickstoff überführt. 


\subsubsection{Revitalisierung von Zellen}

Zur Revitalisierung von kryokonservierten Zellen wurden diese zügig bei $37^{\circ} \mathrm{C}$ im Wasserbad aufgetaut. Danach wurden sie in vorgewärmtes Kulturmedium ohne Selektionsantibiotikum überführt und darin über Nacht inkubiert. Am folgenden Tag wurde das Medium vollständig gewechselt, da DMSO bei längerer Kultivierungsdauer und Temperaturen über $4^{\circ} \mathrm{C}$ zytotoxisch wirkt.

\subsubsection{Bestimmung der Zellzahl}

Zur Bestimmung der Zellzahl wurde die Neubauer-Zählkammer benutzt. Hierbei wurden $20 \mu \mathrm{l}$ geernteter Zellen mit $20 \mu \mathrm{l}$ Trypanblau vorsichtig gemischt und für 5 min bei RT inkubiert. Die Berechnung der Zellmenge erfolgte nach folgender Formel: Zellmenge / $\mathrm{ml}=$ (gezählte Zellzahl / Anzahl gezählter Quadrate) $\mathrm{x}$ Verdünnung $\mathrm{x}$ 1000).

\subsubsection{Apoptosenachweis durch den TUNEL-Test}

Der Terminal-deoxynucleotidyl transferase-dUTP-nick-end-labeling-Test (Tunel-Test) bietet eine sichere Methode zur Visualisierung apoptotischer Zellen. Diese Methode nutzt im Verlauf der Apoptose entstehende DNA-Einzelstrangbrüche, an denen das Enzym terminale Desoxyribosyl-Transferase (TdT) Fluoreszenz-markierte Nukleotide elongiert. In dieser Versuchsreihe wurde das In Situ Cell Death Detection Kit TMR red verwendet und genau nach den Vorgaben des Herstellers verfahren. Es wurde mit HeLa-Zellen gearbeitet, die mit verschiedenen siRNAs oder mit Plasmiden transfiziert wurden. Die Auswertung erfolgte durch Immunfluoreszenzmikroskopie.

\subsubsection{Luziferasemessung}

Die Luziferasemessung nutzt die katalytische Eigenschaft der Luziferasen, aus $\mathrm{O}_{2}$ und Adenosintriphosphat (ATP) Licht herzustellen. Lumineszenz entsteht durch die Oxidation eines Pigments (Luziferin). Die Reaktionsgleichung lautet:

Luziferin + ATP $\rightarrow$ Luziferyl Adenylat + PPi

Luziferyl Adenylat $+\mathrm{O} 2 \rightarrow$ Oxyluziferin + AMP + Licht

Die Enzyme Renilla-Luziferase aus Renilla reniformis und die Firefly-Luziferase aus Photinus pyralis dienen der Reaktion als Enzym. Im Rahmen dieser Arbeit wurde das Vorkommen von miRNAs überprüft, sodass eine zur miRNA komplementäre Sequenz in den psiCHECK-2-Vektor (siehe Anhang) kloniert wurde. Auf diesem Vektor liegen das Gen der Firefly-Luziferase, welches den Referenzwert liefert, und 
das der Renilla-Luziferase, in dessen Multipler Klonierungsstelle (MCS) die komplementäre miRNA Sequenz kloniert wurde. Bei vorhandener miRNA wurde die mRNA der Renilla-Luziferase mittels RNAi durch die einklonierte komplementäre Sequenz zur miRNA degradiert (Abb. 5). Es erfolgte eine ausgeprägte Reduktion der Renilla-Lumineszenz.

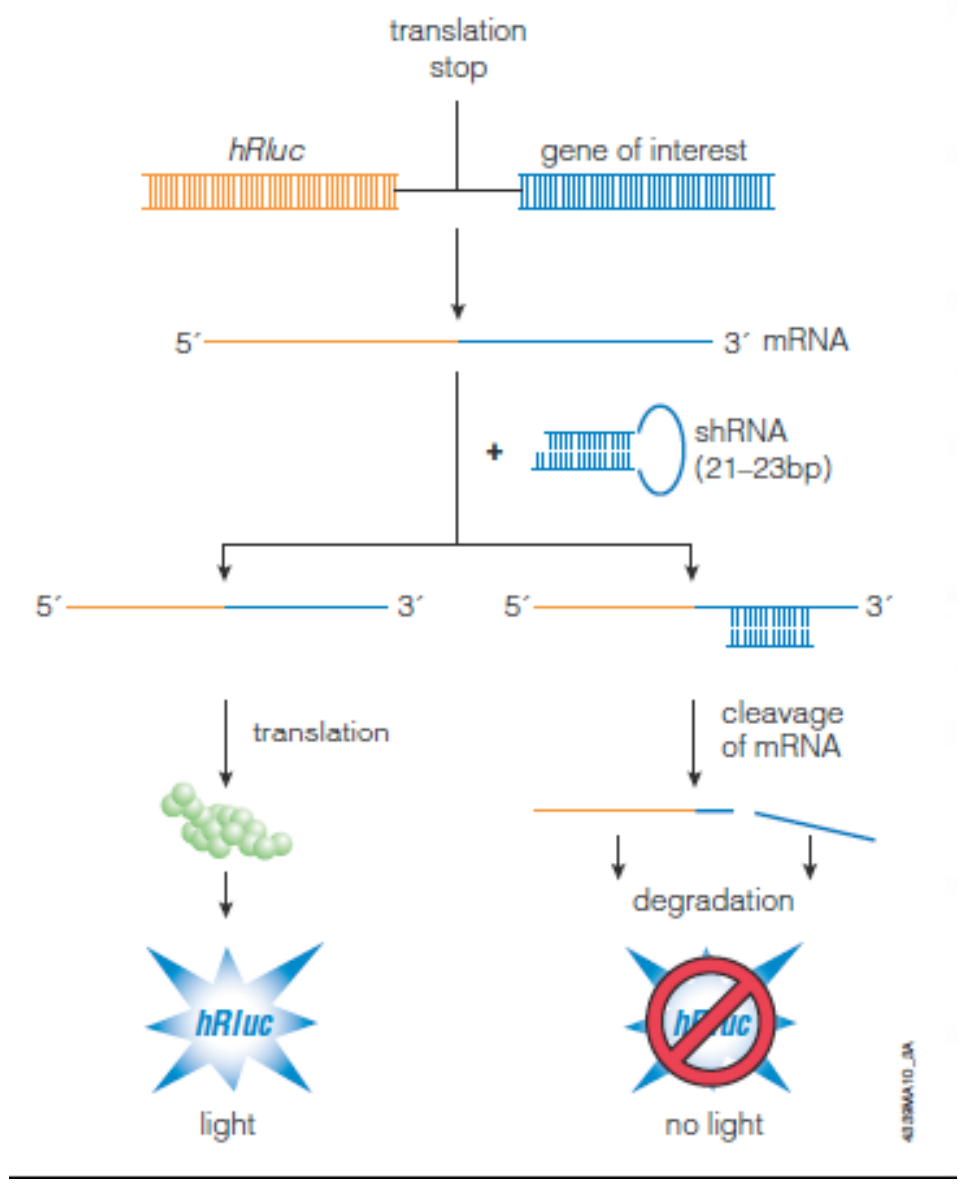

Abb. 5: Darstellung der Luziferasemessung

In die MCS wird eine zur gesuchten miRNA vollständig komplementäre ZielSequenz kloniert. Wenn die gesuchte miRNA vorhanden ist, kommt es im Rahmen der RNAi zum Abbau der Renilla-mRNA. Das Renilla-Signal kann dann nicht mehr detektiert werden (Bildquelle: www.promega.com).

Im Rahmen der Versuchsreihe wurden HeLa-Zellen in 96-Well-Schalen ausplattiert und mit einer siRNA und dem psiCHECK-2-Vektor doppeltransfiziert. Nach 48stündiger Inkubationszeit wurde das Medium abgenommen und $30 \mu \mathrm{l}$ des Dual-GloFirefly-Substrates hinzugegeben. Danach fand eine Resuspension in $100 \mu \mathrm{l}$ des Dual-Glo Puffers statt. Nach 10-minütigem Rütteln der Schale erfolgte die erste Lumineszenz-Messung über $10 \mathrm{sec}$ am Luminometer. Anschließend wurden je $25 \mu \mathrm{l}$ Stop-and-Glo-Substrat hinzugegeben, die Schale nochmals für $10 \mathrm{~min}$ auf den Rüttler gestellt und die Lumineszenz für 10 sec gemessen. 


\subsubsection{Transiente Transfektion eukaryotischer Zellen}

Zur Transfektion eukaryotischer Zellen wurden die Transfektionsreagenzien Metafectene für DNA-Transfektionen und Oligofectamin für siRNA-Transfektionen verwendet. Metafectene und Oligofectamin sind polykationische Transfektionsreagenzien, welche mit einem neutralen Ko-Lipid vorliegen. Mittels Lipofektion erfolgt die Einschleusung der DNA beziehungsweise (bzw.) RNA in die Zelle. Für die Transfektion des TRIM22-GFP-Konstrukts in HeLa-Zellen wurde Metafectene verwendet. Oligofectamin wurde zur Transfektion verschiedener siRNAs eingesetzt.

\subsection{Präparation der Zellen}

Zellen mit einer 80 bis 90\%-igen Konfluenz wurden passagiert und auf eine Zellzahl von $1{ }^{*} 10^{5}$ Zellen pro $1 \mathrm{ml}$ in DMEM mit $10 \%$ FCS ohne Antibiotikazusatz eingestellt. Anschließend wurden die Zellen mit $532 \mu \mathrm{l}$ pro Well in einer 24-WellSchale ausgesät. Bei Versuchen mit dem Laserscanning-Mikroskop (LSM) oder zur konfokalen Mikroskopie wurden die 24-Well-Schalen mit Deckgläschen ausgelegt. Im Anschluss wurden die Zellen für 18 bis $24 \mathrm{~h}$ inkubiert, um die Transfektion vor dem exponentiellen Wachstumsschub durchzuführen.

\subsection{Transfektion}

Für die Transfektion eines Wells einer 24-Well-Platte wurden zwei Ansätze präpariert:

Ansatz A: $3 \mu \mathrm{l}$ des $20 \mathrm{mM}$ siRNA Ansatzes bzw. $1 \mu \mathrm{l}$ des $1 \mu \mathrm{g} / \mu \mathrm{l}$ DNA Ansatzes $50 \mu \mathrm{l}$ RPMI

Ansatz B: $3 \mu$ l Oligofectamin bzw. $4 \mu$ l Metafectene $12 \mu$ I RPMI

Anschließend wurde der Ansatz A vorsichtig auf den Ansatz B gegeben und durch einmaliges Auf- und Abpipettieren gemischt. In den folgenden 15 bis 20 Minuten bildeten sich die RNA/DNA-Lipidkomplexe. Im nächsten Schritt wurden vorsichtig 68 $\mu \mathrm{l}$ des Transfektionsgemischs in jedes Well gegeben und durch leichtes Schwenken der Kulturschale gleichmäßig verteilt. 
Nach 6 bis 8 h Inkubationszeit wurde das Medium abgesaugt und durch normales Zellkulturmedium mit FCS und Antibiotika ersetzt. Je nach zu untersuchendem Protein mussten die Zellen bis zu drei weitere Tage inkubieren.

\subsubsection{Molekularbiologische Methoden}

\subsubsection{Mini-Präparation von Plasmid-DNA}

Die Bakterien wurden auf einer Agarplatte unter spezifischer Antibiotikaselektion kultiviert. Eine einzelne Kolonie wurde mit einem Zahnstocher aufgenommen und über Nacht in LB-Medium in den $37{ }^{\circ} \mathrm{C}$ warmen Schüttelinkubator gestellt. Am folgenden Tag wurden $2 \mathrm{ml}$ der Übernachtkultur bei $16000^{*} \mathrm{~g}$ abzentrifugiert. Das Pellet wurde in $200 \mu \mathrm{l}$ kalter P1-Lösung resuspendiert. Im nächsten Schritt wurde mit $200 \mu \mathrm{l}$ der P2-Lösung eine modifiziert alkalische Lyse durchgeführt. Daran schloss sich die Neutralisierung mit $200 \mu \mathrm{l}$ der P3-Lösung an. Diese Lösung wurde bei $16000^{*} \mathrm{~g}$ zentrifugiert. Der Überstand wurde nun in ein neues Eppendorfgefäß überführt, welches mit 1 Volumen Isopropanol versetzt war. Nach erfolgter PlasmidDNA Fällung bei $16000^{*} \mathrm{~g}$ wurde das Pellet in $500 \mu \mathrm{l} 70 \%$ Ethanol gewaschen und anschließend in der Vakuumzentrifuge getrocknet. Zum Abschluss wurde die Plasmid-DNA in $50 \mu \mathrm{l} \mathrm{H}_{2} \mathrm{O}$ aufgenommen.

\subsubsection{Midi-Präparation von Plasmid-DNA}

Die Plasmidanreicherung wurde nach Anleitung des Herstellers Qiagen unter Verwendung der mitgelieferten Puffer P1, P2, P3, QBT, QC, QF und TE durchgeführt, deren Zusammensetzung vom Hersteller nicht angegeben wird. Es wurden $100 \mathrm{ml}$ einer über Nacht bei $37^{\circ} \mathrm{C}$ inkubierten E.-coli-Kultur für 15 min bei 4 ${ }^{\circ} \mathrm{C}$ und $6000{ }^{*} \mathrm{~g}$ zentrifugiert, der Überstand verworfen, die Zellen in $4 \mathrm{ml} \mathrm{P1-Puffer}$ resuspendiert und mit $4 \mathrm{ml}$ P2-Puffer vorsichtig vermischt. Nach dem Zufügen von 3 $\mathrm{ml}$ des P3-Puffers, wurde die Suspension vorsichtig geschwenkt und dann $20 \mathrm{~min}$ auf Eis inkubiert. Anschließend erfolgte eine Zentrifugation für 30 min bei $4{ }^{\circ} \mathrm{C}$ und $16000^{*} \mathrm{~g}$. Anschließend wurde der Überstand verworfen und abermals zentrifugiert (15 min, $4^{\circ} \mathrm{C}$ und $16000^{*} \mathrm{~g}$ ). Der Überstand wurde auf eine mit QBT-Puffer äquilibrierte Qiagen-tip100-Säule gegeben. An die Säule gebundene Plasmid-DNA wurde zweimal mit $10 \mathrm{ml} \mathrm{QC-Puffer} \mathrm{gewaschen} \mathrm{und} \mathrm{in} 5 \mathrm{ml}$ QF-Puffer in einem 50ml-Falkon-Röhrchen eluiert. Mit 3,5 ml Isopropanol wurde die DNA 60 min bei $4{ }^{\circ} \mathrm{C}$ und 5000 *g präzipitiert. Der Überstand wurde vorsichtig abgenommen, die DNA mit 
$2 \mathrm{ml} 70 \%$-igem Ethanol gewaschen, erneut $60 \mathrm{~min}$ bei $4{ }^{\circ} \mathrm{C}$ und $5000{ }^{*} \mathrm{~g}$ zentrifugiert. Der Überstand wurde verworfen und die DNA für 10 min bei RT getrocknet. Das getrocknete DNA-Pellet wurde in $150 \mu \mathrm{ddH}_{2} \mathrm{O}$ aufgenommen und die Konzentration der DNA entweder mithilfe des Spektrofotometers oder eines DNAStandards über Gelelektrophorese bestimmt. Die mit dieser Methode isolierte Plasmid-DNA konnte für die Transfektion von Zelllinien, für die Restriktionsanalyse, zur Subklonierung oder Sequenzierung eingesetzt werden.

\subsubsection{Transformation kompetenter Bakterien mittels Elektroporation}

Die kompetenten Escheria-coli (E. coli)-Zellen wurden aus dem $-80{ }^{\circ} \mathrm{C}$ Gefrierschrank auf Eis $5 \mathrm{~min}$ aufgetaut. Anschließend wurden 3 bis $5 \mu \mathrm{l}$ des Ligationsansatzes zu $50 \mu \mathrm{l}$ kompetenter Zellen gegeben. Dieser Ansatz wurde in eine auf $-20^{\circ} \mathrm{C}$ gekühlte Elektroporationsküvette gegeben und eine Elektroporation mit 1,6 kV, $250 \mu \mathrm{F}$ und 200 Ohm im Elektroporator durchgeführt. Unmittelbar nach der Elektroporation wurde dieser Ansatz mit $1 \mathrm{ml} \mathrm{SOC} \mathrm{Medium} \mathrm{bei} 37^{\circ} \mathrm{C}$ für $1 \mathrm{~h}$ in den Schüttelinkubator gestellt. Anschließend wurden $100 \mu \mathrm{l}$ des Ansatzes auf einer Agarplatte mit dem entsprechenden Antibiotikum ausgestrichen und über Nacht bei $37^{\circ} \mathrm{C}$ inkubiert. Am nächsten Tag konnten die Kolonien aufgenommen werden.

\subsubsection{Agarosegel-Elektrophorese}

Die Agarosegel-Elektrophorese wurde in dieser Arbeit hauptsächlich zur Größenund Mengenbestimmung der DNA durchgeführt. Die DNA konnte anschließend aus dem Agarosegel isoliert werden. Die Zusammensetzung des Agarosegels richtete sich nach der erwarteten Größe der DNA-Fragmente. Für die Herstellung eines Agarosegels wurde die benötigte Menge Agarose in der Mikrowelle mit 1x-TBE aufgekocht. Unter ständigem Rühren wurde die flüssige Agarosemasse auf $55^{\circ} \mathrm{C}$ abgekühlt und Ethidiumbromid auf eine Endkonzentration von $0,5 \mu \mathrm{g} / \mathrm{ml}$ hinzugefügt. Die Lösung wurde in eine Gelform mit entsprechendem Kamm gegossen und auf RT abgekühlt.

\subsubsection{DNA-Extraktion aus Agarosegelen}

Die gewünschte DNA-Bande wurde unter UV-Licht mithilfe eines sterilen Skalpells mit möglichst geringer UV-Bestrahlung sorgfältig herausgeschnitten. Mithilfe von Silikamilch wurden die DNA-Fragmente isoliert. Silikate haben die Eigenschaft, in Kombination mit chaotropen Salzen DNA spezifisch zu binden. Diese kann in einem 
weiteren Waschschritt mit Wasser leicht eluiert werden. Das Agarosegelstück wurde mit $500 \mu$ l einer $6 \mathrm{M} \mathrm{NaJ}$ Lösung unter Schütteln auf einem $55^{\circ} \mathrm{C}$-warmen Heizblock gelöst. Anschließend wurden 10 bis $20 \mu \mathrm{l}$ der Silikamilch hinzugefügt, bevor eine erneute Inkubation über $10 \mathrm{~min}$ bei $55^{\circ} \mathrm{C}$ auf dem Schüttler erfolgte. Nach einer 30 sec-andauernden Zentrifugation bei $16000^{*} \mathrm{~g}$ wurde das entstandene Pellet zweimal mit $300 \mu$ 70\%-igem EtOH gewaschen. Anschließend wurde das Pellet in 20 bis 30 $\mu \mathrm{l} \mathrm{H}_{2} \mathrm{O}$ aufgenommen und die Konzentration bestimmt.

\subsubsection{Polymerase-Kettenreaktion}

Die Polymerase-Kettenreaktion (PCR) ist die Methode der Wahl zur in vitro Amplifikation von DNA (Mullis und Faloona 1987). Für das Erreichen einer möglichst hohen Bindungsspezifität der Oligonukleotide wurde in dieser Arbeit eine „Hot-Start"PCR durchgeführt. Hierbei trennt eine Wachsschicht die Taq-DNA-Polymerase von den Oligonukleotiden. Ein typischer PCR-Ansatz setzt sich wie folgt zusammen:

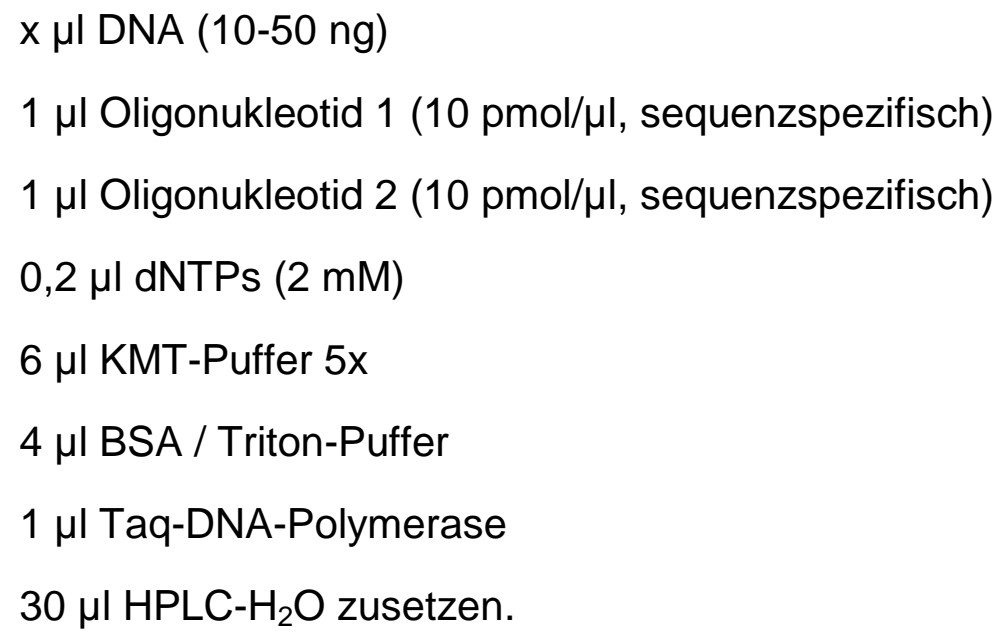

Mithilfe eines Thermocyclers wurde die DNA-Amplifikation durchgeführt. In der Regel wurden 30 bis 40 Zyklen benötigt, wobei grundsätzlich die eingesetzten Oligonukleotide und die DNA die genaue Zahl der Zyklen bestimmen. Ein Zyklus setzte sich aus folgenden Schritten zusammen:

$\begin{array}{lll}\text { Denaturierung } & 95^{\circ} \mathrm{C} & 20-45 \mathrm{sec} \\ \text { Annealing } & 50-65^{\circ} \mathrm{C} & 30-90 \mathrm{sec} \\ \text { Elongation } & 72^{\circ} \mathrm{C} & 30-90 \mathrm{sec}\end{array}$


Vor dem ersten Zyklus wurde eine Denaturierung bei $95^{\circ} \mathrm{C}$ für 2 bis 5 min durchgeführt. Nach dem letzten Zyklus erfolgte für 10 min eine abschließende Elongation bei $72^{\circ} \mathrm{C}$. Nach der Entfernung des festen Wachses konnte das Produkt mittels Agarosegel-Elektrophorese aufgetrennt werden.

\subsubsection{RNA-Isolation aus eukaryotischen Zellen}

Die Zellen wurden aus dem Well einer 24-Well-Schale abgelöst und bei 400 *g für 10 min abzentrifugiert und das Medium abgenommen. Die Zellpellets wurden anschließend jeweils in $1 \mathrm{~mL}$ TRIZOL resuspendiert, indem sie in 2-mlEppendorfgefäßen für $25 \mathrm{sec}$ maximal gevortext wurden. Anschließend wurden sie für 2 bis $3 \mathrm{~min}$ bei RT inkubiert, bevor $200 \mu \mathrm{l}$ Chloroform pro Reaktionsgefäß hinzugefügt wurden. Anschließend wurden die beiden Lösungen per Hand geschüttelt, für $3 \mathrm{~min}$ bei RT inkubiert und für $20 \mathrm{~min}$ bei $8600{ }^{*} \mathrm{~g}$ und $4{ }^{\circ} \mathrm{C}$ zentrifugiert. Nun lag ein dreiphasiges Gemisch in dem Eppendorfgefäß vor. Die obere Phase wurde vorsichtig abgenommen und in ein neues Reaktionsgefäß überführt. Die mittlere und untere Phase wurden verworfen. Pro Reaktionsgefäß wurden jeweils $700 \mu$ Isopropanol hinzugegeben und $10 \mathrm{~min}$ bei RT stehen gelassen. Anschließend wurden die Reaktionsgefäße erneut für 20 min bei $4^{\circ} \mathrm{C}$ und $15700^{*} \mathrm{~g}$ zentrifugiert. Nach Entfernung des Überstandes wurde das Pellet mit $500 \mu \mathrm{l}$ $-20^{\circ} \mathrm{C}$ kaltem, $80 \%$-igem $\mathrm{EtOH}$ für 15 min gewaschen und mit $15700^{*} \mathrm{~g}$ bei $4{ }^{\circ} \mathrm{C}$ zentrifugiert. Der Überstand wurde erneut abgenommen und das trockene Pellet in $20 \mu \mathrm{H}_{2} \mathrm{O}$ gelöst. Die RNA konnte anschließend bei $-80^{\circ} \mathrm{C}$ gelagert oder direkt für weitere Versuche verwendet werden.

\subsubsection{Reverse Transkription}

Das Umschreiben von RNA in DNA ist ein Standardverfahren. Hierbei wird die Gesamt-RNA einer Zellpopulation mit der moloney-murine-leukemia-virus (M-MLV)Transkriptase und Oligo(dt)Primern, welche an den Poly-A-Enden der mRNA binden, in die komplementäre DNA (cDNA) umgeschrieben.

Für die reverse Transkription wurden 2 bis $5 \mu \mathrm{g}$ RNA mit $1 \mu \mathrm{l}$ Oligo(dT)-Primer (0,5 $\mu \mathrm{g} / \mu \mathrm{l}$ ) in $12 \mu \mathrm{l} \mathrm{Gesamtvolumen} \mathrm{gemischt} \mathrm{und} 10 \mathrm{~min}$ bei $70^{\circ} \mathrm{C}$ inkubiert. 
Nach Zugabe von:

$4 \mu \mathrm{l} 5 \mathrm{x}$ First Strand Buffer

$2 \mu \mathrm{DTT}(0,1 \mathrm{M})$

$5 \mu \mathrm{dNNTP}(2 \mathrm{mM})$

$1 \mu \mathrm{l}$ RNase-Inhibitor $(40 \mathrm{U} / \mu \mathrm{l})$

wurde die Probe 2 min bei $42^{\circ} \mathrm{C}$ inkubiert und $1 \mu \mathrm{l} \mathrm{M-MLV-Transkriptase}(200 \mathrm{U} / \mu \mathrm{l})$ hinzugefügt. Die reverse Transkription wurde in 50 min bei $42^{\circ} \mathrm{C}$ durchgeführt. Die erhaltene cDNA konnte nun mit DNA-abhängigen Polymerasen (Taq-Polymerase) weiter bearbeitet werden.

\subsubsection{Ethanolfällung der DNA aus wässrigen Lösungen}

Zur Reduktion von Salzverunreinigungen und zur Konzentration der DNA wurde die Ethanolfällung der DNA (Sambrook und Gething 1989) aus wässrigen Lösungen angewendet. Hierzu wurde das 3 -fache Vol 99\% Ethanol und 1/10 Vol $3 \mathrm{M}$ Kaliumacetat $(\mathrm{pH} \mathrm{4,8)}$ eingesetzt. Anschließend erfolgte eine Zentrifugation für 15 min bei $16000^{*} \mathrm{~g}$ und $4^{\circ} \mathrm{C}$. Der Überstand wurde verworfen und das entstandene Pellet mit $500 \mu \mathrm{l}$ 70\%-igem Ethanol gewaschen. Danach wurde das Pellet in einer Vakuumzentrifuge getrocknet und in $\mathrm{HPLC}-\mathrm{H}_{2} \mathrm{O}$ aufgenommen.

\subsubsection{Quantitative Echtzeit-PCR}

Zur Bestimmung des Gehaltes einer spezifischen mRNA in einem Zellverband wurde das Verfahren der quantitativen Echtzeit-PCR eingesetzt. Zuvor wurde die RNAIsolation mit anschließender reverser Transkription durchgeführt. Mit der daraus gewonnenen cDNA, den Primern für den zu untersuchenden Genabschnitt und dem dsDNA-interkalierenden Farbstoff SYBR $\circledast$ Green wurde eine quantitative EchtzeitPCR durchgeführt. Nach jedem PCR-Zyklus erfolgte hierbei eine Fluoreszenzmessung, in der die exponentielle Phase bestimmt wurde. Anschließend wurde der Cycle-treshold-Wert (Ct-Wert) erfasst, bei dem erstmals ein signifikantes Reportersignal auftrat. Die Detektion des Fluoreszenzanstieges wurde mithilfe des Relative-Quantification-ABI-7500 Real-time-PCR-Systems durchgeführt. Ein vorinstalliertes Programm für SYBR $\otimes G$ reen ermöglichte das Messen. 
Der Ansatz für das Experiment war wie folgt:

$12,5 \mu \mathrm{l} 2 \mathrm{x}$ Immomix

$0,25 \mu \mathrm{l}$ ROX

$0,125 \mu \mathrm{l} \mu \mathrm{l}$ forward Primer

$0,125 \mu$ l reverse Primer

$0,5 \mu \mathrm{l}$ SYBR $\AA_{\text {Green }}$

$1,5 \mu \mathrm{l} \mathrm{cDNA}$

Auffüllen auf $25 \mu \mathrm{l}$ mit HPLC $\mathrm{H}_{2} \mathrm{O}$

Die gewonnen Daten wurden mithilfe der $\Delta \Delta$ Ct-Wert-Methode ausgewertet, wobei die Transkription des Zielgens auf die Transkription eines Kontrollgens bezogen wurde.

$\Delta \mathrm{Ct}=\mathrm{Ct}_{\text {Probe }}-\mathrm{Ct}_{\text {Kontrollgen }}$

$\Delta \Delta \mathrm{Ct}=\Delta \mathrm{Ct}_{\text {Probe }}-\Delta \mathrm{Ct}_{\text {Kontrolle }}$

Umrechnung in Prozent:

Prozentuale Angabe $=100-\left(100^{\star} 2^{\wedge}\left(-1^{*} \Delta \Delta \mathrm{Ct}\right)\right)$

\subsubsection{Konzentrationsbestimmung von Nukleinsäuren}

Für die Konzentrationsbestimmung von Nukleinsäuren wurden zwei verschiedene Methoden eingesetzt. Für näherungsweise Werte wurde die Nukleinsäureprobe mit Proben bekannter Konzentration gemeinsam auf einem Ethidiumbromid gefärbten Agarosegel aufgetragen. Durch den optischen Vergleich der Proben konnte eine ungefähre DNA/RNA-Konzentration angegeben werden. Für eine genauere Bestimmung der Nukleinsäurekonzentration wurden die Proben an einem Spektrofotometer nach Vorgaben des Geräteherstellers gemessen. 


\subsubsection{Proteinchemische Methoden}

\subsubsection{Koimmunpräzipitation}

Die Koimmunpräzipitation (Co-IP) ist ein Proteinaufreinigungsverfahren, welches zur Aufreinigung eines Proteinlysats durch Antikörper eingesetzt wurde (Abb. 6). Weitere Proteine, die mit dem Antigen interagierten, wurden durch diese Methode präzipitiert und konnten nach Eluierung von Antikörper und Protein durch einen Westernblot genauer bestimmt werden. Zur Präzipitation wurde Protein-G-Sepharose eingesetzt, welche eine hohe Affinität zu Immunglobulinen besitzt.

Im Rahmen dieser Dissertation wurden in einer T75-Flasche ausgesäte HeLa-Zellen nach Erreichen der Konfluenz mit eiskaltem PBS gewaschen und anschließend trypsiniert. Nachdem die Zellen erneut in kaltem PBS aufgenommen wurden, erfolgte anschließend eine Zentrifugation für 10 min bei $400{ }^{*} \mathrm{~g}$. Als nächstes wurden die HeLa-Zellen zweimal mit $10 \mathrm{ml}$ kaltem PBS gewaschen und je für 10 min bei $4^{\circ} \mathrm{C}$ zentrifugiert. Anschließend wurde das Pellet in einem Lysepuffer aufgenommen.

Lyse-Puffer: 20mM TRIS-HCL pH8

$137 \mathrm{mM}$ Natriumchlorid $(\mathrm{NaCl})$

$10 \%$ Glycerol

$1 \%$ Nonidet-P-40

2 mM EDTA

Im nächsten Schritt wurde das Lysat in ein neues 2-ml-Reaktionsgefäß überführt und für 30 min unter gelegentlichem Schwenken auf Eis inkubiert. Danach erfolgte eine erneute Zentrifugation bei $4^{\circ} \mathrm{C}$ für $15 \mathrm{~min}$ bei $10000^{*} \mathrm{~g}$. Der Überstand wurde wieder in ein neues 2-ml-Reaktionsgefäß überführt.

Die weitere Proteinisolation erfolgte nach der Anleitung des Pierce CoImmunoprecipitation Kit. Das gewonnene Proteinlysat wurde anschließend durch einen Westernblot analysiert. 


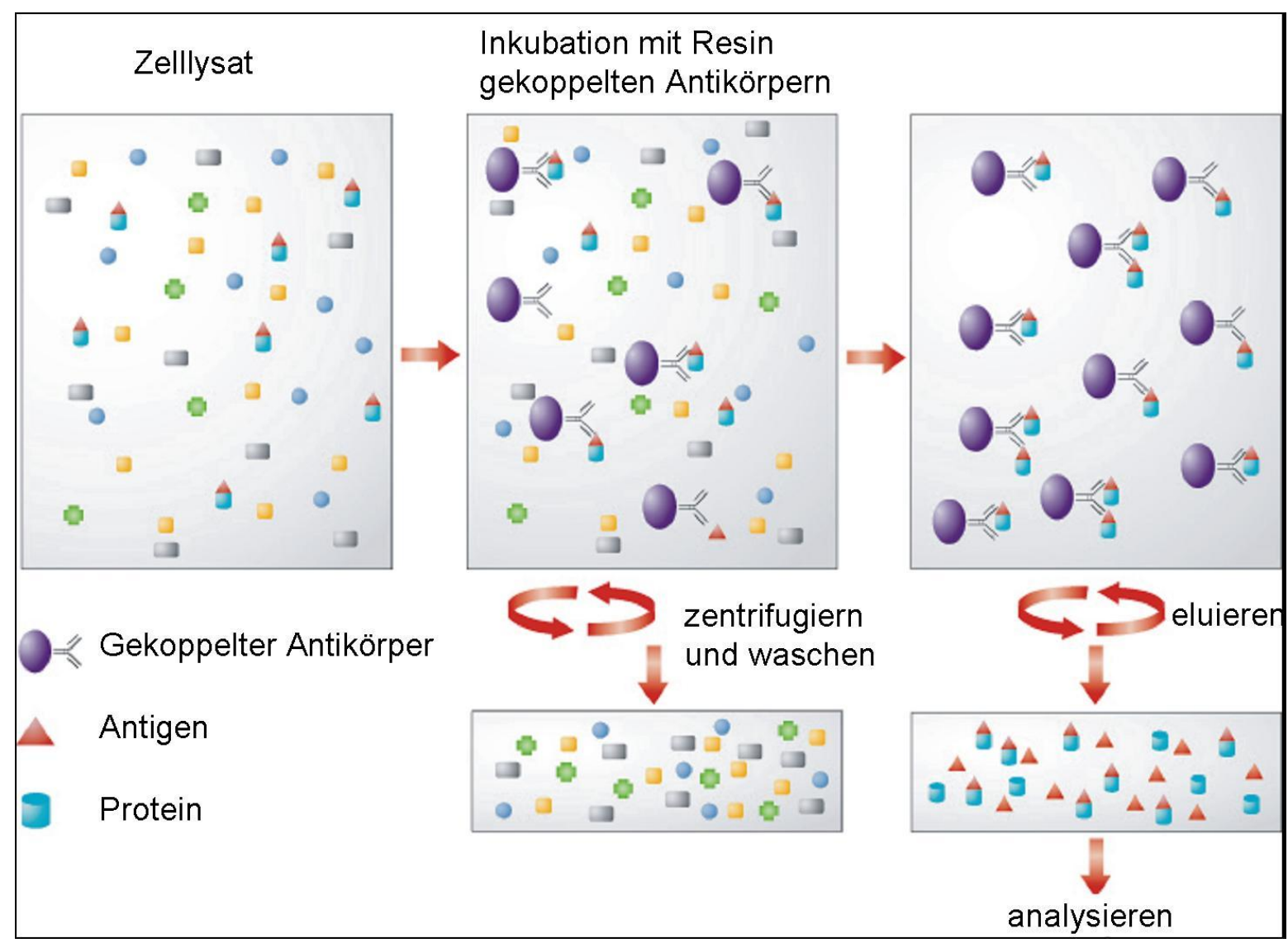

Abb. 6: Koimmunpräzipitation

Die Koimmunpräzipitation wird an einem Zelllysat durchgeführt. Zuerst erfolgt eine Inkubation mit Resin-gekoppelten Antikörpern, bevor der Überstand abzentrifugiert und gewaschen wird. Im letzten Schritt wird das Eluat für einen Westernblot genutzt (Quelle: modifiziert nach www.piercenet.com).

\subsubsection{Isolation des Gesamtproteins aus Zellkulturen}

Für die Isolation des Gesamtproteins aus Zellkulturen wurden Zellen in 24-WellSchalen kultiviert und entweder 24 h, 48 h oder 72 h nach Transfektion mit 1x PBS gewaschen und mit Trypsin-EDTA gelöst. Anschließend wurden die Zellen in PBS resuspendiert und 5 min bei $4000{ }^{*} \mathrm{~g}$ und $4^{\circ} \mathrm{C}$ zentrifugiert. Der Überstand wurde nun verworfen, das Zellpellet in $25 \mu \mathrm{l}\left(90^{\circ} \mathrm{C}\right) 2 \mathrm{x}$ Laemmli-Puffer mit $10 \mu \mathrm{M}$ Dithiothreitol (DTT) aufgenommen und $5 \mathrm{~min}$ bei $90{ }^{\circ} \mathrm{C}$ denaturiert. Danach wurde das Proteinlysat gevortext. 


\subsubsection{SDS-Polyacrylamid-Gelelektrophorese (SDS-PAGE)}

Die diskontinuierliche Natriumdodecylsulfat-Polyacrylamidgelelektrophorese (SDSPAGE) (Laemmli 1970) wurde zur Auftrennung von Proteinen nach ihrem molekularem Gewicht benutzt. Hierzu wurden Gelkammern mit horizontal ausgerichteten Glasplatten verwendet.

Tabelle 10: SDS-PAGE-Gelzusammensetzung

\begin{tabular}{lcl|c}
\hline \hline & \multicolumn{2}{c}{ Trenngel } & Sammelg \\
\hline \hline Acrylamid-Konz. & $\mathbf{8} \%$ & $\mathbf{1 0} \%$ & $\mathbf{5} \%$ \\
\hline \hline PAA 30\% & 5,3 & 6,7 & 1,7 \\
Trenngelpuffer $(\mathbf{m l})$ & 5 & 5 & - \\
Sammelgelpuffer $(\mathrm{ml})$ & - & - & 1,25 \\
APS $(\boldsymbol{\mu l})$ & 75 & 75 & 50 \\
TEMED $(\boldsymbol{\mu l})$ & 20 & 20 & 20 \\
$\mathbf{d d H}_{2} \mathrm{O}$ & Ad 9,3 ml & Ad 7,9ml & Ad 6,8 ml \\
\hline
\end{tabular}

Das Trenngel wurde in die Kammer gegossen und mit Isopropanol bedeckt, welches nach erfolgter Polymerisation des Gels nach 30 min abgegossen werden konnte und mit Filterpapier vollständig entfernt wurde. Anschließend wurde das Sammelgel eingegossen und der Probenkamm eingesetzt. Nach weiteren $30 \mathrm{~min}$ lag das Gel polymerisiert vor und der Probenkamm konnte entfernt werden. Die Proteinprobe wurde im Verhältnis 1:1 mit dem Probenpuffer gemischt und 10 min bei $95^{\circ} \mathrm{C}$ inkubiert. Anschließend wurde das Proteinlysat mithilfe einer Hamilton-Spritze vorsichtig in die Geltaschen gegeben. Die Gelelektrophorese wurde im Sammelgel bei 25 Milli-Ampere $(\mathrm{mA})$ und im Trenngel bei $35 \mathrm{~mA}$ durchgeführt.

\subsubsection{Westernblot}

Drei Whatman-Filterpapiere und eine Nitrozellulose-Membran wurden mit einer Schere auf die Größe des Polyacrylamidgels zugeschnitten und in einem Semi-DryTransferpuffer äquilibriert. Die drei Whatman-Filterpapiere wurden auf die glänzende Seite der Nitrozellulose-Membran und das nach der SDS-PAGE mit Wasser abgespülte Gel auf die Matte Seite der Nitrozellulose-Membran gelegt. Nach dem Sandwich-Modell wurden nun drei weitere angefeuchtete Whatman-Filterpapiere auf das Gel gelegt. Es war stets darauf zu achten, dass keine Luftblasen zwischen dem Gel und der Membran entstanden. Anschließend wurde mit einem Semi-Dry-Blotter 
der Transfer bei $2 \mathrm{~mA}$ pro $1 \mathrm{~cm}^{2}$ der Membran für $1 \mathrm{~h}$ durchgeführt. Hierbei war darauf zu achten, dass die Nitrozellulose-Membran zur Anode gerichtet war.

Um alle unspezifischen Bindungsstellen zu blockieren, wurde die Nitrozellulosemembran mit der Blocklösung für $1 \mathrm{~h}$ bei RT inkubiert. Anschließend wurde die Membran mit dem Antikörper, welcher zuvor mit der Blocklösung spezifisch verdünnt wurde, über Nacht inkubiert. Am nächsten Tag wurde die Membran 5x mit der Blocklösung III gewaschen und anschließend für $2 \mathrm{~h}$ bei RT mit der Blocklösung und dem Sekundärantikörper (Verdünnung 1:2000 bis 1:10000) inkubiert. Nach erneutem Waschen mit der Blocklösung (4x) und TBS (1x) konnten die Proteine mithilfe der Chemilumineszenz nachgewiesen werden. Dazu wurde die enhanced-chemiluminescence (ECL)-Lösung frisch angesetzt, in der die Membran 1 min inkubierte. Der benutzte Sekundärantikörper war an die Horseradish Peroxidase (HRP) gekoppelt, die Luminol in seine oxidierte Form umsetzt, wodurch die Lumineszenzreaktion erzeugt wurde. Die Membran wurde eingeschweißt und in der Dunkelkammer auf einen Film in die Filmkassette gelegt. Die initiale Entwicklungszeit betrug $30 \mathrm{sec}$. In Abhängigkeit des Ergebnisses wurde die Belichtungszeit entsprechend angepasst.

\subsubsection{Immunzytologische Methoden}

\subsubsection{Indirekte Immunfluoreszenz}

Für die indirekte Immunfluoreszenzmikroskopie wurden HeLa-Zellen einen Tag vor Transfektion auf beschichteten Deckgläschen in 24-Well-Schalen ausgesät. Nach einem bestimmten Zeitintervall wurden die Zellen auf den beschichteten Deckgläschen über $5 \mathrm{~min}$ in $-20^{\circ} \mathrm{C}$ Methanol fixiert und permeabilisiert, bevor sie an der Luft getrocknet und in eine dunkle und feuchte Kammer gelegt wurden. Der Primärantikörper wurde in seiner spezifischen Konzentration in $1 \times$ PBS mit $5 \%$ Rinderserumalbumin gegeben, vorsichtig auf die beschichteten Deckgläschen pipettiert und $1 \mathrm{~h}$ bei $37^{\circ} \mathrm{C}$ inkubiert. Anschließend wurden die beschichteten Deckgläschen dreimal mit 1 x PBS gewaschen und danach sorgfältig mit Filterpapier trockengetupft. Der Fluoreszenzfarbstoff-markierte Sekundärantikörper wurde spezifisch zu dem Primärantikörper ausgewählt und in seiner spezifischen Konzentration vorsichtig auf die beschichteten Deckgläschen gegeben. Die beschichteten Deckgläschen wurden erneut $1 \mathrm{~h}$ in der dunklen und feuchten Kammer bei $37^{\circ} \mathrm{C}$ inkubiert. Anschließend wurde dreimal mit $1 \times$ PBS gewaschen. 
Es konnte abschließend noch eine Kernfärbung mit Propidiumiodid (PI) oder 4',6Diamidin-2-phenylindol (DAPI) durchgeführt werden. Für die DAPI-Färbung wurden $40 \mu \mathrm{l}$ DAPI in $1 \mathrm{ml} 1$ x PBS und für die PI-Färbung $40 \mu \mathrm{PI}$ in $1 \mathrm{ml} 1$ x PBS gelöst. Die jeweilige Kernfärbung wurde vorsichtig auf die Zellen pipettiert. Es folgte eine 5minütige Inkubation in der dunklen und feuchten Kammer bei $37^{\circ} \mathrm{C}$ mit darauffolgender, dreimaliger Waschung mit 1 x PBS.

Ein Objektträger wurde mit einem Tropfen Fluorescent-Mounting-Medium versehen, auf den das beschichtete Deckgläschen invers aufgelegt und mit Nagellack versiegelt wurde.

Um Fotobleichung zu vermeiden wurde nach Verwendung eines Fluorophors in möglichst dunkler Umgebung gearbeitet. Im Anschluss konnten die Proben mikroskopisch analysiert werden.

\subsubsection{Inverse Mikroskopie mit dem AxioObserver}

Der AxioObserver ist ein inverses Mikroskop, welches zur Analyse vitaler Zellen benutzt wurde. Mittels Phasenkontrastmikroskopie konnten sowohl vitale als auch fixierte Zellen analysiert und fotografiert werden. Die eingebauten Filter erlaubten die Analyse von folgenden gelben, grünen und roten Fluoreszenzfarbstoffen. Es wurde mit den grünen Fluoreszenzfarbstoffen grün fluoreszierendes Protein (GFP) und Fluoreszeinisothiozyanat (FITC), dem roten Fluoreszenzfarbstoff Tetramethylrhodamin-Isothiozyanat (TRITC) und Tetramethylrhodamin (TMR) gearbeitet. Des Weiteren wurde zur DNA-Färbung mit dem blauen Farbstoff DAPI und dem roten Farbstoff PI gearbeitet. Bilder wurden mit der Kamera des Mikroskops aufgenommen und mit dem Programm AxioVision bearbeitet.

\subsubsection{Konfokale Laserscanning-Mikroskopie mit dem LSM 5 PASCAL}

Das Laserscanning-Mikroskop tastete die Probe anhand eines bestimmten Rasters punktweise $a b$, bevor ein Computer die einzelnen Bildpunkte zu einem fertigen Bild zusammensetzte. Der Detektor nahm hierbei nur die Konfokalebene auf. Punkte, die außerhalb der Konfokalebene lagen, wurden nur mit einer sehr geringen Lichtintensität bestrahlt und durch eine Lochblende nahezu ausgeblendet.

Für diese Arbeit wurde das LSM 5 PASCAL benutzt. Dieses Mikroskop ist mit einem Helium/Neon-Laser $(\lambda=543 \mathrm{~nm}, \quad \lambda=633 \mathrm{~nm})$ und einem Argon-Laser ausgestattet. 
Leider war dieses Gerät nicht mit einem UV-Laser $(\lambda=345 \mathrm{~nm})$ ausgestattet, sodass keine Kerndarstellungen mittels DAPI gemacht werden konnten.

\subsubsection{Durchflusszytometrie (Fluorescence Activated Cell Scanning)}

Für die Beurteilung des Zellzyklus wurden Zellen mit PI, einer interkalierenden Substanz, gefärbt, die sich stochastisch unspezifisch zwischen jedes viertes bzw. fünftes Basenpaar legt. PI kann keine vitalen Zellwände passieren, sodass die Zellen für die Zellzyklusbeurteilung fixiert und permeabilisiert wurden (Moore et al. 1998).

Die Fluoreszenzemission hängt direkt von dem DNA-Gehalt der Zelle ab. Die Messungen erfolgten am FACS-Durchflusszytometer, welches Zellen in einem Flüssigkeitsstrom zählte und nach physikalischen und molekularen Eigenschaften analysierte.

Hierfür wurden Zellen in einer Einzelzellsuspension in einem Flüssigkeitsstrom, der idealerweise nur eine Zelle pro Zeiteinheit enthielt, vor einem gebündelten Laserstrahl spezifischer Wellenlänge vorbeigeleitet.

Die Streuung in Vorwärtsrichtung wurde über den Forward Scatter erfasst und gab Auskunft über die Größe des Partikels. Der Sideward Scatter erfasste die Seitwärtsstreuung und gab daher Auskunft über die Granularität der Zellen.

Ein monochromatischer Lichtstrahl hob die Elektronen eines Fluoreszenzfarbstoffes auf ein höheres Energieniveau. Bei Wiedererlangen des ursprünglichen Energieniveaus wurde Energie in Form von Fotonen frei, welche mittels eines Fotodetektors registriert werden konnten.

Die Auswertung der Ergebnisse erfolgte mit der Hilfe des Computerprogramms FlowJo.

\subsection{Apoptosenachweis durch die Sub-G1-peak-Methode}

Die Verteilung einer Zellpopulation konnte nach erfolgter PI-DNA-Färbung durch eine Durchflusszytometrie (FACS)-Messung ermittelt werden. Typischerweise teilt sich eine gesunde Zellpopulation in eine G1-Population, die sich in der G1-Phase des Zellzyklus befindet, eine S-Population, die sich in der Synthese-Phase des Zellzyklus befindet, und eine G2-Population, die sich in der G2-Phase des Zellzyklus befindet. Apoptotische Zellen und Zellvesikel befinden sich in der Sub-G1-Population, die auf dem Graphen vor der G1-Population lokalisiert ist. Diese Population stellt fragmentierte DNA-Oligonukleotide sowie eine generell geminderte DNA-Menge in apoptotischen Zellen und Zellvesikeln dar (Nicoletti et al. 1991). Polyploide Zellen 
besitzen mehr als zwei Chromosomensätze und sind je nach Anzahl der Chromosomensätze auf dem Graphen jenseits der G2-Population lokalisiert. 


\section{Ergebnisse}

\subsection{Lokalisationsstudien zu TRIM22}

Die Lokalisation des TRIM22 wurde bereits in unterschiedlichen Arbeiten untersucht, jedoch wurden in diesen Arbeiten widersprüchliche Angaben über die subzelluläre Verteilung des Proteins gemacht. So wurden bisher Lokalisationen im Nukleus (Gao et al. 2009), im Zytoplasma (Herr et al. 2009; Reymond et al. 2001), im Nukleolus sowie im Zytoplasma angegeben (Sivaramakrishnan et al. 2009). In der vorliegenden Arbeit sollten die unterschiedlichen Angaben zur subzellulären TRIM22-Verteilung eingehender untersucht werden, um dadurch ein tieferes Verständnis für die Funktionen des Proteins zu erhalten.

\subsubsection{Lokalisation des ektopisch exprimierten TRIM22 in Relation zu den Mikrotubuli}

Zu Beginn wurde die subzelluläre Lokalisation des ektopisch exprimierten TRIM22 untersucht. Dazu wurden HeLa-Zellen bis zu einer Konfluenz von 60\% auf beschichteten Deckgläschen kultiviert und mit einem TRIM22-GFP-Konstrukt (siehe Anhang: 6.1) transient transfiziert (Abb. 7). Nach $48 \mathrm{~h}$ wurden die Zellen mit Methanol fixiert und dadurch zeitgleich permeabilisiert. Die Zellen wurden mit einem $\alpha$-Tubulin-Antikörper als Primärantikörper und einem mit einer TRITC-Fluoreszenz gefärbten Sekundärantikörper behandelt (Abb. 7A, D, G). Anschließend erfolgte die Auswertung mithilfe des Laserscanning-Mikroskops (LSM). In den Zellen konnten drei verschiedene Verteilungsmuster des TRIM22-GFP (ektopisch exprimiertes TRIM22) gefunden werden (Abb. 7B, E, H), die auch kombiniert in einer Zelle zu finden waren. Zum einen konnte punktförmig entlang des Mikrotubulussystems organisiertes TRIM22-GFP beobachtet werden (Abb. 7B). Das Protein kolokalisierte mit dem Mikrotubulussystem in Form kleinerer Anhäufungen bis hin zu Aggregaten (Abb. 7A, C).

In der Abbildung 7E lag das TRIM22-GFP hingegen in der perinukleären Umgebung vor, wo es homogen verteilt auf die unmittelbare Lokalisation und die Umgebung des Nukleus beschränkt war (Abb. 7D, F). 
Die Abbildung 7H zeigte TRIM22 innerhalb des Nukleus, welcher sich als größere Aussparung der roten Fluoreszenz präsentierte (Abb. 7G, I). Leider konnte mit dem zur Verfügung stehenden LSM keine zusätzliche Zellkernfärbung visualisiert werden. Aus diesem Grund wird die Lokalisation des Zellkerns durch die intrazelluläre Aussparung der roten Fluoreszenz bestimmt. TRIM22 zeigt in diesem Bild intranukleäre punktuell organisierte Anhäufungen. 

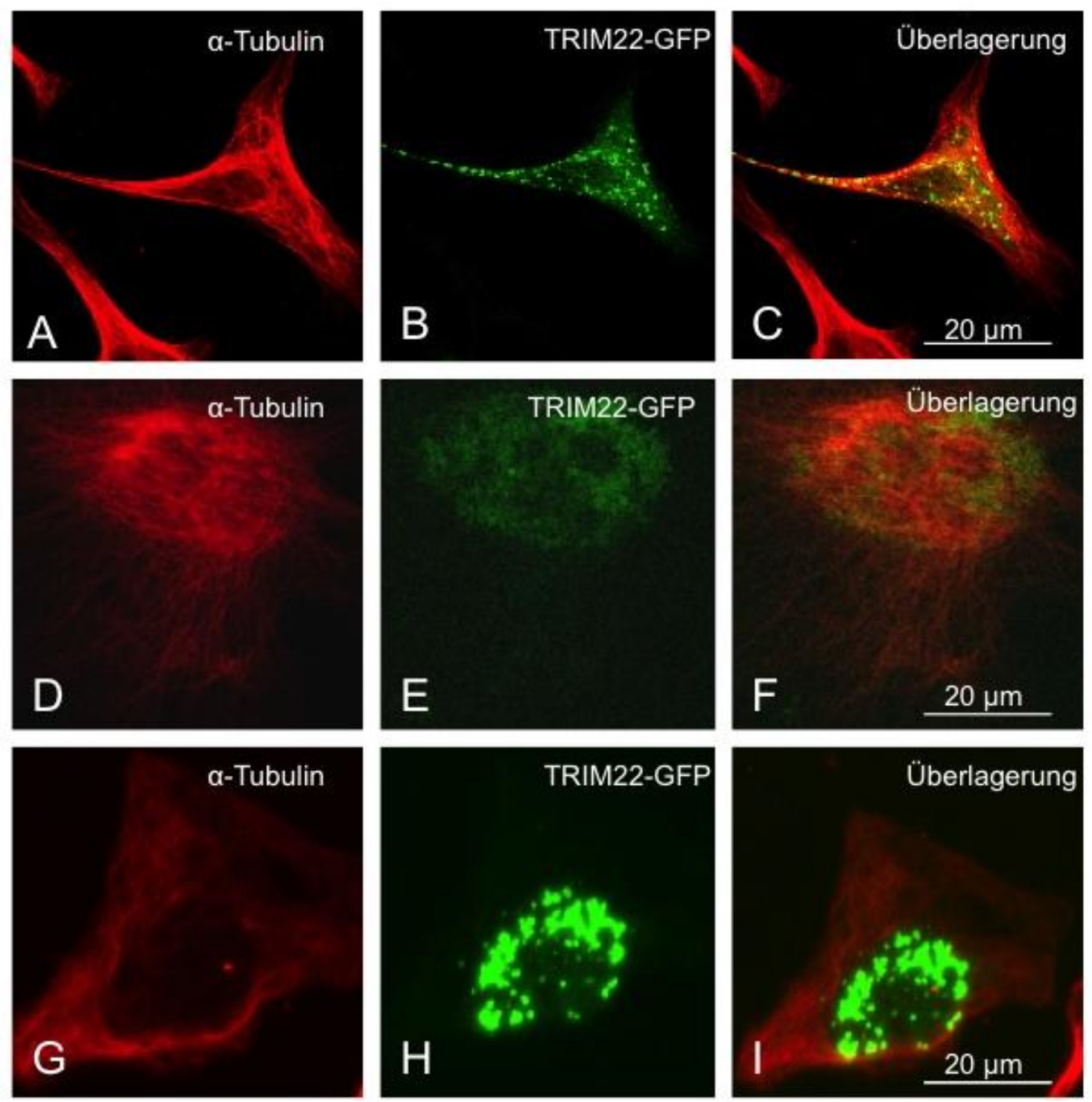

Abb. 7: Unterschiedliche subzelluläre Lokalisationen des TRIM22-GFP

Das Expressionskonstrukt TRIM22-GFP wurde transient in HeLa-Zellen transfiziert. Nach 48h wurden die Zellen fixiert und das Zytoskelett mit einem TRITCgekoppelten Antikörper gegen $\alpha$-Tubulin (A, D, G) gefärbt. Das GFP-markierte TRIM22 wurde im grünen Kanal $(B, E, H)$ und die Überlagerung von $\alpha$-Tubulin und TRIM22-GFP in den Abbildungen 7C, F, I dargestellt. Kolokalisationen erschienen gelb. TRIM22-GFP war an den Mikrotubuli (rot) punktförmig und in kleineren Ansammlungen nachweisbar (A, B, C). Weiterhin lag TRIM22-GFP oft perinukleär und nukleär verteilt vor (D, E, F). Auch eine Verteilung ausschließlich im Nukleoplasma oder Kernplasma der Zellen war häufig nachweisbar (G, H, I). (Mikroskop: LSM 5 PASCAL) 


\subsubsection{Lokalisation des endogenen TRIM22 in Relation zu den Mikrotubuli}

Um auszuschließen, dass TRIM22-GFP aufgrund des großen (27kDa) GFP-Anhangs artifiziell in den Zellen lokalisiert ist oder strukturelle Änderungen des rekombinanten Proteins vorliegen, sollte untersucht werden, wo das endogene TRIM22 in HeLaZellen lokalisiert ist.

Dazu wurden HeLa-Zellen auf beschichteten Deckgläschen kultiviert und nach $24 \mathrm{~h}$ mit Methanol fixiert. Anschließend wurde mit einem polyklonalen Antiserum gegen TRIM22 und einem Sekundärantikörper mit TRITC-Markierung sowie einem $\alpha$ Tubulin-FITC-Antikörper gefärbt. Die Analyse wurde mit dem LSM durchgeführt. Das endogene TRIM22 war ubiquitär in der Zelle vorhanden, wobei primär eine Anhäufung perinukleär nachweisbar war (Abb. 8A-C). Des Weiteren ist TRIM22 teilweise mit $\alpha$-Tubulin kolokalisiert (Abb. 8C). Die intrazelluläre Verteilung des endogenen TRIM22 entsprach der Verteilung des ektopisch exprimierten TRIM22GFP. Jedoch kumulierte endogenes TRIM22 und TRIM22-GFP unterschiedlich. TRIM22-GFP bildete größere punktuelle Anhäufungen, die durch TRIM22-GFPÜberexpression auch als Aggregate bezeichnet werden könnten, wohingegen endogenes TRIM22 ein diffuseres Verteilungsmuster zeigte.
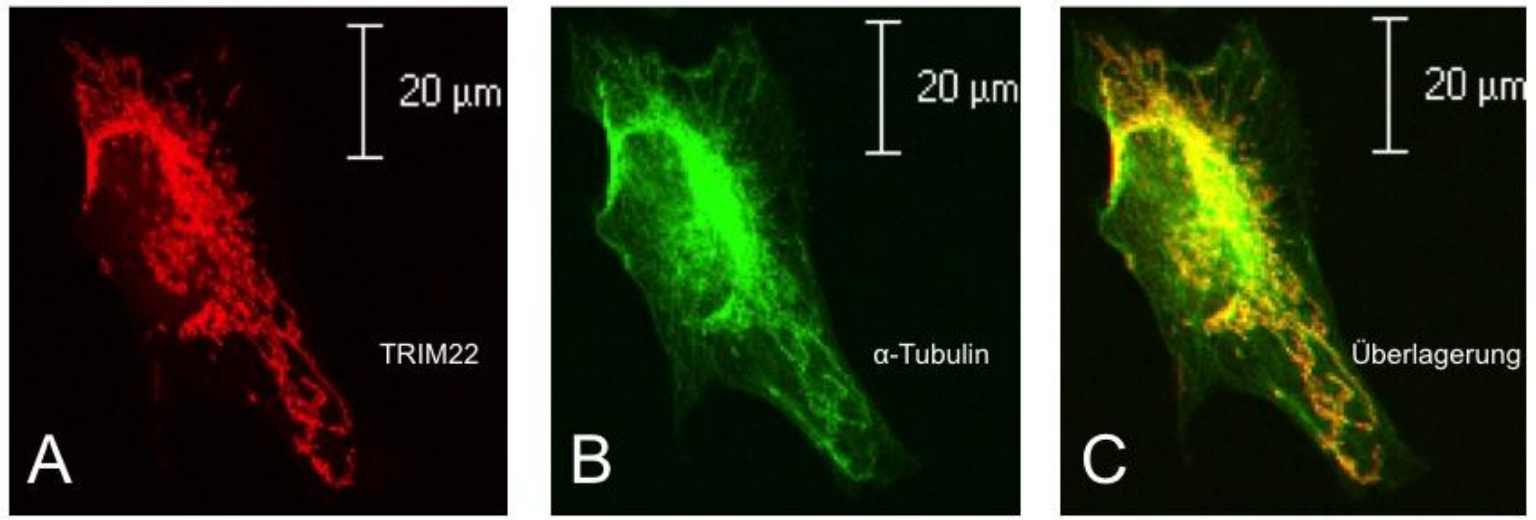

Abb. 8: Verteilung des endogenen TRIM22

HeLa-Zellen wurden auf beschichteten Objektträgern kultiviert und nach $24 \mathrm{~h}$ fixiert. Endogenes TRIM22 (rot) wurde mithilfe eines polyklonalen TRIM22-Antikörpers und eines TRITC-gekoppelten Sekundärantikörpers gefärbt, während das Mikrotubulussystem (grün) mittels eines FITC-gekoppelten $\alpha$-Tubulin Antikörpers visualisiert wurde. (Mikroskop: LSM 5 PASCAL)

Mithilfe eines LSM konnte gezeigt werden, dass TRIM22 (Abb. 8A) fadenförmig im Zytosol mit Anhäufungen nahe dem Nukleus lokalisiert war. Vereinzelt lag TRIM22 auch im Nukleus vor (Abb. 8A). Die Darstellung des $\alpha$-Tubulins verdeutlichte die Organisation des Mikrotubulussystems (Abb. 8B). In der Überlagerung (Abb. 8C) 
kolokalisierte TRIM22 im Zytosol mit $\alpha$-Tubulin und war auch im Nukleus nachweisbar.

\subsubsection{Lokalisation des TRIM22 in Relation zu dem Zentrosom}

Das Zentrosom reguliert und koordiniert viele zelluläre Prozesse direkt oder indirekt in seiner Eigenschaft als Mikrotubulusorganisationszentrum (MOZ). Es besteht aus über 500 verschiedenen Proteinen (Andersen et al. 2003). Die bekanntesten zentrosomalen Proteine sind $\mathrm{y}$-Tubulin, Centrin, Pericentrin, Ninein, Vimentin und $\alpha$ Tubulin, wobei $\mathrm{y}$-Tubulin, Ninein, zentrosomales Protein E (CENP-E) Centrin und Pericentrin spezifische MOZ-Markerproteine sind. Vimentin und $\alpha$-Tubulin zeigen eine filamentöse zytoplasmatische Verteilung und sind Bestandteil des MOZ, sind jedoch nicht spezifisch für das MOZ. Von dem MOZ ausgehend sind die Mikrotubuli polar organisiert, wobei das Minus-Ende der Mikrotubuli zum Zentrosom und das Plus-Ende in die Peripherie zeigt (Bornens 2002).

Das Zentrosom liegt in Zellen nicht membrangebunden in der Nähe des Nukleus vor. $\mathrm{Da}$ in den Lokalisationsbestimmungen des TRIM22 eine perinukleäre Lage beobachtet werden konnte, sollte nun in folgenden Experimenten untersucht werden, ob TRIM22 mit dem Zentrosom kolokalisiert.

\subsubsection{Endogenes TRIM22 und das Zentrosom}

Um eine potentielle Kokalisation des endogenen TRIM22 mit dem Zentrosom zu untersuchen, wurden HeLa-Zellen auf beschichteten Deckgläschen 48 h kultiviert und anschließend mit $-20^{\circ} \mathrm{C}$ kaltem Methanol fixiert und permeabilisiert. In diesem Versuch wurden die Zentrosomen mithilfe eines $\mathrm{Y}$-Tubulin-Antikörpers und eines TRITC-markierten Sekundärantikörpers dargestellt. Jede Zelle besitzt in Abhängigkeit ihrer Zellzyklusphase ein oder zwei Zentrosomen (Abb. 9B). Das endogene TRIM22 wurde durch ein TRIM22-Antiserum und einen FITC-markierten Sekundärantikörper visualisiert (Abb. 9A). In der Überlagerung zeigte sich eine Kolokalisation von y-Tubulins und TRIM22 (gelb) (Abb. 9C). Eine Kreuzreaktion des Nullserums sowie des Sekundär-AKs wurde ausgeschlossen (siehe Anhang 6.2). Das Nullserum der zugehörigen Tiere entsprach dem Serum vor der ersten Immunisierung mit dem rekombinanten TRIM22-Protein. 

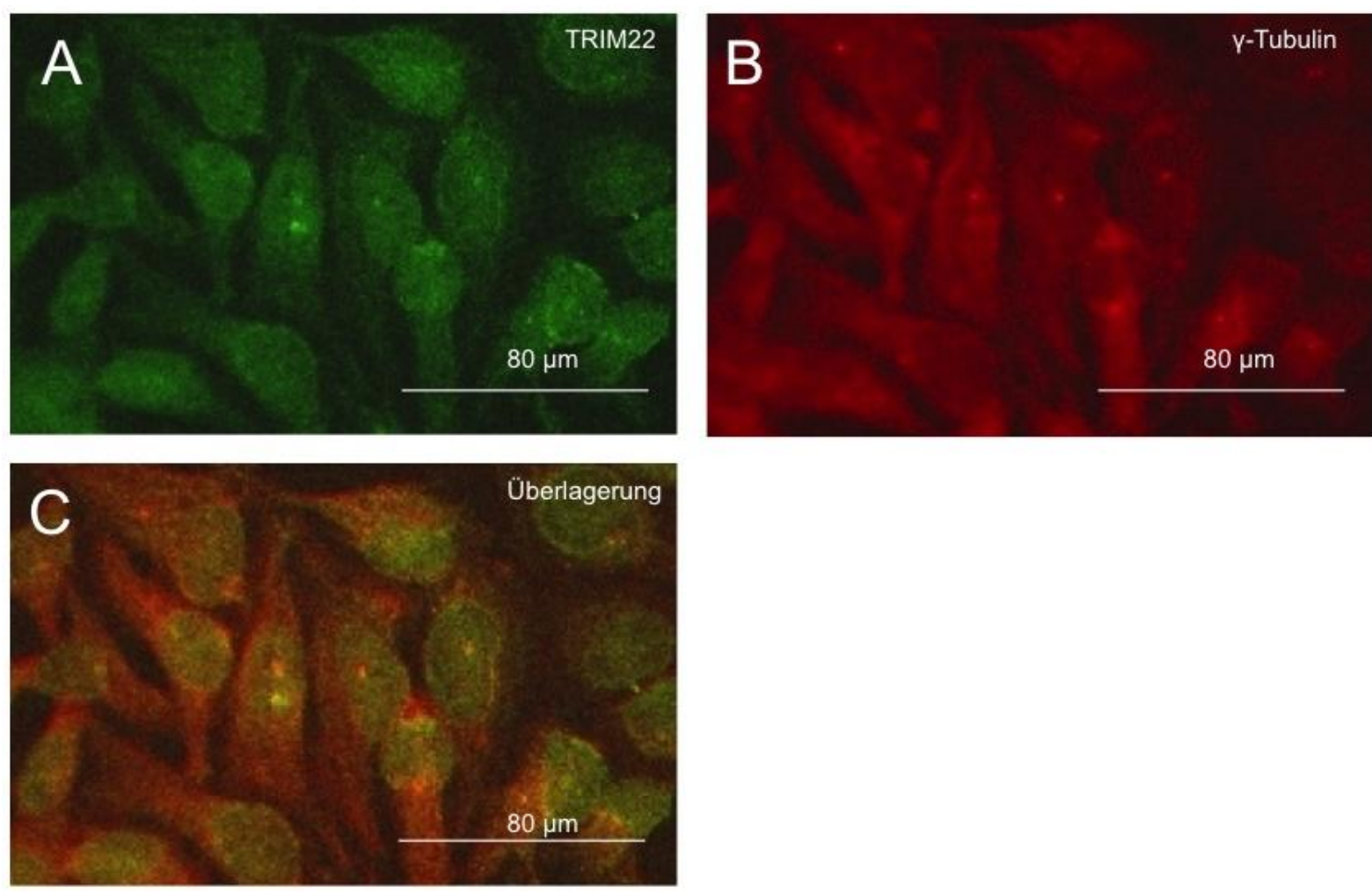

Abb. 9: Endogenes TRIM22 kolokalisierte mit $\gamma$-Tubulin in HeLa-Zellen

Das Zentrosom wurde durch das $\mathrm{y}$-Tubulin dargestellt (B). $\mathrm{Y}$-Tubulin ist ein zentrosomales Markerprotein, das je nach Zellzyklusphase ein- oder zweifach intrazellulär vorliegt. TRIM22 zeigte eine geringe ubiquitäre Verteilung, jedoch waren punktuelle Anhäufungen in nahezu jeder Zelle sichtbar. Diese präsentierten sich überwiegend perinukleär $(A)$ und zeigten hier eine Kolokalisation (gelb) mit $\gamma^{-}$ Tubulin und TRIM22 (C). (Mikroskop: AxioObserver)

\subsubsection{Ektopisch exprimiertes TRIM22 und das Zentrosom}

Um die Lokalisation von TRIM22-GFP und Zentrosom zueinander zu untersuchen, wurden HeLa-Zellen auf beschichtete Deckgläschen ausgesät und nach $24 \mathrm{~h}$ mit TRIM22-GFP transient transfiziert. Nach $48 \mathrm{~h}$ wurden die Zellen mit $-20^{\circ} \mathrm{C}$ kaltem Methanol fixiert, permeabilisiert und anschließend mit einem Antikörper gegen das zentrosomale Markerprotein CENP-E und einem Sekundärantikörper mit einer TRITC-Fluoreszenz gefärbt. Die Analyse erfolgte anhand des AxioObservers.

Überraschenderweise konnte zwischen dem CENP-E und TRIM22-GFP keine Kolokalisation gefunden werden (Abb. 10). 


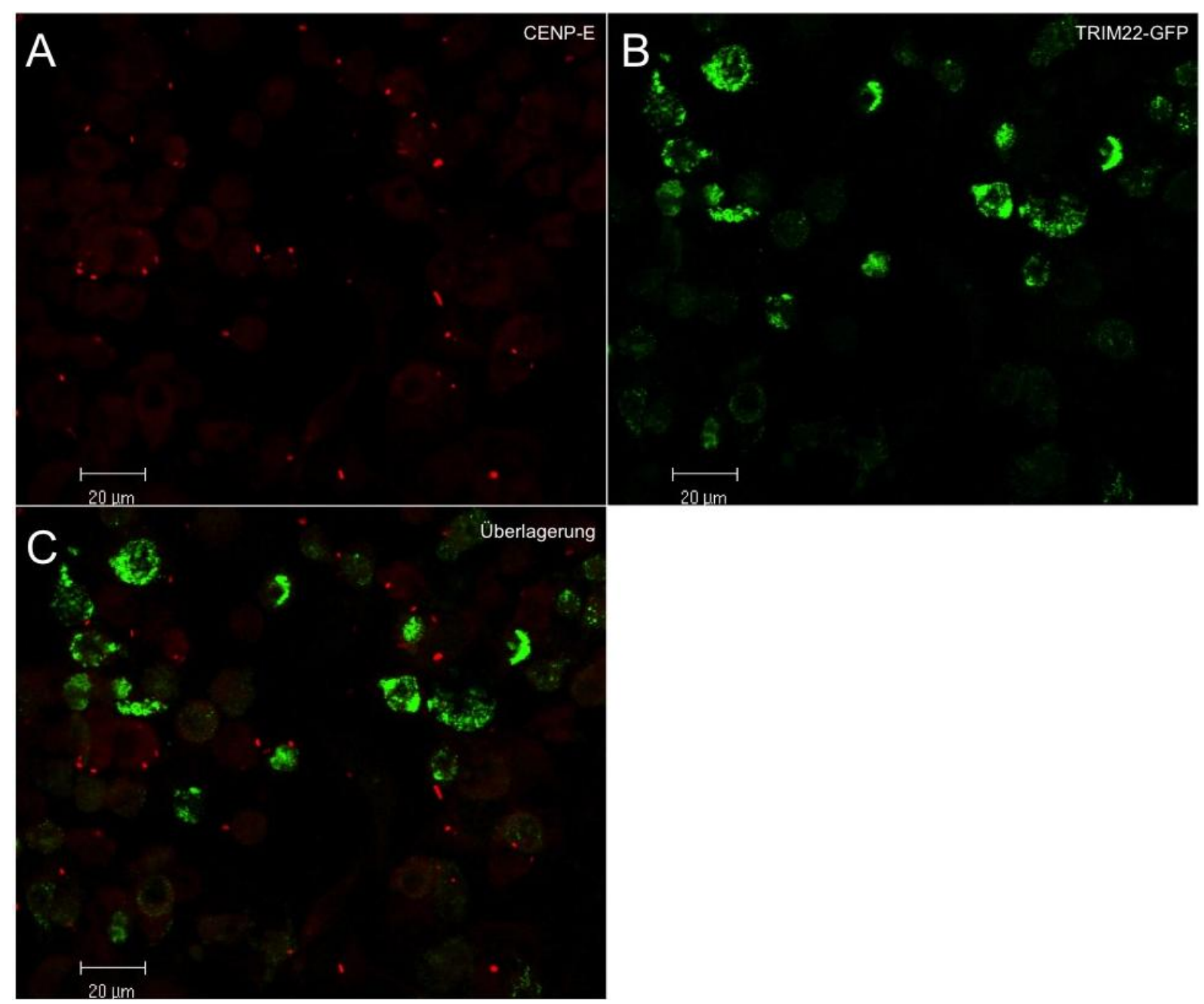

Abb. 10: TRIM22-GFP kolokalisierte nicht mit CENP-E

Das Zentrosom wird durch das zentrosomale Markerprotein CENP-E visualisiert (A). TRIM22-GFP stellte sich in Form grüner intrazellulärer Anhäufungen dar, deren Intensität in den verschiedenen Zellen stark schwankte (B). In der Überlagerung war keine Kolokalisation von TRIM22-GFP und CENP-E sichtbar (C). (Mikroskop: AxioObserver)

\subsection{4. Überblick über die Lokalisationsstudien}

1. TRIM22-GFP liegt im Zytoplasma vor. Punktuelle Anhäufungen kolokalisieren mit dem Mikrotubulussystem.

2. TRIM22-GFP befindet sich intranukleär.

3. TRIM22-GFP liegt perinukleär vor.

4. TRIM22-GFP könnte bei Überexpression zur Aggregatbildung neigen.

5. Endogenes verteilt sich wie ektopisch exprimiertes TRIM22, jedoch kommen keine größeren punktuellen Anhäufungen vor.

6. Endogenes TRIM22 kolokalisiert mit zentrosomalen Markerproteinen, wohingegen ektopisch exprimiertes TRIM22-GFP nicht mit zentrosomalen Markerproteinen kolokalisiert. 


\subsection{Effekte von TRIM22 auf die Zellvitalität}

Bei der Auswertung der Immunfluoreszenzstudien zur Lokalisation des TRIM22-GFP fiel auf, dass HeLa-Zellen, die mit TRIM22-GFP-transfiziert waren, eine veränderte Zellmorphologie zeigten. Diese wies Anzeichen des Zelluntergangs auf und schien mit der TRIM22-GFP-Expression zu korrelieren.

Des Weiteren sollte neben dem Einfluss der TRIM22-Überexpression auch der Einfluss der unterdrückten TRIM22-Expression mittels RNAi auf die Zellvitalität untersucht werden. Im letzten Schritt sollte anhand des TUNEL-Tests überprüft werden, ob dabei eine verstärkte Apoptose nachweisbar ist.

\subsubsection{TRIM22-GFP kann die Zellvitalität negativ beeinflussen}

Zur genaueren Beschreibung der morphologischen Veränderungen wurden die HeLa-Zellen nach der TRIM22-GFP-Überexpression über mehrere Tage lichtmikroskopisch beobachtet. Die Zellen wurden mit $-20^{\circ} \mathrm{C}$ kaltem Methanol fixiert und dadurch permeabilisiert, bevor sie mit einem $\alpha$-Tubulin-Primärantikörper und mit einem TRITC-markierten Sekundärantikörper gefärbt wurden. Anschließend erfolgte die Analyse mithilfe des LSM.

Erste morphologische Veränderungen konnten ca. $48 \mathrm{~h}$ nach der Transfektion beobachtet werden. Bei einer besonders starken Expression des TRIM22-GFPKonstruktes traten Veränderungen schon früher auf. Die ersten Veränderungen bestanden in einer Volumenabnahme der Zellen und einer Ausbildung filiformer Ausläufer (Abb. 11). 

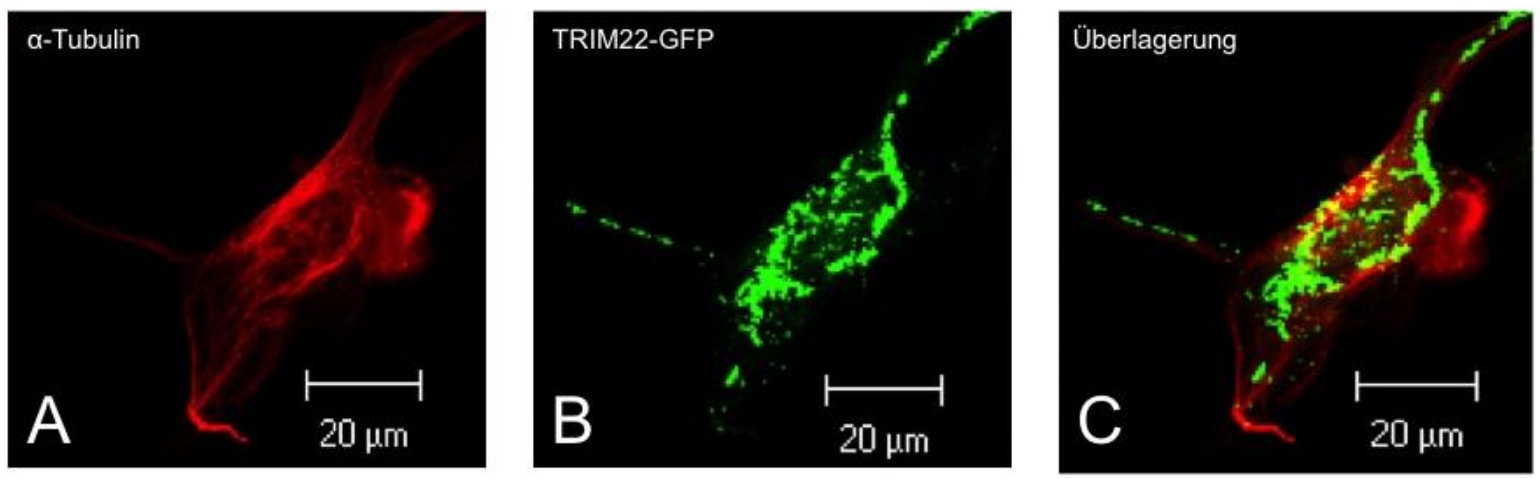

Abb. 11: Veränderte HeLa-Zellmorphologie durch TRIM22-GFP

Das $\alpha$-Tubulin zeigte das Mikrotubulusnetzwerk (A). TRIM22-GFP lag in Form größerer Akkumulationen vor (B). In der Überlagerung zeigten sich die TRIM22GFP-Anhäufungen im Bereich des Zytoskeletts und im Nukleus (C). Die Zellen verschmälerten sich in der Zellperipherie und bildeten Ausziehungen. (Mikroskop: LSM 5 PASCAL)

In den nächsten Schritten präsentierten sich Zeichen zellulären Vitalitätsverlusts: Die Zellen kondensierten, rundeten sich ab und lösten sich schließlich vom Kulturschalengrund ab (exemplarisch in Abb. 12). Besonders auffällig erschien dabei, dass die Zellen mit einem hohen TRIM22-GFP-Anteil am stärksten zur Abrundung neigten. 

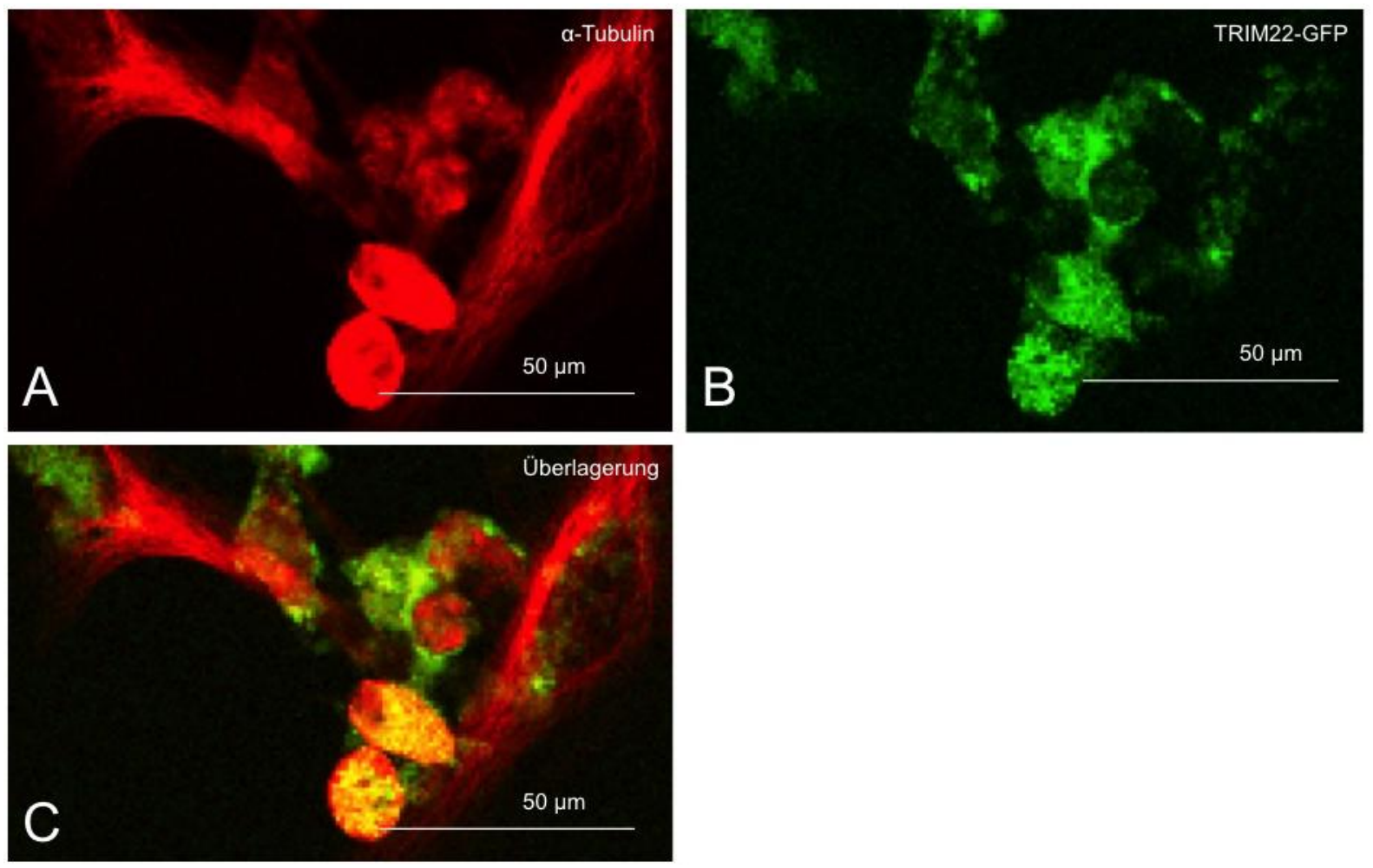

Abb. 12: Effekt von TRIM22-GFP in HeLa-Zellen nach 72h

Die $\alpha$-Tubulin-Färbung stellte das Mikrotubulusnetzwerk in HeLa-Zellen dar (A), die mit TRIM22-GFP transfiziert wurden (B). In der Überlagerung zeigte sich, dass HeLa-Zellen mit besonders hohem TRIM22-GFP-Gehalt die Tendenz zur Mikrotubulikondensation besaßen. Im weiteren zeitlichen Verlauf rundeten sich die HeLa-Zellen ab und lösten sich vom Boden. Mikroskopisch zeigten Zellen mit hohem TRIM22-GFP-Gehalt Anzeichen der Apoptose. (Mikroskop: LSM 5 PASCAL)

\subsubsection{Induktion von RNAi im TRIM22-Gen}

In diesem Versuch sollte die Herunterregulation der endogenen TRIM22-Expression (Knockdown) in HeLa-Zellen durch RNAi etabliert und nachgewiesen werden. Die RNAi dient der Expressionsreduktion eines Proteins. In weiteren Versuchen sollte untersucht werden, ob diese Reduktion Auswirkungen auf die Zelle hat. Im Rahmen dieser Arbeit wurden nach durchgeführter RNAi im TRIM22-Gen u.a. ein TUNELund ein Luziferase-Test durchgeführt .

Es wurden zwei verschiedene siRNAs gegen das TRIM22-Gen erstellt. Die TRIM22mRNA-Sequenz wurde von www.ncbi.nih.gov abgerufen. Das siRNA-Design erfolgte anhand der komplementären Desoxyribonukleinsäure (cDNA). Generell sollte die Zielsequenz idealerweise 21 Nukleotide lang sein, einen Guanin (G)/Cytosin (C)Anteil von etwa $40 \%$ bis $60 \%$ haben und einen strukturellen Aufbau von 5'-(N19)-UU in Leserichtung haben (N19 steht für 19 beliebige Nukleotide, U steht für Uracil). 


\begin{tabular}{|c|c|c|}
\hline siTRIM22-1 & 1 & GCUAAUGCCUUAAUGAAAUUU \\
\hline TRIM22-CDNA & 2281 & $\begin{array}{l}|||||||||||||||||||||| \\
\text { GCTAATGCCTTAATGAAAT }\end{array}$ \\
\hline siTRIM22-2 & 1 & UAGCAAAGCAUCAUAGAUUUU \\
\hline TRIM22-CDNA & 2016 & $\begin{array}{l}|||||||||||||||||||||||| \\
\text { TAGCAAAGCATCATAGATT }\end{array}$ \\
\hline
\end{tabular}

Die beiden siRNAs binden an die komplementäre mRNA und bewirken entweder einen Translationsstop oder eine Degradation der mRNA (siehe 1.3).

\subsubsection{Knockdown des TRIM22}

HeLa-Zellen wurden in 24-Well-Platten ausgesät und nach $24 \mathrm{~h}$ entweder mit siTRIM22-1, siTRIM22-2 oder siGL2 transfiziert. Die siRNA siGL2 diente als Negativkontrolle, da sich die Zielsequenz im Genom des Schleimpilzes Dictyostelium discoideum befindet und für das humane Genom unspezifisch ist. 48h nach Transfektion wurden die Zellen mit $-20^{\circ} \mathrm{C}$ kaltem Methanol fixiert und dadurch permeabilisiert. Anschließend erfolgte die Färbung mit dem TRIM22-Antiserum und DAPI. Die Analyse unter dem AxioObserver wurde je mit identischer Belichtungszeit durchgeführt (DAPI-25ms, TRITC-6270ms). Die siTRIM22-1- und siTRIM22-2transfizierten Zellen zeigten im Gegensatz zu den siGL2-transfizierten Zellen eine deutlich geringere Immunfluoreszenz im TRITC-Kanal, was auf eine geringere TRIM22-Expression schließen ließ (Abb. 13A-I). Parallel wurde an den Zellen durch eine quantitative Echtzeit-PCR überprüft, ob die TRIM22-Expression unterdrückt wurde. Hierbei wurde eine etwa 50\%-ige Reduktion der TRIM22-mRNA nach Transfektion der siTRIM22-1 und siTRIM22-2 beobachtet (Abb. 13J). Dies entspricht einem effizienten Silencing (Hu et al. 2004; Nair et al. 2005). 

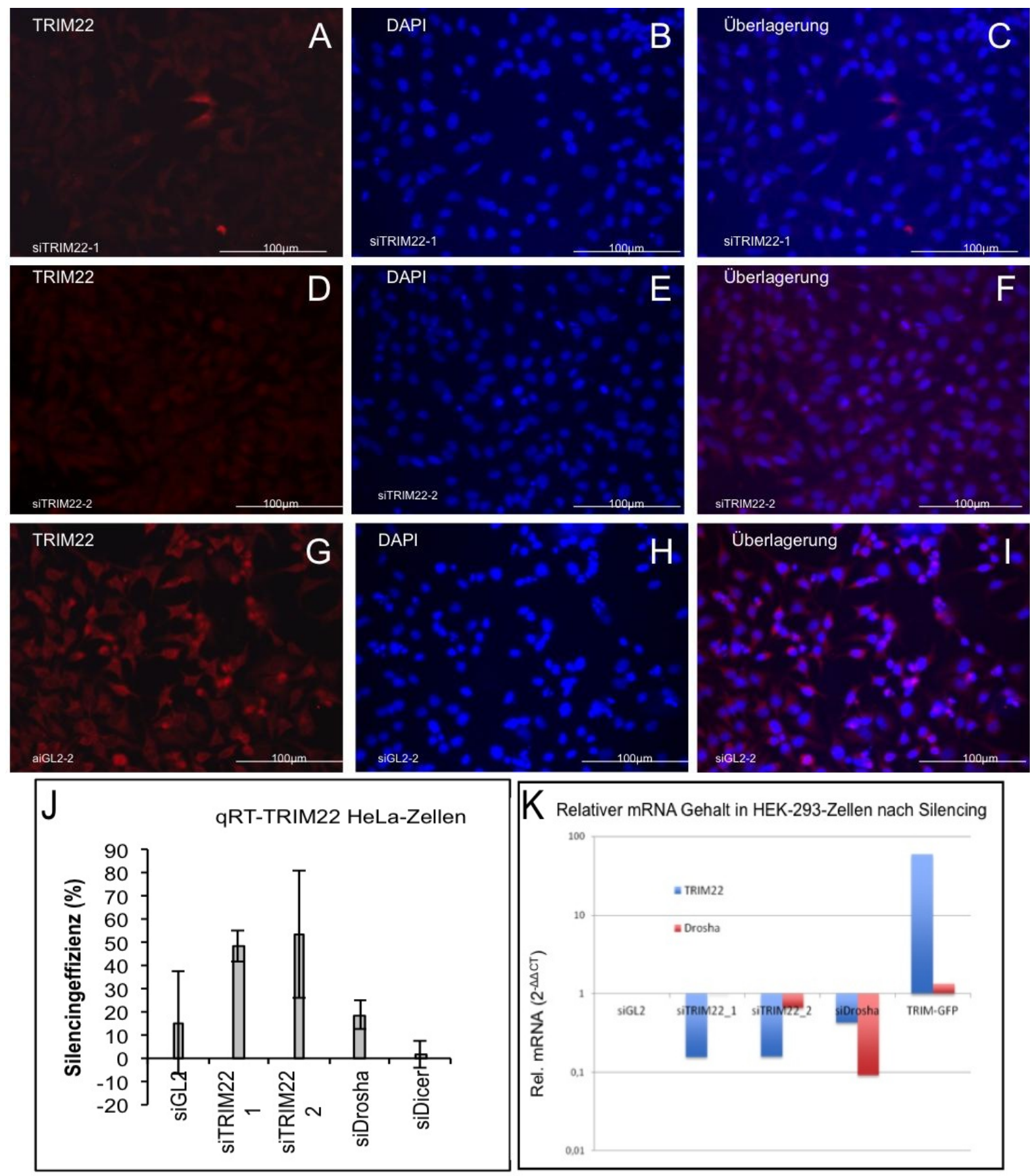

Abb. 13: Dokumentation des TRIM22-Knockdown

HeLa-Zellen wurden entweder mit siTRIM22-1, siTRIM22-2 oder mit siGL2 transfiziert und nach TRIM22-Färbung und DAPI-Zellkernfärbung unter dem Mikroskop ausgewertet. Bei identischen Belichtungszeiten zeigten die siTRIM22-1transfizierten ( $A, B, C)$ und siTRIM22-2-transfizierten HeLa-Zellen (D, E, F) eine deutlich geringere Fluoreszenz als die siGL2-transfizierte Negativkontrolle $(G, H, I)$. Alle Zellen wurden mit identischer Belichtungszeit analysiert (DAPI-25ms, TRITC$6270 \mathrm{~ms}$ ). Des Weiteren wurde die Silencing-Effizienz nach der $\Delta \Delta$-Ct-Methode in der quantitativen Echtzeit-PCR gemessen, wodurch das TRIM22-Silencing bestätigt wurde $(\mathrm{J})$. Zusätzlich wurde an HEK-293-Zellen der relative mRNA-Gehalt durch 2$\triangle \Delta \mathrm{Ct}$ dargestellt $(\mathrm{K})$. Die TRIM22-mRNA war in siTRIM22-1- oder siTRIM22-2transfizierten HEK-293-Zellen deutlich reduziert (siehe Anhang: 6.5 QuantitativeEchtzeit-PCR-Rohdaten). Die TRIM22-GFP-positiven Zellen zeigten eine deutliche Erhöhung der TRIM22-mRNA. (Mikroskop: AxioObserver) 
Bei der Analyse der Immunfluoreszenzdaten zur Knockdown-Dokumentation fielen vermehrt Zellen mit aberranten Mitosen auf. Zur genaueren Untersuchung dieses Phänotyps wurde die TRIM22-Herunterregulation in HeLa-Zellen durch RNAi wiederholt. Für die anschließende Immunfluoreszenzmikroskopie wurden eine chromosomale Färbung durch PI und eine $\alpha$-Tubulin-Färbung durchgeführt. Mithilfe des Mikroskops LSM 5 PASCAL wurde die Zellmorphologie anhand der Chromatinund Chromosomenverteilung und der Struktur des Mikrotubulussystems bewertet.

Bei der mikroskopischen Inspektion der siTRIM22-transfizierten HeLa-Zellen zeigten sich aberrante und atypische Mitosefiguren (Abb. 14), die häufiger auftraten als in der Kontrollpopulation (Abb. 15). Des Weiteren waren vermehrt triploide HeLa-Zellen detektierbar (Abb. 14 A, B, C), die neben HeLa-Zellen mit deformierten Chromosomenplatten (Abb. 14D, E, F) und atypischen Spindelapparaten vorkamen. Letztere äußerten sich durch Mikrotubuli, die nicht direkt zu den Chromosomen in die Äquatorialebene verliefen, sondern ungeordnet in der Zelle vorlagen (Abb. 14G, H, I). Exemplarisch sind einige Beispiele in Abb. 14 dargestellt.
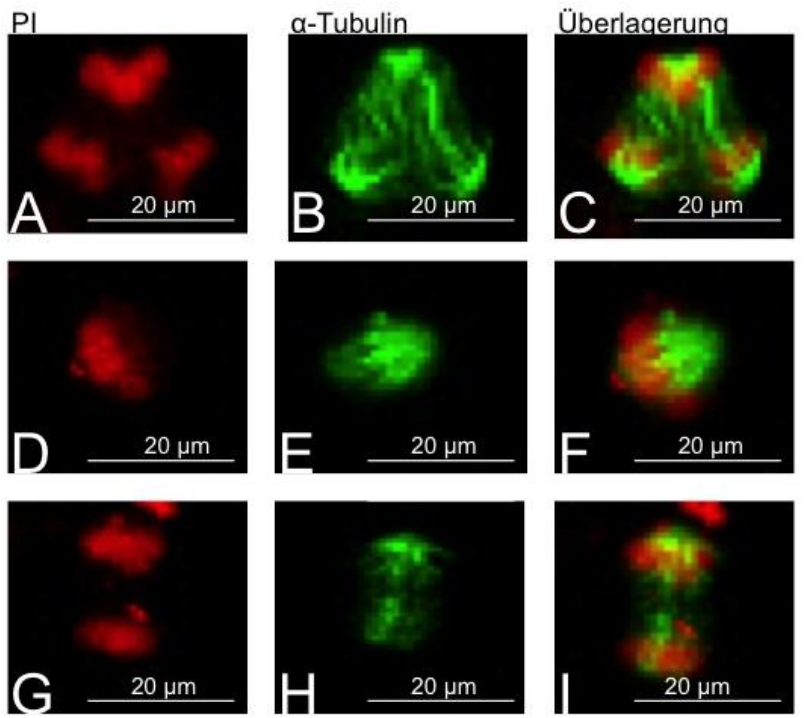

Abb. 14: Exemplarische Darstellung der gestörten Mitose nach TRIM22-Knockdown

Die DNA wurde durch PI (A, D, G) und das Mikrotubulussystem durch $\alpha$-Tubulin visualisiert $(B, E, H)$. In der Überlagerung wurde das Lageverhältnis der DNA zum Mikrotubulussystem deutlich (C, F, I). Aberrante mitotische Zellen traten gehäuft auf und waren u.a. durch Triploidie (A-C), deformierte Chromosomenplatten (D-F) und fehlerhaft ausgebildete Spindelapparate (E, F) gekennzeichnet. (Mikroskop: LSM 5 PASCAL)

Als Kontrolle dienten siGL-2-transfizierte HeLa-Zellen, die sämtliche Mitosestufen aufwiesen (Abb. 15). In der Kontrollpopulation konnten nahezu keine mitotisch aberranten HeLa-Zellen gefunden werden. Bei dieser orientierenden qualitativen 
Analyse wurden deutlich weniger triploide HeLa-Zellen in der Kontrollpopulation als in der siTRIM22-1- und -2-transfizierten Zellpopulation gefunden.
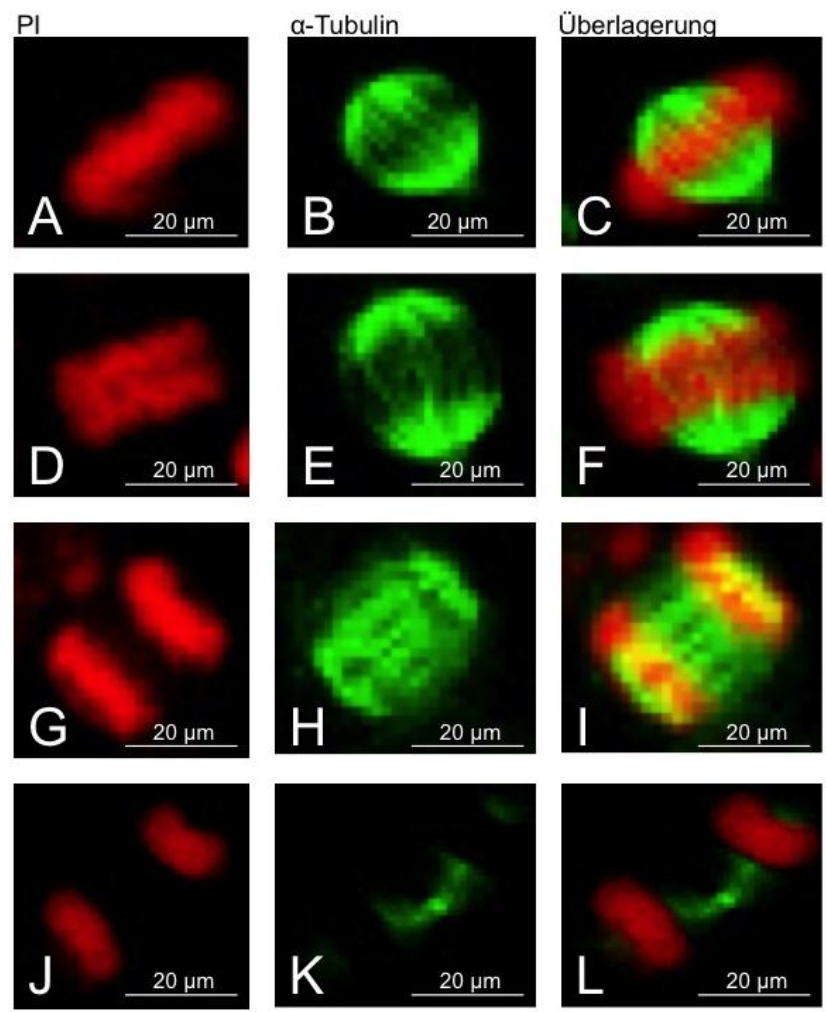

Abb. 15: Mitose bei siGL-2-transfizierten HeLa-Zellen

Die DNA wurde durch PI (A, D, G, J) und das Mikrotubulussystem durch $\alpha$-Tubulin visualisiert $(B, E, H, K)$. In der Überlagerung waren alle Mitosestufen auffindbar. In der Prophase bilden sich die Spindelpole und die Chromosomen kondensieren. In der Metaphase ordnen sich die homologen Chromosomen in der Äquatorialebene an und die Mikrotubuli wachsen von den Spindelpolen zu den Zentromeren (C). In der Anaphase wandern die Chromosomen zu den sich gegenüber liegenden Spindelpolen (F). In der Telophase dekondensieren die Chromosomen in den beiden Tochterzellen (I). Während der Zytokinese wird schließlich die zelluläre Verbindung der beiden Tochterzellen getrennt. (Mikroskop: LSM 5 PASCAL) 


\subsubsection{Untersuchungen zum Zellzyklus und zur Zellvitalität mittels Sub-G1- peak-Messung}

Um den Einfluss des TRIM22-GFP und des endogenen, Inf- $\beta$-induzierten TRIM22 auf Zellzyklus und Zellvitalität zu eruieren, wurde eine Sub-G1-peak-Messung durchgeführt. Hierbei erfolgte eine Zellzyklusanalyse, bei welcher das Chromatin durch PI angefärbt (Vermeulen et al. 2005) und anschließend mittels Durchflusszytometrie (FACS) analysiert wurde.

In diesem Versuch wurden HeLa-Zellen mit TRIM22-GFP transfiziert und nach $24 \mathrm{~h}$ mittels PI angefärbt. Als Kontrolle wurden HeLa-Zellen mit einem HLA-B`35-GFPKonstrukt transfiziert. Des Weiteren wurde das endogene TRIM22 durch Inf- $\beta$ induziert und dessen Wirkung auf HeLa-Zellen untersucht. In beiden Versuchen wurden unbehandelte HeLa-Zellen, Wildtypzellen (WT-Zellen), als Kontrolle mitgemessen. Die Analyse der Daten erfolgte mit dem Computerprogramm FlowJo. Zur Analyse wurde auf der x-Achse des Diagramms die Fluoreszenzintensität und auf der y-Achse die Zellzahl aufgetragen. Gesunde Zellen werden in eine G1-, Sund G2-Population unterteilt. Apoptotische Zellen sind durch eine Sub-G1-Population gekennzeichnet, die auf der x-Achse vor der G1-Population liegt (Nicoletti et al. 1991), wohingegen sich polyploide Zellen hinter der G2-Population präsentieren.

In Abbildung 16 ist das Ergebnis der FACS-Messung dargestellt. HeLa-Zellen, die mit TRIM22-GFP oder HLA-B*35-GFP transfiziert wurden, und WT-HeLa-Zellen zeigten keine Sub-G1-Population. Die G1/G0-Population nahm in allen drei Messansätzen den größten, etwa gleichwertigen Anteil ein (Abb. 17). Die S- und G2Populationen waren in allen Messansätzen ebenfalls vergleichbar. G1-, S- und G2Population konnten in allen Ansätzen als unauffällig physiologisch gewertet werden. Es fiel jedoch in der TRIM22-GFP-transfizierten Zellpopulation ein hoher Anteil polyploider Zellen auf, der nicht der Norm entsprach. In den Kontrollen der HLAB*35-GFP-transfizierten Zellen und der WT-Zellen war ebenfalls ein Anteil polyploider Zellen nachweisbar. Beim Vergleich der Graphen zeigte sich ein deutlich anderer Verlauf nach der G2-Phase zwischen TRIM22-GFP-positiven Zellen und Kontrollzellen (vgl. Abb. 16A).

Ebenfalls zeigten die mit Inf- $\beta$ behandelten Zellen das Auftreten polyploider Zellen. Interessanterweise zeigt der Graph dieser Zellen einen ähnlichen Verlauf wie die WT-Zellen (Abb. 16B). Es konnte keine Sub-G1-Population nachgewiesen werden. 


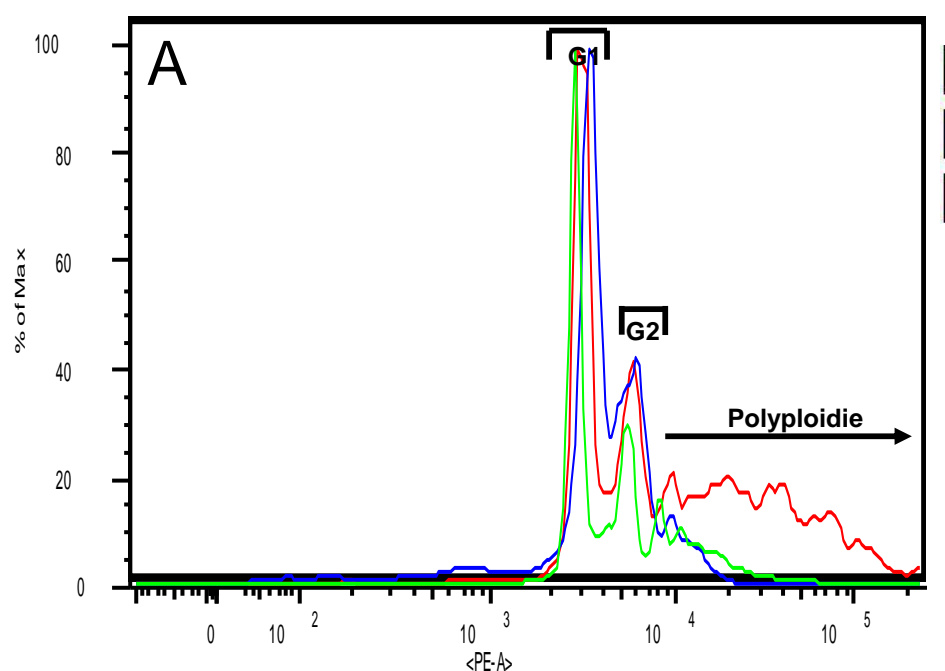

$$
\begin{aligned}
& \square \boxminus \text { WT_2 +fcs } \\
& \square \boxminus \text { HLA-B35-GFP2_2 + } \\
& \square \boxminus \text { TRIM-GFP1_2 +.fcs }
\end{aligned}
$$

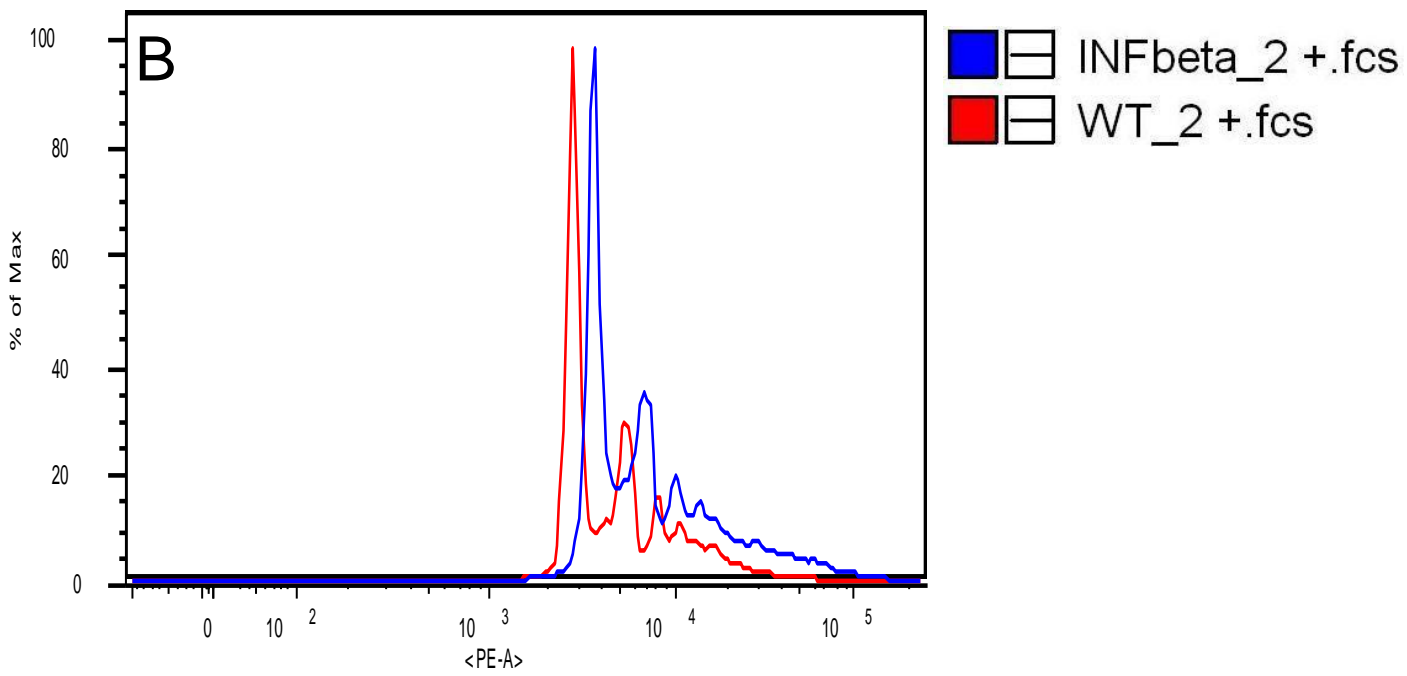

Abb. 16: Zellzyklusanalyse mit PI

Der G1-Peak war bei untransfizierten (grüner Graph), HLA-B*35-GFP-transfizierten (blauer Graph) und TRIM22-GFP-transfizierten HeLa-Zellen (roter Graph) nahezu identisch (A). Zwischen dem ersten und dem zweiten Peak präsentierten sich die in der S-Phase befindlichen Zellen. Der zweite Peak entsprach der G2-Population und zeigte die Anzahl diploider Zellen. Alle rechts davon liegenden Zellen besaßen einen höheren Chromatingehalt und wurden daher als polyploid gewertet. Der rote Graph, welcher die TRIM22-GFP-positiven HeLa-Zellen darstellte, zeigte im Vergleich zu dem blauen Graphen (HLA-B*35-GFP-transfizierte Zellen) und zu dem grünen Graphen (untransfizierte HeLa-Zellen) mit Abstand den größten Anteil polyploider Zellen. Des Weiteren wurde eine Zellzyklusanalyse bei WT-HeLa-Zellen (roter Graph) und mit Interferon- $\beta$-behandelten HeLa-Zellen (blauer Graph) durchgeführt (B). Der blaue Graph verlief rechts des G2-Peaks auf einem höheren Niveau als der rote Graph, ist jedoch im Verlauf dem roten Graph sehr ähnlich. Bei der Messung der FACS-Daten wurden nur die GFP-positiven Zellen berücksichtigt, sofern in der Messpopulation GFP-positive Zellen vorhanden waren. 


\subsubsection{TUNEL-Tests an HeLa-Zellen}

Mit einem TUNEL-Test wurde überprüft, ob die beobachteten zellmorphologischen Veränderungen eine Apoptose widerspiegeln. Bei einer verminderten TRIM22Expression durch RNAi zeigten sich im Vorfeld dieses Versuchs lichtmikroskopisch Veränderungen des zellulären Phänotyps wie polyploide oder mitotisch aberrante Zellen (Abb. 14).

Bei dem TUNEL-Test wurden Einzelstrangbrüche, die während der Apoptose durch verschiedene Nukleasen gesetzt werden, durch die terminale DesoxyribosylTransferase (TdT) aufgespürt. Die TdT baut Nukleotide, die mit dem Fluoreszenzfarbstoff TMR gekoppelt sind, an die Einzelstrangbrüche an. In der Fluoreszenzmikroskopie können so apoptotische Zellen erkannt werden. Der TUNEL-Test wurde mit dem In Situ Cell Death Detection Kit TMR red durchgeführt.

HeLa-Zellen wurden hierzu in 24-Well-Schalen auf beschichteten Deckgläschen ausgesät und ein TRIM22-Knockdown mit siTRIM22-1 und siTRIM22-2 durchgeführt. Als Kontroll-siRNA wurde siGL2 verwendet. 48h nach der Transfektion erfolgte eine Fixierung mit Methanol, die zugleich zur Permeabilisierung führte. Anschließend wurde die DNA durch eine DAPI-Färbung visualisiert und der TUNEL-Test durchgeführt. Im nächsten Schritt wurden die Zellen unter dem AxioObserver qualitativ analysiert. Nach TRIM22-Knockdown durch RNAi waren nach 48h mehr HeLa-Zellen TUNEL-positiv als in der siGL2-transfizierten Negativkontrolle (Abb. 17 $A-I)$. 

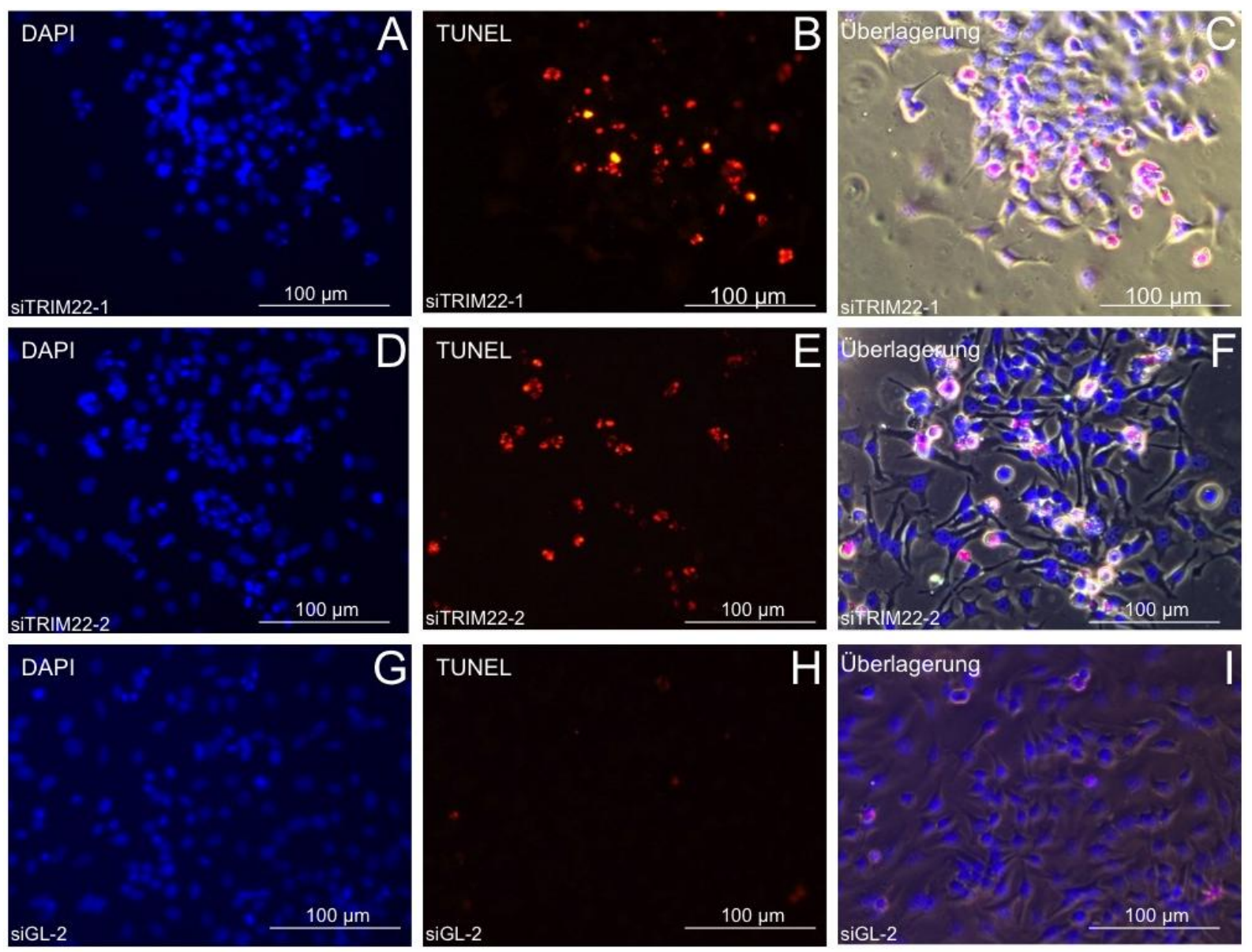

Abb. 17: TUNEL-Test

HeLa-Zellen wurden auf beschichteten Deckgläschen in 24-Well-Schalen ausgesät und am nächsten Tag entweder mit siGL2 (A, B, C), siTRIM22-1 (D, E, F) oder siTRIM22-2 (G, H, I) transfiziert und für 48h inkubiert. Die Fixierung und Permeabilisierung erfolgte mittels $-20^{\circ} \mathrm{C}$ kaltem Methanol. Anschließend wurde ein TUNEL-Test durchgeführt. Die Zellkerne wurden durch DAPI angefärbt $(A, D, G)$. Das TMR des TUNEL-Tests wurde im roten Kanal aufgenommen (B, E, H). In der Überlagerung (C, F, I) zeigte sich, dass ein großer Anteil der siTRIM22-1- und siTRIM22-2-transfizierten Zellen ebenfalls im TUNEL-Test positiv war. In der siGL2Kontrolle (G, H, I) waren nur wenig apoptotische Zellen (G) nachweisbar. (Mikroskop: AxioObserver)

Anschließend erfolgte eine quantitative Auswertung am Mikroskop durch manuelle Auszählung. Zu diesem Zweck wurden Objektträger aus zwei verschiedenen Versuchsreihen verwendet, die entweder mit siTRIM22-1-, siTRIM22-2- oder siGL2transfizierten HeLa-Zellen und unbehandelten HeLa-Zellen (WT) bedeckt waren. Nach $48 \mathrm{~h}$ wurden die Zellen mit $-20^{\circ} \mathrm{C}$ kaltem Methanol fixiert und permeabilisiert. Anschließend wurde ein TUNEL-Test durchgeführt. Die Auswertung erfolgte mit dem Mikroskop AxioObserver, wobei im roten Kanal die TUNEL-positiven Zellen und in der Durchlichteinstellung sämtliche Zellen mit einem manuellen Zählgerät in 10 unterschiedlichen, zufällig eingestellten Ausschnitten gezählt wurden. Die Mittelwerte 
aus zwei unabhängigen Versuchsreichen zeigten, dass siTRIM22-1- bzw. siTRIM222-transfizierte HeLa-Zellen einen apoptotischen Zellanteil von 40\% (+/-17\%) bzw. $48 \%(+/-28 \%)$ aufwiesen (Abb. 18).

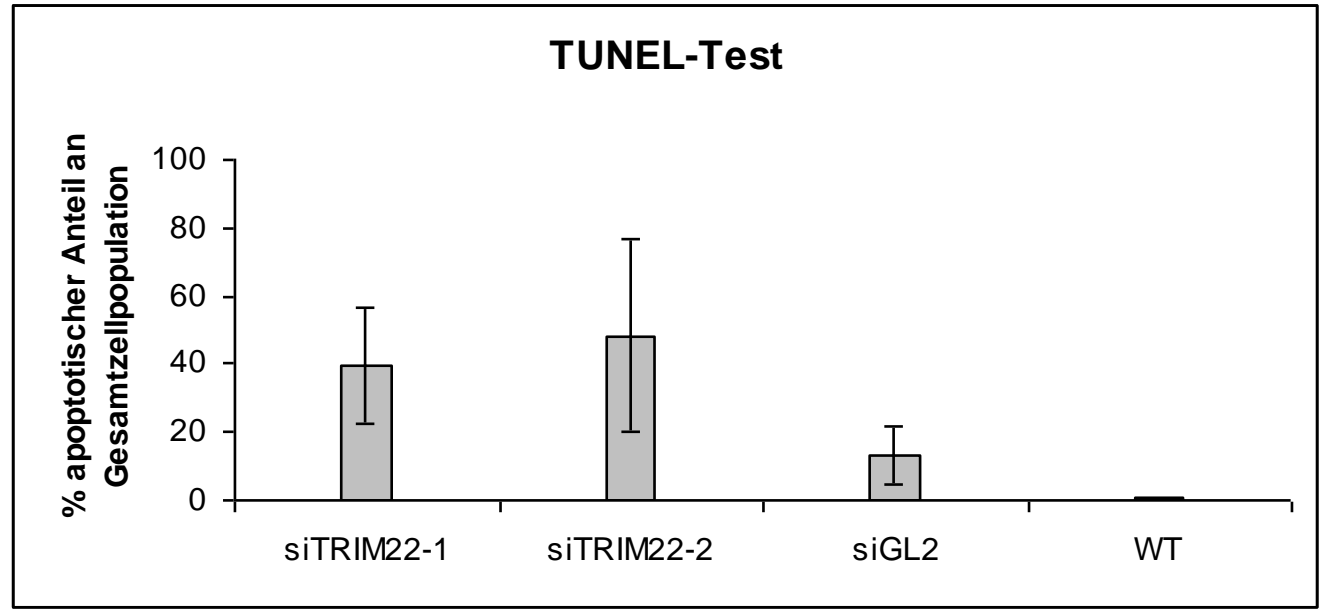

\begin{tabular}{|l|r|r|r|r|}
\hline & siTRIM22-1 & siTRIM22-2 & siGL2 & WT \\
\hline \%-Mittelwert Exp.1 und 2 & 39,5 & 48,2 & 13,3 & 0,5 \\
\hline Stabw & 17,1 & 28,3 & 8,4 & 1,1 \\
\hline
\end{tabular}

Abb. 18: Anteil apoptotischer Zellen an der Gesamtzellpopulation

Sämtliche Zellen einer Mikroskopeinstellung wurden manuell ausgezählt. Anschließend wurden im roten Kanal alle TUNEL-positiven Zellen ausgezählt. Diese Auszählung erfolgte in allen vier Zellpopulationen in je zehn Mikroskopeinstellungen aus zwei unabhängigen Experimenten. Anschließend wurde der prozentuale Anteil der apoptotischen Zellen berechnet (siehe Anhang: 6.4 Rohdaten).

\subsection{5. Überblick zu den Ergebnissen der Zusammenhänge von TRIM22 und der}

\section{Zellvitalität}

1. TRIM22-GFP führt nach ca. $24 \mathrm{~h}$ zu einem vermehrten Auftreten polyploider Zellen.

2. Überexprimiertes TRIM22-GFP führt nach ca. 48h zu einem veränderten Phänotyp, der durch Volumenabnahme und Ausbildung filiformer Ausläufer charakterisiert ist.

3. TRIM22-GFP und endogenes TRIM22 zeigen bei Überexpression vermehrt polyploide Zellen.

4. Die Induktion der RNAi im TRIM22-Gen ist erfolgreich.

5. TRIM22-defiziente Zellen zeigen vermehrt mitotisch aberrante Zellen.

6. TRIM22-defiziente Zellen zeigen eine erhöhte Apoptoserate. 


\subsection{TRIM22 und RNAi}

Bei der Auswertung der Immunfluoreszenzbilder zeigte sich eine Ähnlichkeit zwischen dem subzellulären Verteilungsmuster des TRIM22 und der Proteine der Silencing-Maschinerie u.a. AGO2, DICER oder PABP (siehe Einleitung 1.2). Ein möglicher Zusammenhang sollte in weiteren Versuchen untersucht werden. Hierzu wurde initial mittels Immunfluoreszenzmikroskopie nach einer Kolokalisation von TRIM22 und Proteinen der Silencing-Maschinerie gesucht. Im nächsten Schritt wurden mittels Co-IP fragliche Kolokalisationspartner auf eine Interaktion überprüft. Im letzten Versuch sollte anhand einer Luziferasemessung ein funktioneller Zusammenhang zwischen TRIM22 und der Silencing-Maschinerie untersucht werden.

\subsubsection{TRIM22 komplexiert mit Komponenten der Silencing-Maschinerie}

TRIM22 zeigte in seinem subzellulären Verteilungsmuster Ähnlichkeit zu dem Verteilungsmuster von Proteinen der Silencing-Maschinerie. Um dies näher zu untersuchen, sollte in einem ersten Schritt durch Immunfluoreszenzmikroskopie die Lage von TRIM22 zu Komponenten der Silencing-Maschinerie beschrieben werden. Hierzu wurden HeLa-Zellen auf beschichteten Deckgläschen kultiviert und mit $-20^{\circ} \mathrm{C}$ kaltem Methanol fixiert und zeitgleich permeabilisiert. Anschließend wurden sie je mit einem TRIM22-AK und entweder einem PABP-, AGO2- oder DICER-AK behandelt. Die Auswertung erfolgte mit dem AxioObserver.

TRIM22 zeigte unmittelbar perinukleär eine Kolokalisation mit DICER (Abb. 19A-C), die als Endoribonuklease den ersten Schritt der miRNA-Biogenese katalysiert und die Bildung des RISC initiiert. Des Weiteren konnte zwischen AGO2 und TRIM22 eine örtliche Übereinstimmung gefunden werden (Abb. 19D-F). Schließlich zeigte sich ebenfalls eine Kolokalisation zwischen PABP und TRIM22 im Zytoplasma, die sich jedoch im Vergleich zu AGO2 weiter vom Nukleus entfernt darstellte (Abb. 19GI). 

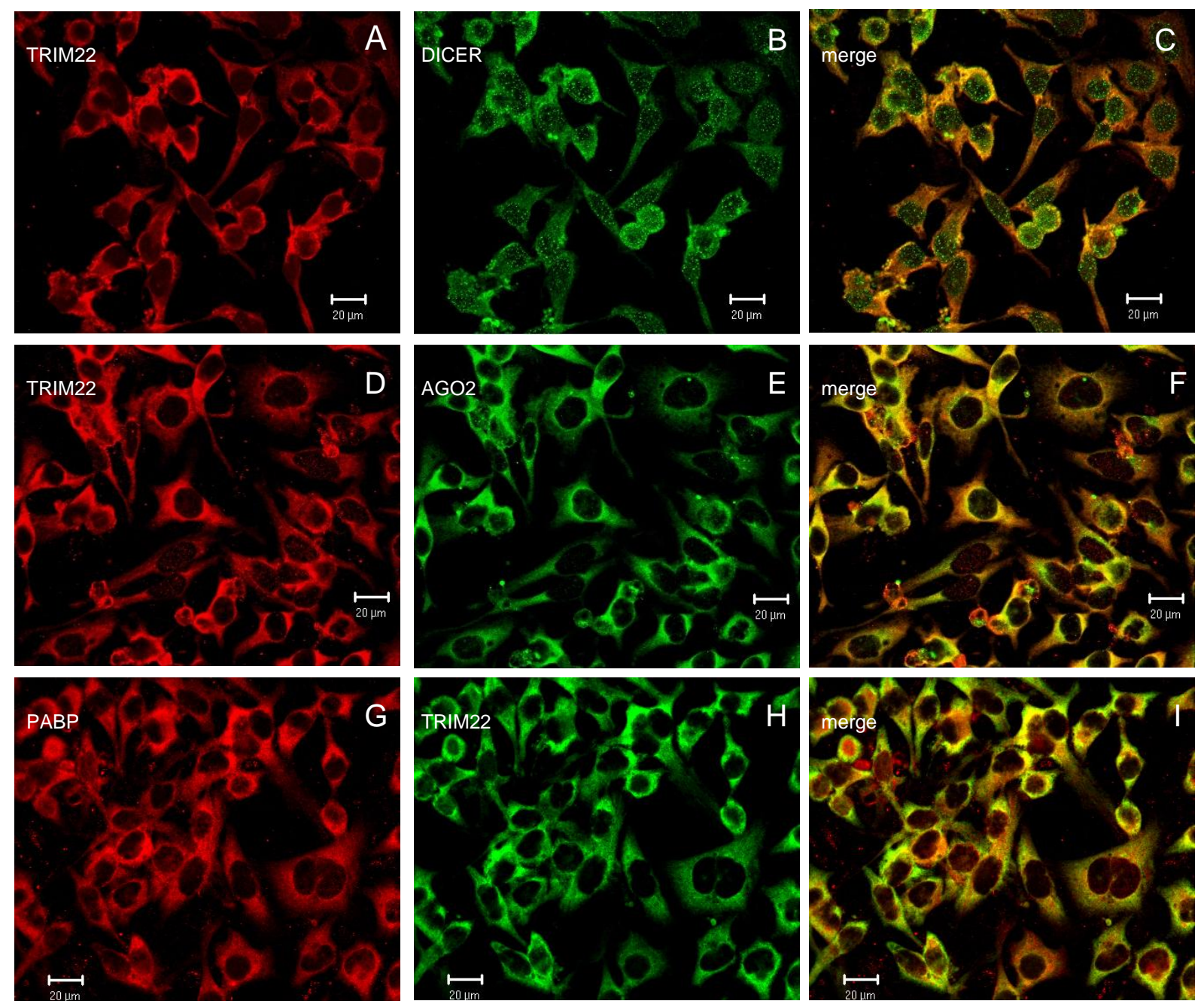

Abb. 19: IF-Mikroskopie von TRIM22 mit Komponenten der Silencing-Maschinerie

HeLa-Zellen wurden in 24-Well-Schalen ausgesät, nach $24 \mathrm{~h}$ mit $-20^{\circ} \mathrm{C}$ kaltem Methanol fixiert und dadurch permeabilisiert. Anschließend erfolgte die Färbung mit dem TRIM22-AK in Kombination mit dem DICER-, AGO2- oder PABP-AK. TRIM22 kolokalisierte in der IF-Mikroskopie mit DICER (A, B, C), AGO2 (D, E, F) und PABP (G, H, I). (Mikroskop: AxioObserver)

Weitergehend sollte durch eine Co-IP überprüft werden, ob die Beobachtungen aus der IF-Mikroskopie auf direkten Proteininteraktionen oder inzidentellen Übereinanderprojektionen beruhten. Hierzu wurden HeLa-Zellen in 6-Well-Schalen kultiviert, nach $24 \mathrm{~h}$ trypsiniert und anschließend homogenisiert. Das Proteinhomogenisat wurde zur Hälfte geteilt und in zwei Säulen mit einem TRIM22bzw. AGO2-AK gewaschen, sodass ein TRIM22- bzw. AGO2-Eluat mit den jeweils interagierenden Proteinen isoliert werden konnte. Diese Eluate wurden durch eine SDS-Page-Gelelektrophorese aufgetrennt und anschließend im Westernblot anhand der AK gegen TRIM22, AGO2, DICER, PABP und DROSHA untersucht (Abb. 20). 
In dem AGO2-Eluat zeigten sich im Westernblot neben einer deutlichen AGO2Bande eine TRIM22- und PABP-Bande (Abb. 20). In dem TRIM22-Eluat konnte additiv zur erwartungsgemäßen TRIM22-Bande je eine Bande für AGO2 und PABP nachgewiesen werden (Abb. 20). Eine allenfalls schwache Bande war in dem DICER-Westernblot des TRIM22-Eluats sichtbar, wobei hier keine AGO2-Bande detektierbar war. In keinem der Eluate konnte eine Bande für DROSHA gefunden werden.

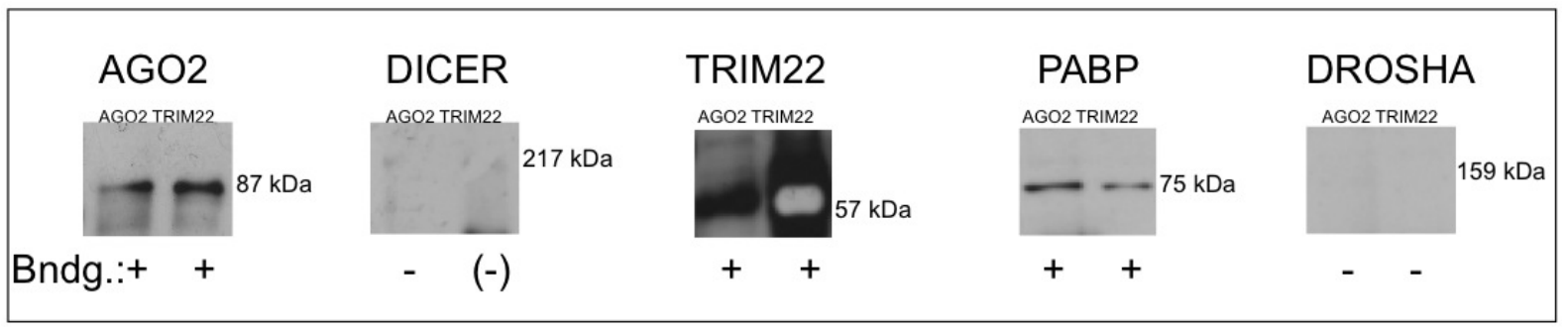

Abb. 20: Co-IP von TRIM22 und AGO2

Die Abbildung zeigt die Westernblots nach Co-IP. Aufgetragen wurde das AGO2bzw. TRIM22-Eluat. Anschließend erfolgte die Färbung mit dem AGO2-, DICER-, TRIM22-, PABP- und DROSHA-AK. TRIM22 und AGO2 komplexierten mit AGO2 und PABP. Des Weiteren zeigte das TRIM22-Eluat eine allenfalls schwache DICERBande, wohingegen im AGO2-Eluat DICER nicht nachweisbar war. DROSHA wurde in keinem der Eluate detektiert. 


\subsubsection{Funktioneller Nachweis von TRIM22 in der RNAi}

Es konnte in vorherigen Versuchen durch IF-Mikroskopie und Co-IP gezeigt werden, dass TRIM22 mit Komponenten der Silencing-Maschinerie interagiert. TRIM22 kolokalisiert und interagiert mit AGO2, PABP und eventuell auch mit DICER (siehe 3.3.1). Nun sollte überprüft werden, ob TRIM22 funktionell an der miRNA-Genese beteiligt ist. Für die Untersuchung dieses Zusammenhanges wurde folgender Versuch konzipiert:

Die miRNA23a wurde als Untersuchungsobjekt ausgewählt, da diese in HeLa-Zellen auf konstantem Niveau exprimiert wird. Nach Knockdown der essentiellen Bestandteile der Silencing-Maschinerie DICER und DROSHA sollte in einem dualen Luziferaseassay die gemessene Fluoreszenz mit der Fluoreszenz nach TRIM22Knockdown verglichen werden (Abb. 21).

Hierzu wurde in die multiple Klonierungsstelle des psiCHECK-2-Vektors eine miRNA23a-komplementäre Sequenz kloniert, die mit dem Renilla-Luziferasegen eine funktionelle Transkriptionseinheit bildete. Die miRNA23a wurde in den untersuchten HeLa-Zellen auf einem stetig hohen Niveau exprimiert und müsste bei intakter Silencing-Maschinerie durch die komplementäre miRNA23a-Sequenz mittels RNAi degradiert werden. Dabei müsste die Renilla-Fluoreszenz reduziert sein (Abb. 21). Beim Knockdown der essentiellen Silencing-Maschinerie-Bestandteile DICER oder DROSHA dürfte demnach die komplementäre miRNA23a mit dem RenillaLuziferasegen nicht durch RNAi abgebaut werden. Die Renilla-Fluoreszenz müsste in diesem Fall deutlich messbar sein. 


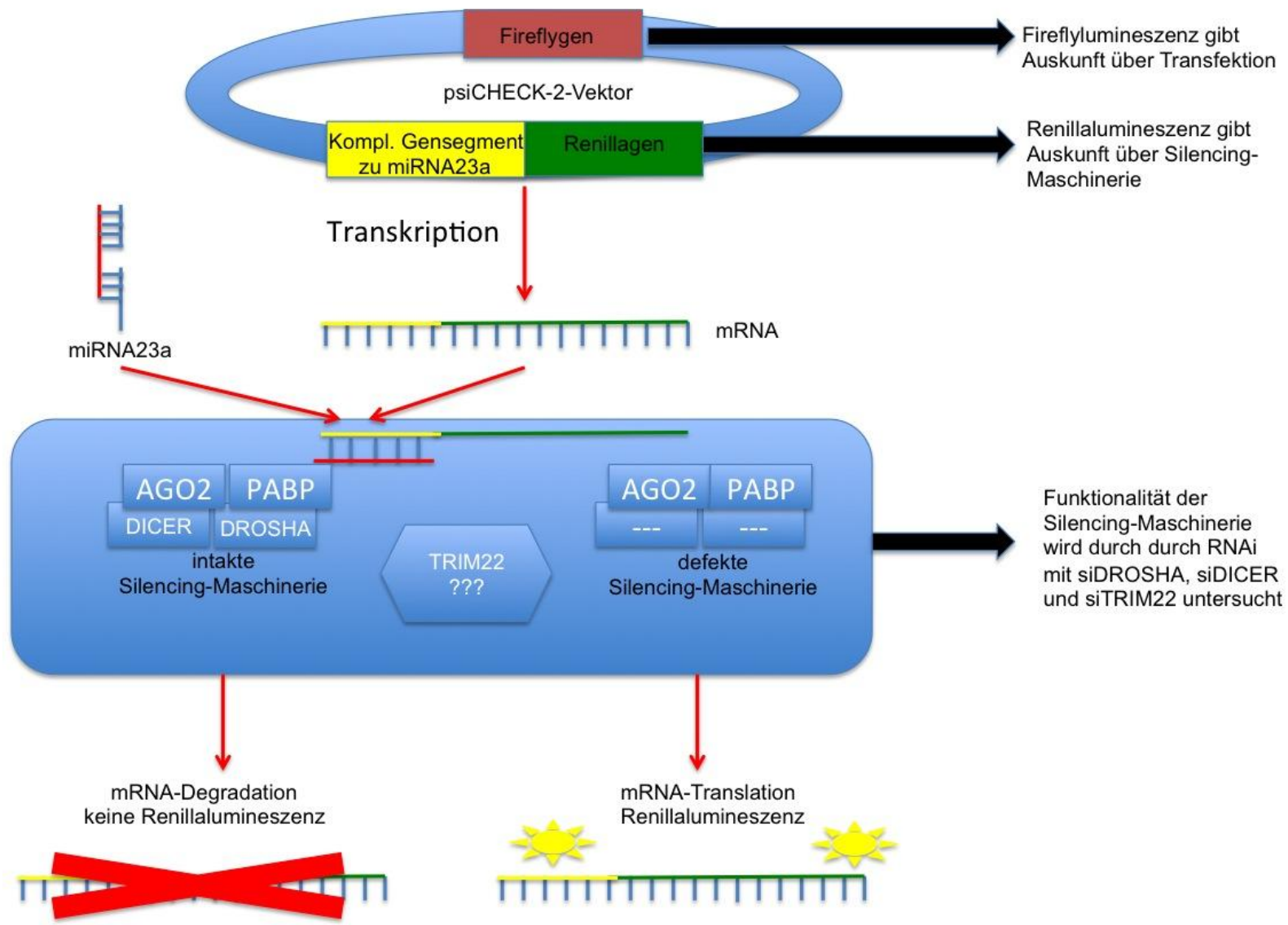

Abb. 21: Versuchsaufbau zur Luziferasemessung

Der psiCHECK-2-Vektor enthielt das der Transfektionskontrolle dienende FireflyLuziferasegen und das als funktionelle Transkriptionseinheit fungierende RenillaLuziferasegen mit dem zur miRNA23a-komplementären Gensegment. Die miRNA23a liegt in HeLa-Zellen auf konstantem Niveau vor. Dieser psiCHECK-2Vektor wurde in HeLa-Zellen entweder mit siDROSHA, siDICER, siTRIM22 oder siGL2 kotransfiziert. Bei intakter Silencing-Maschinerie müsste die mRNA des Renilla-Gens abgebaut werden. Eine Renilla-Lumineszenz wäre somit nicht messbar. Bei defekter Silencing-Maschinerie hingegen würde die mRNA translatiert werden und eine Renilla-Lumineszenz wäre zu erwarten.

Als Positivkontrolle diente bei diesem Versuch der DICER- bzw. DROSHAKnockdown durch RNAi. Hierbei dürfte die Renilla-Lumineszenz nicht reduziert sein, da die Silencing-Maschinerie ohne diese zwei essentiellen Proteine nicht funktioniert und daher die mRNA der funktionellen Transkriptionseinheit aus RenillaLuziferasegen und komplementärem Gensegment zur miRNA23a translatiert werden würde. Somit wäre eine Renilla-Lumineszenz messbar. Diese Zellen wurden als Silencing-defizient bezeichnet.

Als Negativkontrolle dienten siGL2-transfizierte Zellen. Die Silencing-Maschinerie dürfte dadurch in ihrer Funktion nicht beeinflusst werden und die mRNA der funktionellen Transkriptionseinheit aus Renilla-Luziferasegen und dem zur 
miRNA23a-komplementärem Gensegment müsste abgebaut werden. Eine starke Reduktion der Renilla-Expression wäre bei diesen Zellen zu erwarten. Diese Zellen wurden als Silencing-kompetent bezeichnet.

Das Verhältnis der Renilla- zu den Firefly-Werten (R/F-Wert) der Negativ- und Positivkontrollen diente als Referenz für die Proben. Hierfür wurden HeLa-Zellen mit zwei verschiedenen siRNAs gegen TRIM22 (siTRIM22-1 und -2) transfiziert und wurden somit als TRIM22-defiziente Zellen bezeichnet. Sollte TRIM22 eine Funktion in der Silencing-Maschinerie haben, wäre der R/F-Wert der TRIM22-defizienten Zellen erwartungsgemäß ähnlich wie bei Silencing-defizienten Zellen. Sollte TRIM22 hingegen keine Funktion in der Silencing-Maschinerie haben, wäre der R/F-Wert der TRIM22-defizienten Zellen mit dem R/F-Wert der Silencing-kompetenten Zellen vergleichbar.

Es wurden drei unabhängige Versuchsreihen durchgeführt (Anhang 6.3 LuziferaseRohdaten). Die R/F-Werte wurden für jeden Versuch einzeln angegeben (Abb. 22). Hierbei handelte es sich um relative Werte, die nur im Bezug zu den anderen Messwerten der jeweiligen Versuchsreihe betrachtet werden dürfen. In den Versuchsreihen 1 und 2 lagen die R/F-Werte der siTRIM22-1- und siTRIM22-2transfizierten HeLa-Zellen zwischen den R/F-Werten der Silencing-kompetenten und Silencing-defizienten Zellen. In der Versuchsreihe 3 lagen die R/F-Werte der TRIM22-defizienten Zellen auf einem ähnlichen Niveau wie die R/F-Werte der Silencing-defizienten Zellen, jedoch deutlich über den R/F-Werten der Silencingkompetenten Zellen (siGL2; Abb. 22). In allen drei Versuchsreihen zeigten TRIM22defiziente Zellen also größere R/F-Werte als Silencing-kompetente Zellen, jedoch geringere RF-Werte als Silencing-defizienten Zellen (Abb. 22). 

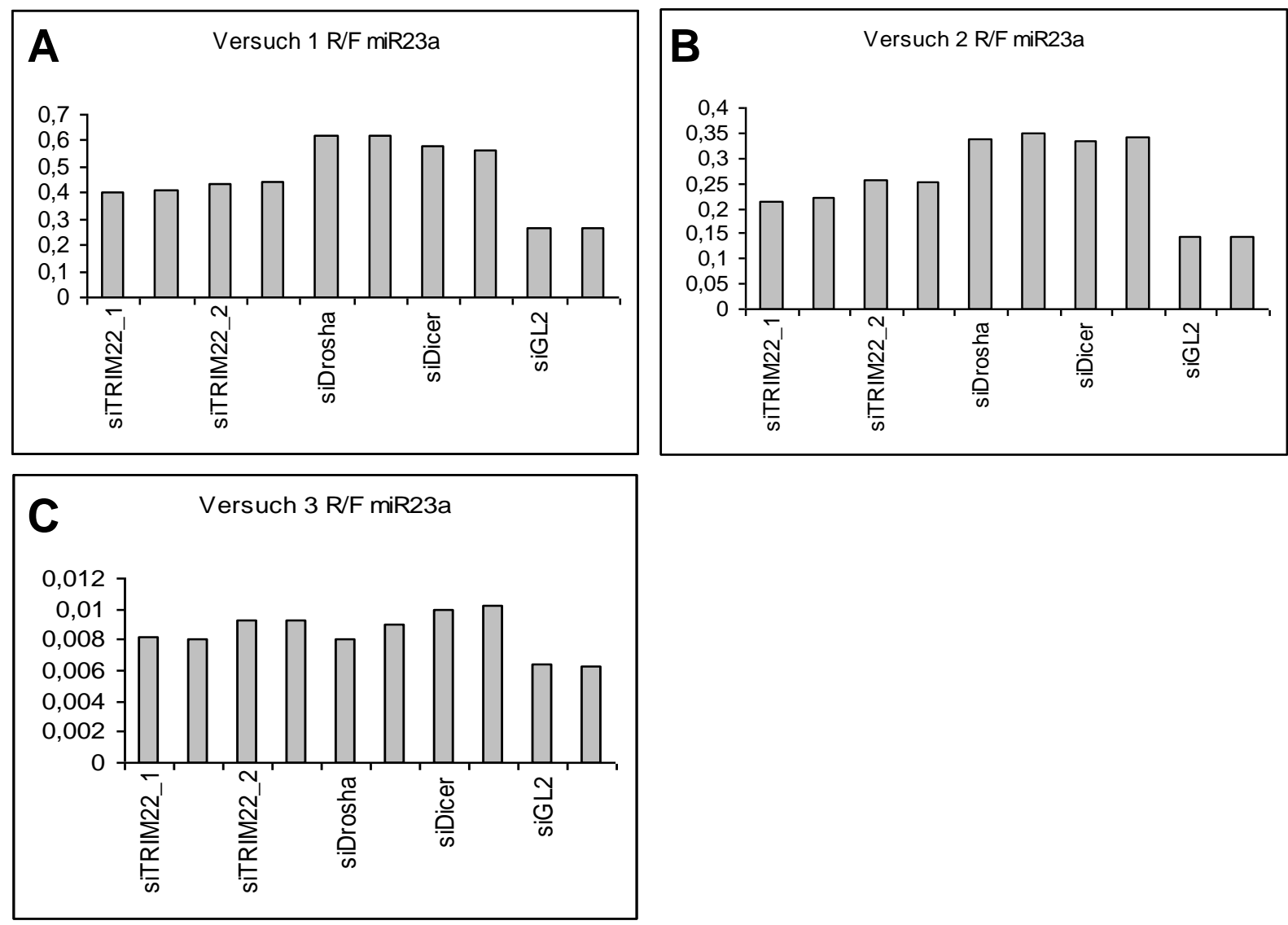

Abb. 22: Luziferasemessung: TRIM22 und Prozessierung der miRNA23a.

Aufgetragen wurden die R/F-Werte aus drei verschiedenen Versuchsreihen, wobei HeLa-Zellen entweder mit siTRIM22-1, siTRIM22-2, siDROSHA, siDICER oder siGL2 transfiziert wurden. In den ersten beiden Versuchsreihen lagen die R/F-Werte der TRIM22-defizienten Zellen zwischen den R/F-Werten der DROSHA- bzw. DICER-defizienten Zellen und den siGL2-transfizierten Zellen (A, B). Die dritte Versuchsreihe (C) gab für TRIM22-defiziente Zellen und DROSHA- bzw. DICERdefiziente Zellen ähnliche R/F-Werte an, die aber deutlich höher waren als die der siGL2-transfizierten Zellen.

\subsection{3. Überblick zu den Ergebnissen von TRIM22 und RNAi}

1. TRIM22 interagiert direkt oder indirekt mit AGO2 und PABP.

2. Die Luziferasemessungen zeigen eine Beteiligung des TRIM22 in der Prozessierung der miRNA23a. 


\section{Diskussion}

TRIM22 ist ein Mitglied der TRIM-Proteinfamilie, für welche bereits antivirale Eigenschaften gegen HIV-1 (Bouazzaoui et al. 2006; Tissot und Mechti 1995), EBV (Zhang et al. 2004) oder HBV (Gao et al. 2009) beschrieben sind. Des Weiteren besitzt TRIM22 eine E3-Ubiquitin-Ligase-Aktivität (Duan et al. 2008) und ist an der Zelldifferenzierung und Zellproliferation beteiligt (Obad et al. 2004). Diese Vielfalt an unterschiedlichen Funktionen ging zum Teil mit diversen Beschreibungen über die subzelluläre Lokalisation von TRIM22 einher.

Im ersten Teil dieser Arbeit wurde eine subzelluläre Lokalisationsbestimmung durchgeführt, um dadurch Rückschlüsse auf die Funktion des Proteins zu erhalten. Im zweiten Teil dieser Arbeit wurde TRIM22 mithilfe der RNAi auf zellproliferative Eigenschaften und hinsichtlich weiterer Funktionen untersucht.

\subsection{Visualisierung der subzellulären Lokalisation des TRIM22}

Erste Hinweise auf die Funktion von Proteinen kann deren subzelluläre Lokalisation geben. TRIM22 konnte bisher in unterschiedlichen Zellkompartimenten beschrieben werden. Jedoch ergaben die bisher durchgeführten Arbeiten diesbezüglich widersprüchliche Ergebnisse. Die Lokalisation des Proteins wurde bereits im Nukleus (Gao et al. 2009), im Nukleolus (Sivaramakrishnan et al. 2009) und im Zytoplasma beschrieben (Herr et al. 2009; Reymond et al. 2001).

In der vorliegenden Arbeit wurde die subzelluläre Lokalisation von TRIM22 mittels eines TRIM22-GFP-Konstuktes sowie eines TRIM22-Antikörpers in HeLa-Zellen bestimmt.

TRIM22-GFP wurde im Nukleus, in der perinukleären Umgebung und im Zytosol durch IF-Mikroskopie (Abb. 7) gefunden. Dies entspricht den bislang publizierten Daten (Gao et al. 2009; Herr et al. 2009; Reymond et al. 2001; Sivaramakrishnan et al. 2009). Dieses Verteilungsmuster des ektopisch exprimierten TRIM22 (TRIM22GFP) galt auch für endogenes TRIM22 (TRIM22-AK) (Abb.8). Dieser TRIM22-AK wurde bereits in Veröffentlichungen von Petersson et al. (2009) und Herr et al. (2009) verwendet.

Wesentlichen Einfluss auf die subzelluläre Lokalisation von TRIM22 besitzt die Art der Fixierung und Permeabilisierung der Zellen zur Vorbereitung für die IF- 
Mikroskopie. So wurden im Rahmen dieser Arbeit beste Ergebnisse bei einer Fixierung mit $-20^{\circ} \mathrm{C}$ kaltem Methanol erreicht, die als Voraussetzung für den Nachweis des endogenen und ektopisch exprimierten TRIM22 sowohl im Nukleus als auch im Zytoplasma galt. Nach einer Fixierung mit Paraformaldehyd konnte TRIM22 vorwiegend im Zytosol nachgewiesen werden (Herr 2008). Diese Beobachtung könnte erklären, warum TRIM22 als "nur" diffus zytoplasmatisch beschrieben wurde (Herr 2008), obwohl TRIM22 durch den gleichen Antikörper und das gleiche TRIM22GFP-Konstrukt dargestellt wurde.

\subsection{Kolokalisation mit den Zentrosomen}

Zentrosomen sind essentielle Zellorganellen. In der G2-Phase liegen in der Zelle zwei Zentrosomen vor, die während der Mitose die beiden Zellpole und damit den Ursprung der beiden Tochterzellen darstellen (siehe 1.2). Von den Zentrosomen ausgehend organisiert sich das Mikrotubulusnetzwerk, das für die Verteilung der Chromosomen auf die beiden Tochterzellen verantwortlich ist. In der Interphase liegen das Zentrosom bzw. die Zentrosomen in der perinukleären Umgebung und somit in dem Bereich, der in dieser Arbeit als einer der Hauptverteilungspunkte des TRIM22 beschrieben wurde (Abb. 7 und 8 ).

Aus diesem Grund wurde das Verhältnis von TRIM22 zum Zentrosom untersucht. Als Markerprotein des Zentrosoms wurde $\mathrm{y}$-Tubulin gewählt, das einen integralen Bestandteil des Zentrosoms darstellt und das während des Zellzyklus kontinuierlich exprimiert wird (Stearns et al. 1991). Eine Kolokalisation von y-Tubulin und TRIM22 (Ab. 9) konnte beobachtet werden. Die Kolokalisation des endogenen TRIM22 und des Zentrosoms bestätigt die Ergebnisse einer schwedischen Arbeitsgruppe, die eine vom Zellzyklus unabhängige TRIM22-Lokalisation im Bereich der Zentrosomen beschrieb (Petersson et al. 2009).

In dieser Dissertation konnte hingegen keine Kolokalisation von ektopisch exprimiertem TRIM22 und Zentrosom beschrieben werden (Abb. 10). Als zentrosomales Markerprotein wurde hierbei CENP-E verwendet, das als Motorprotein dem Kinesin ähnlich ist. CENP-E zeigt sich ab der S-Phase am Zentrosom und ist nach der Mitose nicht in der Zelle nachweisbar (Yen et al. 1992).

Für die unterschiedliche Verteilung des endogenen und ektopisch exprimierten TRIM22 gibt es drei mögliche Erklärungen: Erstens könnten die Bindungsstellen für TRIM22 bereits durch endogenes TRIM22 gesättigt und das TRIM22-GFP daher an 
anderen Orten zu finden sein. Zweitens könnte TRIM22-GFP entweder eine veränderte Tertiärstruktur besitzen oder durch Überexpression vom physiologischen Bindungsverhalten abweichen. Es könnte beispielweise zur Bildung von Proteinaggregaten kommen, die durch die Überexpression von TRIM22-GFP durch den CMV-Promoter des pAcGFP-N1-Vektors induziert werden könnten. In der quantitativen Echtzeit-PCR konnte ein etwa 60-fach höherer Gehalt der TRIM22mRNA gezeigt werden (Abb. $13 \mathrm{~K}$ ), was für eine deutliche TRIM22-GFPÜberexpression spricht. Als dritte Möglichkeit könnte das TRIM22-GFP die TRIM22Proteinbindungsstelle zur Interaktion mit den Zentrosomen verdecken oder verändern und so für die nicht vorhandene Kolokalisation von TRIM22-GFP und den Zentrosomen verantwortlich sein.

Da eine andere Arbeitsgruppe die Kolokalisation von TRIM22 und dem Zentrosomen ebenfalls beschrieben hat (Petersson et al. 2009), kann davon ausgegangen werden, dass das TRIM22-GFP in seiner Verteilung nicht mit dem endogenen TRIM22 übereinstimmt.

\subsection{Zellproliferative Aspekte}

Inf- $\beta$ führt zu einer deutlichen Induktion der TRIM22-Expression und besitzt ebenfalls antiproliferative Effekte (Obad et al. 2007b; Tissot und Mechti 1995). Klinisch wird es studienweise erfolgreich als Kombinationsmedikament in multimodalen Therapiekonzepten, beispielsweise bei Nasopharyngealtumoren, eingesetzt (Buehrlen et al. 2012). In der Therapie des Glioblastoma multiforme zeigt Inf- $\beta$ invitro ebenfalls deutlich antiproliferative Effekte (Rosenblum et al. 1990), wird aber wiederum nur als Kombinationstherapeutikum verwendet (Motomura et al. 2011). Auch Progesteron induziert TRIM22 (Sivaramakrishnan et al. 2009). Des Weiteren zeigten verschiedene Publikationen, dass Progesteron den Zellzyklus inhibieren kann (Lin et al. 2001; Lin et al. 1999).

Progesteron und Inf- $\beta$ besitzen demnach beide antiproliferative Effekte und induzieren zudem eine TRIM22-Expression. Diese beiden Effekte könnten in gegenseitiger Wechselwirkung stehen. Eine Veränderung des Zellzyklus auf nur einen veränderten Zellparameter, wie den erhöhten TRIM22-Gehalt, zurückzuführen, wäre jedoch eindimensional und unvollständig. Eine genauere Untersuchung dieser gegenseitigen Wechselwirkung ist schwer möglich, da Zytokineffekte komplex sind. Allein Interferone beeinflussen mehr als 300 verschiedene Gene, die unter anderem 
in Zellproliferation, Apoptose und Zellregulation involviert sind (Kaminskyy und Zhivotovsky 2010; Rosewicz et al. 2004). Zudem induziert p53 als „Wächter des Genoms" die TRIM22-Expression und erhöht ebenfalls die Interferonproduktion (Munoz-Fontela et al. 2008; Obad et al. 2004; Vilcek 2003).

Diese Daten gaben Anlass, über eine Funktion des TRIM22-Proteins in der Zellproliferation nachzudenken. Es konnte gezeigt werden, dass die TRIM22Expression positiv mit der Entdifferenzierung bestimmter Leukämiezellen korreliert (Obad et al. 2004). Des Weiteren wurde TRIM22 in Mikro-Array-Analysen mit dem Nephroblastom in Verbindung gebracht, in dessen Primärmaterial eine signifikante Reduktion der TRIM22-Expression gezeigt werden konnte (Zirn et al. 2006). In einer anderen Arbeit konnte eine signifikante TRIM22-Reduktion bei high-risk und metastasierten Nephroblastomen beschrieben werden (Wittmann et al. 2008).

In weiteren Experimenten sollte also untersucht werden, ob TRIM22 auf die Entdifferenzierung von Tumorzellen Einfluss nimmt, oder ob in der Entdifferenzierung von Tumorzellen zelluläre Prozesse eine Veränderung der TRIM22-Expression bewirken.

\subsubsection{Ektopisch exprimiertes TRIM22-GFP zeigt andere Eigenschaften als endogenes TRIM22}

In dieser Arbeit wurde eine TRIM22-GFP-Verteilung bei geringer Expression homogen entlang des Zytoskeletts und innerhalb des Nukleus beschrieben (Abb.7). Bei stärkerer TRIM22-GFP-Expression bildeten sich punktförmige Ansammlungen entlang des Zytoskeletts und innerhalb des Nukleus, die als Protein-Aggregationen betrachtet werden können (Abb. 11, siehe 4.2).

Protein-Aggregationen entstehen aus missgefalteten Proteinen, die nicht ihre korrekte Tertiärstruktur eingenommen haben. Bei den komplexierten Proteinen kann es sich aber auch um TRIM22-GFP-Heteromultimerisierungen handeln, die durch die Grundstruktur des Proteins erklärt werden können. TRIM22 besteht unter anderem aus der coiled-coil- und der SPRY-Domäne (Nisole et al. 2005), die in Proteinmultimerisierungen involviert sind. $48 \mathrm{~h}$ nach Transfektion bildeten die HeLaZellen mit einer starken TRIM22-GFP-Expression filiforme Zellausläufer aus und nach $72 \mathrm{~h}$ lösten sich viele Zellen mit einer starken TRIM22-GFP-Expression vom Boden der Kulturschale ab (Abb. 12).

Die beobachteten morphologischen Zellveränderungen der TRIM22-GFPtransfizierten Zellen könnten durch eine Überexpression erklärt werden, die durch 
den konstitutiv aktiven CMV-Promotor des Vektors noch verstärkt werden könnte. Durch diese Überexpression könnten physiologische Zellabläufe verlangsamt oder gar unterbunden werden, wodurch ein möglicher Zelluntergang erklärt werden könnte. In mikroskopischen Kontrollen waren apoptotische Tendenzen abgrenzbar (Ergebnisse nicht aufgeführt). Eine genaue Quantifizierung mittels manueller Auszählung war aufgrund der Auswertung bei Doppelfluoreszenz der jeweiligen Zelle nicht möglich.

Ein TUNEL-Test mit anschließender FACS-Messung sollte überprüfen, ob die morphologischen Zellveränderungen im Sinne einer Apoptose vorlagen. Leider stand ein FACS-Gerät zur Messung der TUNEL-Fluoreszenz TMR mit einer Anregungswellenlänge von 520-560 nm und einer Detektionswellenlänge von 570620 nm nicht zur Verfügung. In Probemessungen wurde TMR mit dem FACS-Gerät BD LSR II im Deutschen Primatenzentrum in einem nicht ausreichend hohen Maß detektiert (Ergebnisse nicht aufgeführt). Es konnte also anhand des TUNEL-Assays nicht überprüft werden, ob die Überexpression des ektopisch exprimierten TRIM22GFP zur Apoptose führt. In Zukunft wäre eine nochmalige Analyse mittels FACSMessung erstrebenswert. Im Rahmen dieser Arbeit wurde ergänzend eine Zellzyklusanalyse durchgeführt, um die Apoptose zu untersuchen (siehe 4.3.2).

\subsubsection{Zellzyklusanalyse spricht gegen Apoptoseinduktion bei TRIM22- Überexpression}

In einer Zellzyklusanalyse (Abb. 16) sollte die potentielle Apoptoseinduktion durch TRIM22 überprüft werden. Eine Zellzyklusanalyse stellt die verschiedenen Zellpopulationen in Abhängigkeit ihres DNA-Gehalts dar und unterteilt vitale Zellen entsprechend ihrer Zellzyklusphase auf eine G1-, S- und G2-Population. Apoptotische Zellpopulationen besitzen zusätzlich eine Sub-G1-Population (Nicoletti et al. 1991). Im Rahmen dieser Arbeit konnte weder bei HeLa-Zellen, die mit TRIM22-GFP transfiziert wurden, noch bei HeLa-Zellen, die durch Inf- $\beta$ vermehrt TRIM22 exprimierten, eine Sub-G1-Population nachgewiesen werden. Dies kann mehrere Ursachen haben: Zum einen könnte die Überexpression von TRIM22 bzw. TRIM22-GFP kein positiver Faktor für die Apoptose sein, zum anderen wäre auch eine methodische Fehlerquelle als Ursache möglich. Es wurden adhärent wachsende Zellen verwendet, die sich während einer möglichen Apoptose von dem Boden der Kulturschale ablösen und anschließend in Form von Zellvesikeln im Zellkulturmedium 
gelöst sein könnten. Bei der Vorbereitung der Proben könnte es zu einem Verlust dieser Zellvesikel gekommen sein.

Im Rahmen dieses Versuches konnte zusätzlich beobachtet werden, dass nach TRIM22-GFP-Transfektion vermehrt Zellen mit einem erhöhten DNA-Gehalt vorlagen. Dieses Ergebnis lässt zwei Interpretationen zu. Zum einen könnten die erhöhten DNA-Werte direkt durch das transfizierte Plasmid TRIM22-GFP erklärt werden. Generell haben Plasmide einen doppelsträngigen Aufbau, wodurch PI das Plasmid und die humane DNA interkaliert und dadurch vom FACS-Gerät bei der PIMessung ebenfalls erfasst wird. Als Kontrolle wurde jedoch eine gleiche Plasmidmenge HLA-B ${ }^{\star} 35-$ GFP eingesetzt und es zeigte sich bei diesem ein deutlich niedrigerer Verlauf rechts des G2-Peaks. Aus diesem Grund ist die direkte Messung des Plasmids als Ursache für den erhöhten DNA-Gehalt unwahrscheinlich.

Eine weitere Erklärung wäre das Vorliegen einer gesteigerten Anzahl polyploider Zellen unter den TRIM22-GFP-transfizierten Zellen. Bestärkt wird diese Annahme durch das Vorliegen weiterer Peaks nach dem G2-Peak, die durch die jeweiligen polyploiden Zellen verursacht werden könnten. So könnte der nächste Peak durch triploide Zellen und der darauffolgende Peak durch tetraploide Zellen erklärt werden. Darüberhinaus zeigte die Messung der Inf- $\beta$-behandelten HeLa-Zellen im Vergleich zu HeLa-WT-Zellen einen erhöhten DNA-Gehalt, der ebenfalls auf eine Polyploidie hinweisen könnte.

\subsubsection{Apoptose bei Knockdown}

In der mikroskopischen Analyse TRIM22-defizienter Zellen fielen vermehrt mitotisch aberrante Zellen auf (Abb. 14). In TUNEL-Tests an HeLa-Zellen wurde zudem gezeigt, dass durch einen TRIM22-Knockdown vermehrt apoptotische Zellen auftreten (Abb. 17 und 18). Für die Apoptosehäufung in TRIM22-defizienten Zellen gibt es mehrere mögliche Erklärungen.

Zum einen könnte TRIM22 eine Funktion in der Mitose ausüben. Hierfür spricht die Lokalisation im Bereich der Zentrosomen, die für die Mikrotubulusorganisation während der Mitose verantwortlich sind. TRIM22 könnte durch die verschiedenen Protein-Interaktionsstellen eine Funktion in der Stabilisierung des Zentrosoms einnehmen. Durch fehlendes TRIM22 könnte die Organisation des Zentrosoms gestört werden. Hierfür würde ebenfalls sprechen, dass in TRIM22-defizienten Zellen auch vermehrt polyploide Zellen zu finden waren (Abb. 14). Diese polyploiden Zellen 
sind in einer HeLa-Zellpopulation zu einem geringen Prozentsatz immer vorhanden. In Zellen mit verminderter TRIM22-Expression waren diese jedoch häufiger nachweisbar. Polyploide Zellen entstehen aus einer fehlerhaften Zellteilung. Diese gehen entweder in die Apoptose über, verbleiben dauerhaft polyploid, exozytieren überschüssige Nuklei oder bilden in einer nächsten Mitose weitere polyploide Zellen (Vitale et al. 2011).

Die gesteigerte Apoptosehäufigkeit könnte ebenfalls durch die Beteiligung des TRIM22-Proteins an der miRNA-Prozessierung begründet werden (siehe 3.3.2) (Abb. 21 und 22). Möglicherweise bewirkt der TRIM22-Knockdown eine veränderte miRNAExpression, sodass die Zelle einen Checkpoint nicht passieren kann (siehe 1.2). Diese Checkpoints kontrollieren den korrekten Ablauf des Zellzyklus, führen bei defizienten Prozessen zu einem Zellzyklusarrest und können anschließend die Apoptose induzieren (Musacchio 2011). Es konnte gezeigt werden, dass Komponenten der Silencing-Maschinerie für die Zelle von vitaler Bedeutung sind. Beispielsweise sind DICER-defiziente Mäuseembryone nicht überlebensfähig (Bernstein et al. 2003).

Methodisch wurde bei dem Experiment mit zwei verschiedenen siRNAs gearbeitet, die beide gegen TRIM22 gerichtet waren. Dies entspricht dem gegenwärtigen Standard wissenschaftlichen Arbeitens und wird unter anderem vom Journal of Cancer Research in den Instruktionen für Autoren gefordert. 


\subsection{TRIM22 komplexiert mit AGO2 und PABP}

TRIM22 zeigte in IF-Bildern eine Kolokalisation mit AGO2, PABP und eine mögliche Kolokalisation mit DICER (Abb. 19). Die Komplexierung von TRIM22 mit AGO2 und PABP sowie eine mögliche Komplexierung mit DICER wurden durch eine Co-IPStudie bestätigt (Abb. 20). Zur Veranschaulichung werden hier nochmals die nachgewiesenen Interaktionen zusammengefasst (Tab. 11).

Tabelle 11: Zusammenfassung der gefundenen Interaktionen durch Co-IP (siehe Abb. 20)

\begin{tabular}{|l|c|c|}
\hline & TRIM22-Eluat & AGO2-Eluat \\
\hline TRIM22 & + & + \\
\hline AGO2 & + & + \\
\hline PABP & + & + \\
\hline DICER & $(-)$ & - \\
\hline DROSHA & - & - \\
\hline
\end{tabular}

Im Rahmen dieser Dissertation konnte erstmalig eine Interaktion zwischen TRIM22 und AGO2 bzw. PABP beschrieben werden. Die Interaktion zwischen AGO2 und PABP wurde bereits beschrieben (Fabian et al. 2009) und wird durch die Ergebnisse dieser Arbeit bestätigt.

Eine Proteinkomplexierung zwischen AGO2 und TRIM22 kann angenommen werden, da sowohl im TRIM22-Eluat als auch im AGO2-Eluat im Westernblot Banden für AGO2 bzw. TRIM22 nachgewiesen werden konnten. Eine PABP-Bande im Westernblot wurde bisher nur im TRIM22-Eluat gezeigt. Dies gilt ebenso für die extrem schwache DICER-Bande. PABP- bzw. DICER-Eluate wurden im Rahmen dieser Arbeit nicht angefertigt. In zukünftigen Studien wäre eine Untersuchung dieser Eluate interessant, um eine Komplexierung mit TRIM22 zu überprüfen.

Aus der Zusammenschau dieser Daten kann geschlossen werden, dass TRIM22 mit Komponenten der RNAi-Maschinerie wie AGO2 oder PABP als Proteinkomplex vorliegt. Diese Komplexierung wurde bislang noch nicht in der Literatur beschrieben. Ob diese direkt oder indirekt vorliegt, kann aus den vorliegenden Daten nicht geschlossen werden. Diese Frage wäre in weiterführenden Experimenten zu untersuchen.

Methodisch wurden im Rahmen dieser Arbeit zwei unterschiedliche Antikörper für die Darstellung des TRIM22 benutzt. Der polyklonale Antikörper aus Mausserum wurde für die Färbung der IF-Präparate benutzt. Es gilt zu beachten, dass ein polyklonaler Antikörper mehrere Epitope des Zielproteins erkennt. Ebenfalls ist bei polyklonalen 
Antikörpern ein höherer Hintergrund zu erwarten als bei monoklonalen Antikörpern. Da das Nullserum nach der Färbung jedoch keine Fluoreszenz aufwies, konnten diese beiden Fehlerquellen ausgeschlossen werden (siehe Anhang 6.2). Zusätzlich wurde eine Kreuzreaktivität des Sekundär-AKs ausgeschlossen (siehe Anhang 6.2). Die Co-IP wurde mit einem monoklonalen TRIM22-AK durchgeführt (siehe Tab. 8). Auf diese Weise konnte mit zwei verschiedenen Antikörpern in zwei unterschiedlichen Versuchen eine Kolokalisation bzw. eine Komplexierung beschrieben werden. 


\subsection{Luziferasemessung zeigt TRIM22-Beteiligung an der miRNA- Prozessierung}

Durch eine duale Luziferasemessung konnte TRIM22 in drei unabhängigen Experimenten als funktioneller Bestandteil der miRNA-Prozessierung beschrieben werden (Abb. 21 und 22). Zur Veranschaulichung wurden die drei Versuchsreihen in einer Abbildung zusammengefasst (Abb. 23). Die miRNA23a wurde aufgrund ihrer kontinuierlichen und hohen Expression in HeLa-Zellen ausgewählt und diente als Beispiel der miRNA-Prozessierung.

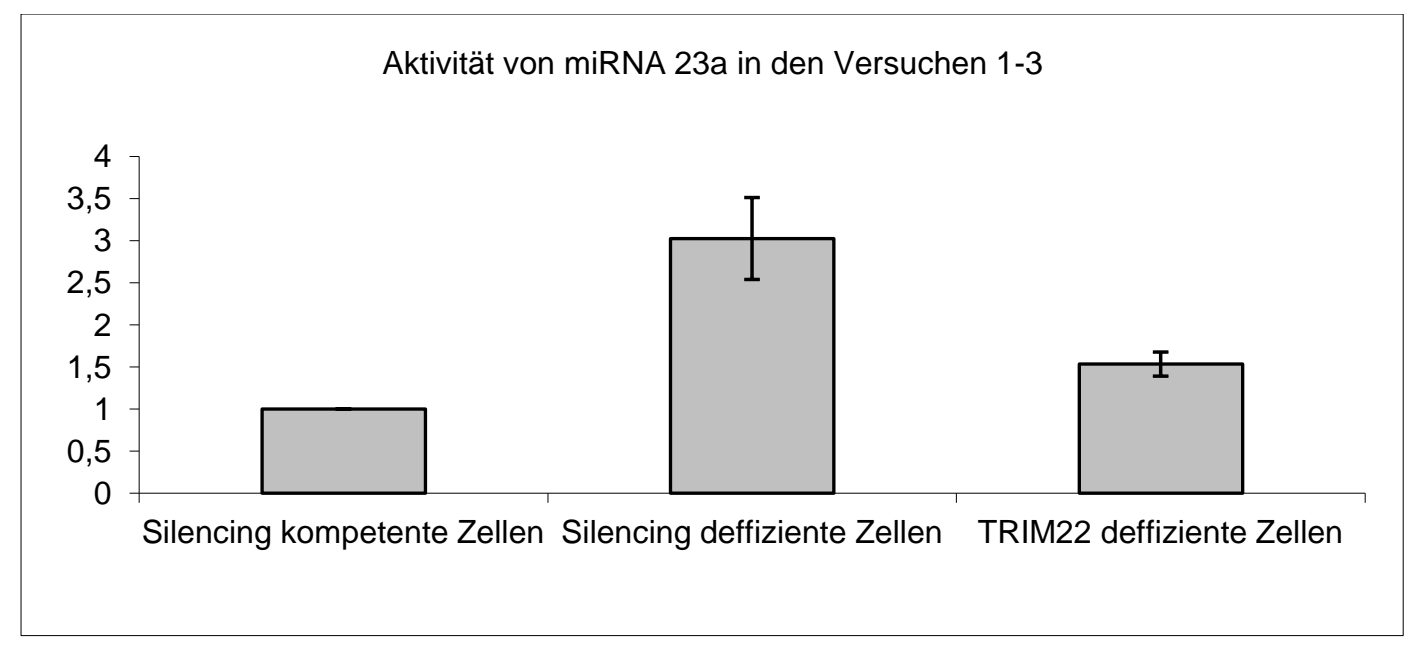

Abb. 23: Zusammenfassung der drei Versuchsreihen der Luziferasemessung

Silencing-kompetente Zellen wurden mit siGL2 behandelt. Silencing-defiziente Zellen wurden mit siDICER oder siDROSHA transfiziert, während TRIM22-defiziente Zellen mit siTRIM22-1 und -2 behandelt wurden. Initial wurde der jeweilige Mittelwert jeder Zellpopulation der einzelnen Versuchsreihen gebildet. Um die drei Versuchsreihen in einer Abbildung darzustellen, wurde folgende Rechnung für jede Versuchsreihe durchgeführt: (Silencing-kompetente Zellen) ${ }^{*} \mathrm{x}=1$ und anschließend $\mathrm{x}^{*}$ (Mittelwert der TRIM22-defizienten Zellen bzw. Mittelwert der Silencingdefizienten Zellen) $=\mathrm{y}$. Anschließend wurde der Mittelwert der drei Versuchsreihen gebildet und in dem Balkendiagramm mit dem oben eingezeichneten Standardfehler dargestellt.

Beim Arbeiten mit Luziferasemessungen muss man sich über die Schwächen der Methode bewusst sein. Erstens haben Luziferasemessungen das Problem, dass die Substrate nach dem Öffnen des Kits oxidieren. Daher sind die relativen Werte, jedoch nicht die absoluten Zahlen der verschiedenen Versuchsreihen vergleichbar. Zweitens beeinflusst die Passagezahl der Zellen die Transfektionseffizienz. Je höher die Passagezahl ist, also je länger ein Klon kultiviert ist, desto geringer ist die Transfektionseffizienz. Drittens ist zu bedenken, dass die Transfektionseffizienz bei dualen Transfektionen deutlich geringer ist als die jeweilige EinzelTransfektionseffizienz (Abb. 24). 


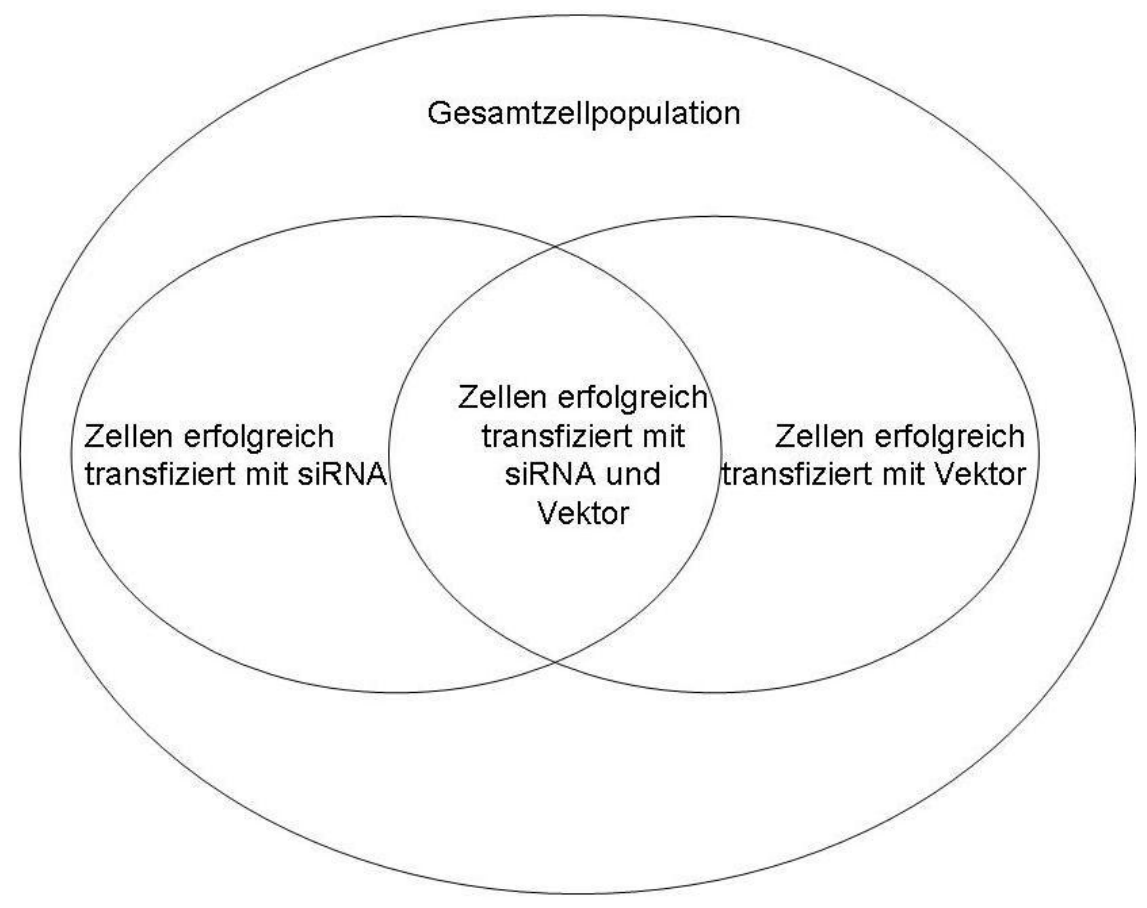

Abb. 24: Problem der dualen Transfektion

Bei dualer Transfektion einer Zellpopulation liegt die erfolgreiche DoppelTransfektionseffizienz deutlich unter der jeweiligen Einzel-Transfektionseffizienz.

In dieser Arbeit konnte durch IF-Studien, Co-IP und duale Luziferaseassays gezeigt werden, dass TRIM22 in die miRNA-Prozessierung involviert ist. Die genaue Funktion des Proteins konnte durch die Untersuchungen nicht erfasst werden. Möglicherweise könnte TRIM22 als Trägerprotein den Komponenten der SilencingMaschinerie bei der Aggregation in den p-Bodies dienen. Hierfür würden die Kolokalisation mit den Mikrotubuli, die Komplexierung mit AGO2 sowie die fragliche Komplexierung mit PABP sprechen (siehe Abb. 20). Des Weiteren zeigten funktionelle Untersuchungen eine TRIM22-Beteiligung in der miRNA-Prozessierung, die in ihrem Ausmaß geringer war als der Einfluss durch DROSHA oder DICER. Dies könnte an einer unterschiedlichen Silencing-Effizienz der bereits etablierten siRNAs gegen DROSHA bzw. DICER und der im Rahmen dieser Arbeit erstellten siRNA gegen TRIM22 liegen (siTRIM22-1 und -2). Eine adäquate Transfektionseffizienz der neu erstellten siRNAs gegen TRIM22 konnte hingegen bestätigt werden (Abb. 13). Möglicherweise könnte TRIM22 aber auch als Trägerprotein zwischen Komponenten der Silencing-Maschinerie, wie beispielsweise AGO2 oder PABP, und dem Zytoskelett fungieren (Abb. 25). 


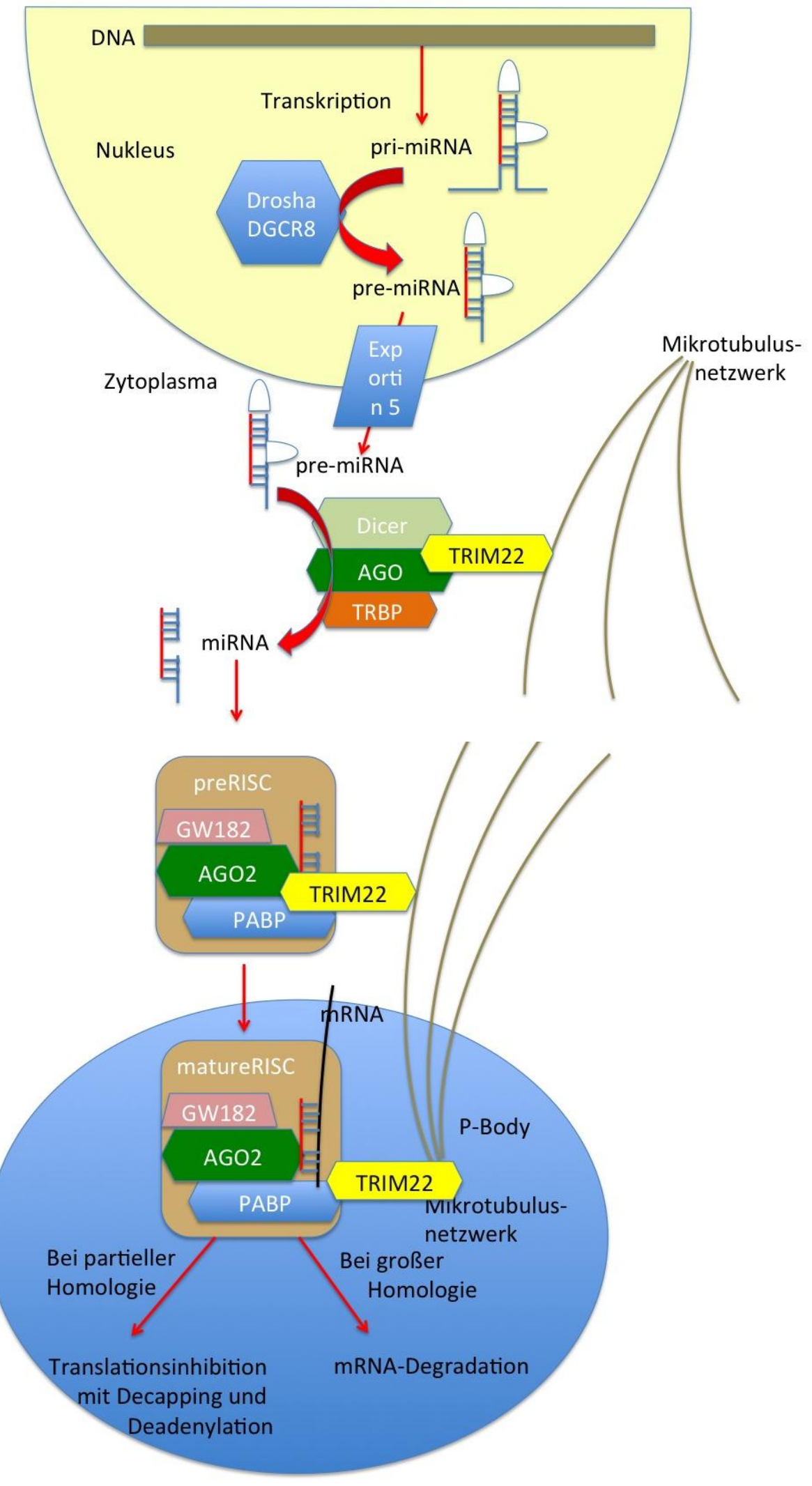

Abb. 25: Putative Funktion des TRIM22-Proteins in der miRNA-Prozessierung

TRIM22 könnte als Verbindungsprotein zwischen Komponenten der SilencingMaschinerie und dem Mikrotubulussystem dienen. Beispielsweise könnte TRIM22 über seine coiled-coil-Domäne oder SPRY-Domäne eine Interaktion mit AGO2, PABP oder DICER und dem Mikrotubulussystem herstellen. 
Möglicherweise interagiert TRIM22 aber auch mit RNAs. Die C-terminale B30.2Domäne des Proteins (Nisole et al. 2005) stammt evolutionär von der SPRY-Domäne ab, die direkt in RNA-Interaktionen involviert sein kann (Gabler et al. 1998). Durch diesen Zusammenhang wäre eine Träger- oder Bindungsfunktion für RNAs im Rahmen der miRNA-Prozessierung durch TRIM22 ebenfalls vorstellbar.

Für eine Beteiligung von TRIM22 an der miRNA-Prozessierung spricht außerdem ein kürzlich in der Primatengenetik des DPZ durchgeführtes Experiment, das jedoch nicht im Rahmen dieser Arbeit angefertigt wurde. Nach TRIM22-Knockdown zeigte sich ein verändertes miRNA-Expressionsprofil in einer Deep-Sequencing-Analyse (persönliche Mitteilung Prof. Dr. rer. nat. L. Walter 2013).

TRIM22 wurde bereits als Effektorprotein des Transkriptionsfaktors p53 beschrieben (Obad et al. 2007b), der eine Schlüsselfunktion in der Zellzyklusregulation und Apoptoseinduktion einnimmt. Unter Berücksichtigung der vorliegenden Ergebnisse wäre eine proapoptotische Funktion des TRIM22-Proteins denkbar, die über eine Regulation auf miRNA-Ebene ausgeführt werden könnte. 


\subsection{Ausblick}

In zukünftigen Experimenten könnte die Funktion des TRIM22-Proteins in der miRNA-Prozessierung genauer untersucht werden. Dabei wäre insbesondere zu eruieren, ob TRIM22 möglicherweise RNAs bindet oder einzelne Komponenten der Silencing-Maschinerie verknüpft. Ebenfalls könnten weitere Bindungspartner des Proteins bestimmt werden. Ein PABP-Eluat könnte beispielsweise mittels Co-IP auf eine TRIM22-Interaktion analysiert werden. Des Weiteren könnte der Zusammenhang zwischen TRIM22-Expression und miRNA-Expressionsprofil untersucht werden. Darüberhinaus könnten die zellproliferativen Eigenschaften des TRIM22 näher betrachtet werden. Nach Über- bzw. Unterexpression des TRIM22Proteins könnte hierfür ein TUNEL-Test im Durchflusszytometer quantitativ ausgewertet werden.

Im Rahmen dieser Dissertation wurde erstmals beschrieben, dass TRIM22 einen Bestandteil der RNA-Silencing-Maschinerie darstellt. Die miRNA-Prozessierung stellt mittlerweile nicht nur ein unverzichtbares Forschungswerkzeug dar, sondern nimmt auch eine zunehmende klinische Relevanz ein. Weitere Studien hierzu könnten zum medizinischen Fortschritt beitragen. 


\section{Zusammenfassung}

TRIM22 ist ein intrazelluläres Protein, das ein heterogenes Aufgabenspektrum erfüllt. Bisher wurden antivirale Funktionen und Zusammenhänge mit zellulären Prozessen wie Zelldifferenzierung und Zellproliferation beschrieben. Im Rahmen dieser Arbeit wurde eine Beteiligung an der miRNA-Prozessierung untersucht sowie Lokalisationsstudien des Proteins durchgeführt.

Lokalisationsstudien erfolgten mittels IF-Mikroskopie, während Proteininteraktionen anhand der Co-IP untersucht wurden. Funktionelle Untersuchungen erfolgten durch Luziferaseassays.

$\mathrm{Zu}$ Beginn wurde die subzelluläre Expression des endogenen und ektopisch exprimierten TRIM22 untersucht. TRIM22 konnte sowohl im Nukleus, als auch in der perinukleären Umgebung und am Zytoskelett lokalisiert werden. Zudem konnte eine Kolokalisation des endogenen TRIM22 mit dem Zentrosom bestätigt werden, was jedoch nicht für ektopisch exprimiertes TRIM22 zutraf.

Anschließend wurde der Einfluss der TRIM22-Über- bzw. Unterexpression auf die Zellvitalität überprüft. Nach TRIM22-Knockdown mittels RNAi zeigten sich vermehrt mitotisch aberrante und apoptotische Zellen. Bei Überexpression konnten vermehrt polyploide Zellen nachgewiesen werden. Zudem gab es hierbei Hinweise auf Zellvitalitätsstörungen.

Im letzten Teil gelang mittels IF-Mikroskopie und Co-IP die Erstbeschreibung einer Interaktion zwischen TRIM22 und Komponenten der Silencing-Maschinerie. Diese Beobachtung konnte durch den Nachweis einer funktionellen Beteiligung des Proteins an der miRNA-Prozessierung erweitert werden.

Die beschriebenen Lokalisationen des TRIM22-Proteins bestätigen die Aussagen externer Publikationen. Das divergente Bindungsverhalten des endogenen und ektopisch exprimierten TRIM22 bezüglich des Zentrosoms wurde erstmalig beschrieben und ist vermutlich auf Proteininteraktionen zurückzuführen.

Das funktionelle Spektrum des TRIM22-Proteins wurde im Rahmen dieser Arbeit um eine Beteiligung in der miRNA-Prozessierung erweitert. Eine Funktion als Trägerprotein und ein Mitwirken in der Silencing-Maschinerie wären denkbar und sollten in zukünftigen Studien überprüft werden. 


\section{Anhang}

\section{1. pAcGFP1-N1}

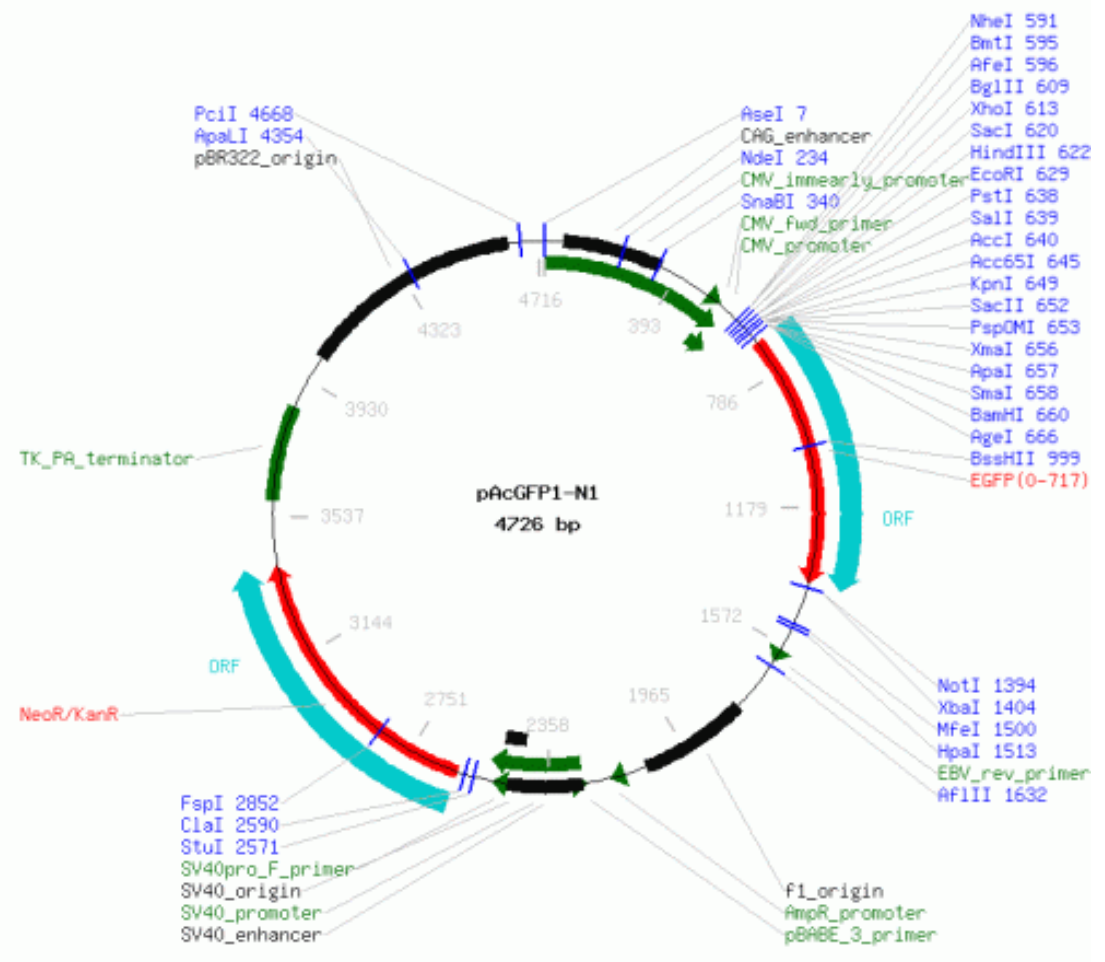

pAcGFP-N1-TRIM22

TAGTTATTAA TAGTAATCAA TTACGGGGTC ATTAGTTCAT AGCCCATATA TGGAGTTCCG CGTTACATAA CTTACGGTAA ATGGCCCGCC TGGCTGACCG CCCAACGACC CCCGCCCATT GACGTCAATA ATGACGTATG TTCCCATAGT AACGCCAATA GGGACTTTCC ATTGACGTCA ATGGGTGGAG TATTTACGGT AAACTGCCCA CTTGGCAGTA CATCAAGTGT ATCATATGCC AAGTACGCCC CCTATTGACG TCAATGACGG TAAATGGCCC GCCTGGCATT ATGCCCAGTA CATGACCTTA TGGGACTTTC CTACTTGGCA GTACATCTAC GTATTAGTCA TCGCTATTAC CATGGTGATG CGGTTTTGGC AGTACATCAA TGGGCGTGGA TAGCGGTTTG ACTCACGGGG ATTTCCAAGT CTCCACCCCA TTGACGTCAA TGGGAGTTTG TTTTGGCACC AAAATCAACG GGACTTTCCA AAATGTCGTA ACAACTCCGC CCCATTGACG CAAATGGGCG GTAGGCGTGT ACGGTGGGAG GTCTATATAA GCAGAGCTGG TTTAGTGAAC CGTCAGATCC GCTAGCGCTA CCGGACTCAG ATCTCGAGCT CAAGCTT

GCAATGGATTTCTCAGTAAAGGTAGACATAGAGAAGGAGGTGACCTGCCCCATCTGCCTGGAGCTCCTGA CAGAACCTCTGAGCCTAGATTGTGGCCACAGCTTCTGCCAAGCCTGCATCACTGCAAAGATCAAGGAGTC AGTGATCATCTCAGAGGGGAAAGCAGCTGTCCTGTGTGTCAGACCAGATTCCAGCCTGGGAACCTCCGAC CTAATCGGCATCTGGCCAACATAGTTGAGAGAGTCAAAGAGGTCAAGATGAGCCCACAGGAGGGGCAGA AGAGAGATGTCTGTGAGCACCATGGAAAAAAACTCCAGATCTTCTGTAAGGAGGATGGAAAAGTCATTTG CTGGGTTTGTGAACTGTCTCAGGAACACCAAGGTCACCAAACATTCCGCATAAACGAGGTGGTCAAGGAA TGTCAGGAAAAGCTGCAGGTAGCCCTGCAGAGGCTGATAAAGGAGGATCAAGAGGCTGAGAAGCTGGAA GATGACATCAGACAAGAGAGAACCGCCTGGAAGAATTATATCCAGATCGAGAGACAGAAGATTCTGAAAG GGTTCAATGAAATGAGAGTCATCTTGGACAATGAGGAGCAGAGAGAGCTGCAAAAGCTGGAGGAAGGTG AGGTGAATGTGCTGGATAACCTGGCAGCAGCTACAGACCAGCTGGTCCAGCAGAGGCAGGATGCCAGCA CGCTCATCTCAGATCTCCAGCGGAGGTTGAGGGGATCGTCAGTAGAGATGCTGCAGGATGTGATTGACGT CATGAAAAGGAGTGAAAGCTGGACATTGAAGAAGCCAAAATCTGTTTCCAAGAAACTAAAGAGTGTATTC 


\begin{abstract}
CGAGTACCAGATCTGAGTGGGATGCTGCAAGTTCTTAAAGAGCTGACAGATGTCCAGTACTACTGGGTGG ACGTGATGCTGAATCCAGGCAGTGCCACTTCGAATGTTGCTATTTCTGTGGATCAGAGACAAGTGAAAACT GTACGCACCTGCACATTTAAGAATTCAAATCCATGTGATTTTTCTGCTTTTGGTGTCTTCGGCTGCCAATATT TCTCTTCGGGGAAATATTACTGGGAAGTAGATGTGTCTGGAAAGATTGCCTGGATCCTGGGCGTACACAGT AAAATAAGTAGTCTGAATAAAAGGAAGAGCTCTGGGTTTGCTTTTTGATCCAAGTGTAAATTATTCAAAAGTT TACTCCAGATATAGACCTCAATATGGCTACTGGGTTATAGGATTACAGAATACATGTGAATATAATGCTTTT GAGGACTCCTCCTCTTCTGATCCCAAGGTTTTGACTCTCTTTATGGCTGTGCCTCCCTGTCGTATTGGGGTT TTCCTAGACTATGAGGCAGGCATTGTCTCATTTTTCAATGTCACAAACCACGGAGCACTCATCTACAAGTTC TCTGGATGTCGCTTTTCTCGACCTGCTTATCCGTATTTCAATCCTTGGAACTGCCTAGTCCCCATGACTGTG TGCCCACCGAGCTCCTGGAAGCTTCGA ATTCTGCAGT CGACGGTACC GCGGGCCCGG
\end{abstract} GATCCACCGG TCATGGTGAG CAAGGGCGCC GAGCTGTTCA CCGGCATCGT GCCCATCCTG ATCGAGCTGA ATGGCGATGT GAATGGCCAC AAGTTCAGCG TGAGCGGCGA GGGCGAGGGC GATGCCACCT ACGGCAAGCT GACCCTGAAG TTCATCTGCA CCACCGGCAA GCTGCCTGTG CCCTGGCCCA CCCTGGTGAC CACCCTGAGC TACGGCGTGC AGTGCTTCTC ACGCTACCCC GATCACATGA AGCAGCACGA CTTCTTCAAG AGCGCCATGC CTGAGGGCTA CATCCAGGAG CGCACCATCT TCTTCGAGGA TGACGGCAAC TACAAGTCGC GCGCCGAGGT GAAGTTCGAG GGCGATACCC TGGTGAATCG CATCGAGCTG ACCGGCACCG ATTTCAAGGA GGATGGCAAC ATCCTGGGCA ATAAGATGGA GTACAACTAC AACGCCCACA ATGTGTACAT CATGACCGAC AAGGCCAAGA ATGGCATCAA GGTGAACTTC AAGATCCGCC ACAACATCGA GGATGGCAGC GTGCAGCTGG CCGACCACTA CCAGCAGAAT ACCCCCATCG GCGATGGCCC TGTGCTGCTG CCCGATAACC ACTACCTGTC CACCCAGAGC GCCCTGTCCA AGGACCCCAA CGAGAAGCGC GATCACATGA TCTACTTCGG CTTCGTGACC GCCGCCGCCA TCACCCACGG CATGGATGAG CTGTACAAGT GAGCGGCCGC GACTCTAGAT CATAATCAGC CATACCACAT TTGTAGAGGT TTTACTTGCT TTAAAAAACC TCCCACACCT CCCCCTGAAC CTGAAACATA AAATGAATGC AATTGTTGTT GTTAACTTGT TTATTGCAGC TTATAATGGT TACAAATAAA GCAATAGCAT CACAAATTTC ACAAATAAAG CATTTTTTTC ACTGCATTCT AGTTGTGGTT TGTCCAAACT CATCAATGTA TCTTAAGGCG TAAATTGTAA GCGTTAATAT TTTGTTAAAA TTCGCGTTAA ATTTTTGTTA AATCAGCTCA TTTTTTAACC AATAGGCCGA AATCGGCAAA ATCCCTTATA AATCAAAAGA ATAGACCGAG ATAGGGTTGA GTGTTGTTCC AGTTTGGAAC AAGAGTCCAC TATTAAAGAA CGTGGACTCC AACGTCAAAG GGCGAAAAAC CGTCTATCAG GGCGATGGCC CACTACGTGA ACCATCACCC TAATCAAGTT TTTTGGGGTC GAGGTGCCGT AAAGCACTAA ATCGGAACCC TAAAGGGAGC CCCCGATTTA GAGCTTGACG GGGAAAGCCG GCGAACGTGG CGAGAAAGGA AGGGAAGAAA GCGAAAGGAG CGGGCGCTAG GGCGCTGGCA AGTGTAGCGG TCACGCTGCG CGTAACCACC ACACCCGCCG CGCTTAATGC GCCGCTACAG GGCGCGTCAG GTGGCACTTT TCGGGGAAAT GTGCGCGGAA CCCCTATTTG TTTATTTTTTC TAAATACATT CAAATATGTA TCCGCTCATG AGACAATAAC CCTGATAAAT GCTTCAATAA TATTGAAAAA GGAAGAGTCC TGAGGCGGAA AGAACCAGCT GTGGAATGTG TGTCAGTTAG GGTGTGGAAA GTCCCCAGGC TCCCCAGCAG GCAGAAGTAT GCAAAGCATG CATCTCAATT AGTCAGCAAC CAGGTGTGGA AAGTCCCCAG GCTCCCCAGC AGGCAGAAGT ATGCAAAGCA TGCATCTCAA TTAGTCAGCA ACCATAGTCC CGCCCCTAAC TCCGCCCATC CCGCCCCTAA CTCCGCCCAG TTCCGCCCAT TCTCCGCCCC ATGGCTGACT AATTTTTTTTT ATTTATGCAG AGGCCGAGGC CGCCTCGGCC TCTGAGCTAT TCCAGAAGTA GTGAGGAGGC TTTTTTGGAG GCCTAGGCTT TTGCAAAGAT CGATCAAGAG ACAGGATGAG GATCGTTTCG CATGATTGAA CAAGATGGAT TGCACGCAGG TTCTCCGGCC GCTTGGGTGG AGAGGCTATT CGGCTATGAC TGGGCACAAC AGACAATCGG CTGCTCTGAT GCCGCCGTGT TCCGGCTGTC AGCGCAGGGG CGCCCGGTTC TTTTTGTCAA GACCGACCTG TCCGGTGCCC TGAATGAACT GCAAGACGAG GCAGCGCGGC TATCGTGGCT GGCCACGACG GGCGTTCCTT GCGCAGCTGT GCTCGACGTT GTCACTGAAG CGGGAAGGGA CTGGCTGCTA TTGGGCGAAG TGCCGGGGCA GGATCTCCTG TCATCTCACC TTGCTCCTGC CGAGAAAGTA TCCATCATGG CTGATGCAAT GCGGCGGCTG CATACGCTTG ATCCGGCTAC CTGCCCATTC GACCACCAAG CGAAACATCG CATCGAGCGA GCACGTACTC GGATGGAAGC CGGTCTTGTC GATCAGGATG ATCTGGACGA AGAGCATCAG GGGCTCGCGC CAGCCGAACT GTTCGCCAGG CTCAAGGCGA GCATGCCCGA CGGCGAGGAT CTCGTCGTGA CCCATGGCGA TGCCTGCTTG CCGAATATCA TGGTGGAAAA TGGCCGCTTT TCTGGATTCA TCGACTGTGG CCGGCTGGGT GTGGCGGACC GCTATCAGGA CATAGCGTTG GCTACCCGTG ATATTGCTGA AGAGCTTGGC GGCGAATGGG CTGACCGCTT CCTCGTGCTT TACGGTATCG CCGCTCCCGA TTCGCAGCGC ATCGCCTTCT ATCGCCTTCT TGACGAGTTC TTCTGAGCGG GACTCTGGGG TTCGAAATGA CCGACCAAGC GACGCCCAAC CTGCCATCAC GAGATTTCGA TTCCACCGCC GCCTTCTATG AAAGGTTGGG CTTCGGAATC GTTTTCCGGG ACGCCGGCTG GATGATCCTC CAGCGCGGGG ATCTCATGCT GGAGTTCTTC GCCCACCCTA GGGGGAGGCT 
AACTGAAACA CGGAAGGAGA CAATACCGGA AGGAACCCGC GCTATGACGG CAATAAAAAG ACAGAATAAA ACGCACGGTG TTGGGTCGTT TGTTCATAAA CGCGGGGTTC GGTCCCAGGG CTGGCACTCT GTCGATACCC CACCGAGACC CCATTGGGGC CAATACGCCC GCGTTTCTTC CTTTTCCCCA CCCCACCCCC CAAGTTCGGG TGAAGGCCCA GGGCTCGCAG CCAACGTCGG GGCGGCAGGC CCTGCCATAG CCTCAGGTTA CTCATATATA CTTTAGATTG ATTTAAAACT TCATTTTTAA TTTAAAAGGA TCTAGGTGAA GATCCTTTTT GATAATCTCA TGACCAAAAT CCCTTAACGT GAGTTTTCGT TCCACTGAGC GTCAGACCCC GTAGAAAAGA TCAAAGGATC TTCTTGAGAT CCTTTTTTTC TGCGCGTAAT CTGCTGCTTG CAAACAAAAA AACCACCGCT ACCAGCGGTG GTTTGTTTGC CGGATCAAGA GCTACCAACT CTTTTTCCGA AGGTAACTGG CTTCAGCAGA GCGCAGATAC CAAATACTGT CCTTCTAGTG TAGCCGTAGT TAGGCCACCA CTTCAAGAAC TCTGTAGCAC CGCCTACATA CCTCGCTCTG CTAATCCTGT TACCAGTGGC TGCTGCCAGT GGCGATAAGT CGTGTCTTAC CGGGTTGGAC TCAAGACGAT AGTTACCGGA TAAGGCGCAG CGGTCGGGCT GAACGGGGGG TTCGTGCACA CAGCCCAGCT TGGAGCGAAC GACCTACACC GAACTGAGAT ACCTACAGCG TGAGCTATGA GAAAGCGCCA CGCTTCCCGA AGGGAGAAAG GCGGACAGGT ATCCGGTAAG CGGCAGGGTC GGAACAGGAG AGCGCACGAG GGAGCTTCCA GGGGGAAACG CCTGGTATCT TTATAGTCCT GTCGGGTTTC GCCACCTCTG ACTTGAGCGT CGATTTTTGT GATGCTCGTC AGGGGGGCGG AGCCTATGGA AAAACGCCAG CAACGCGGCC TTTTTACGGT TCCTGGCCTT TTGCTGGCCT TTTGCTCACA TGTTCTTTCC TGCGTTATCC CCTGATTCTG TGGATAACCG TATTACCGCC ATGCAT

$---:$ HindIII

---: Primer pAcGFPf/r

$---:$ BamHI

---: EcoRI

---: TRIM22

---: Primer TRIM22

gatc: Kan/Neo-Resistenz

\subsection{Antiserum-Nullserum}

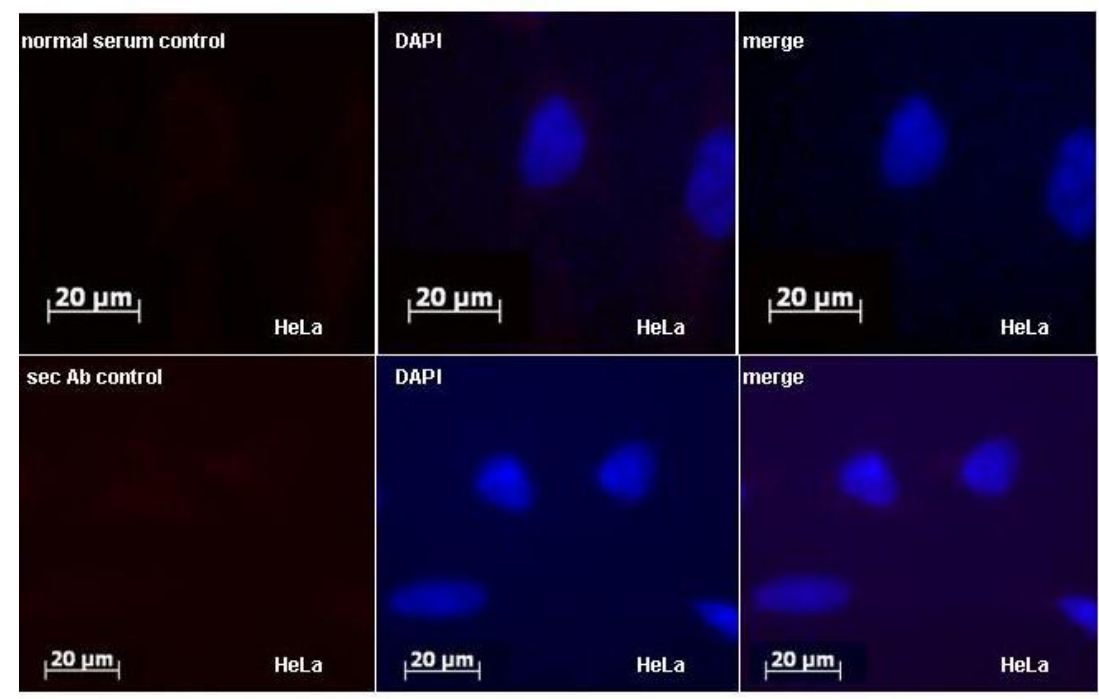




\subsection{Luziferase-Rohdaten}

\section{Versuch 1:}

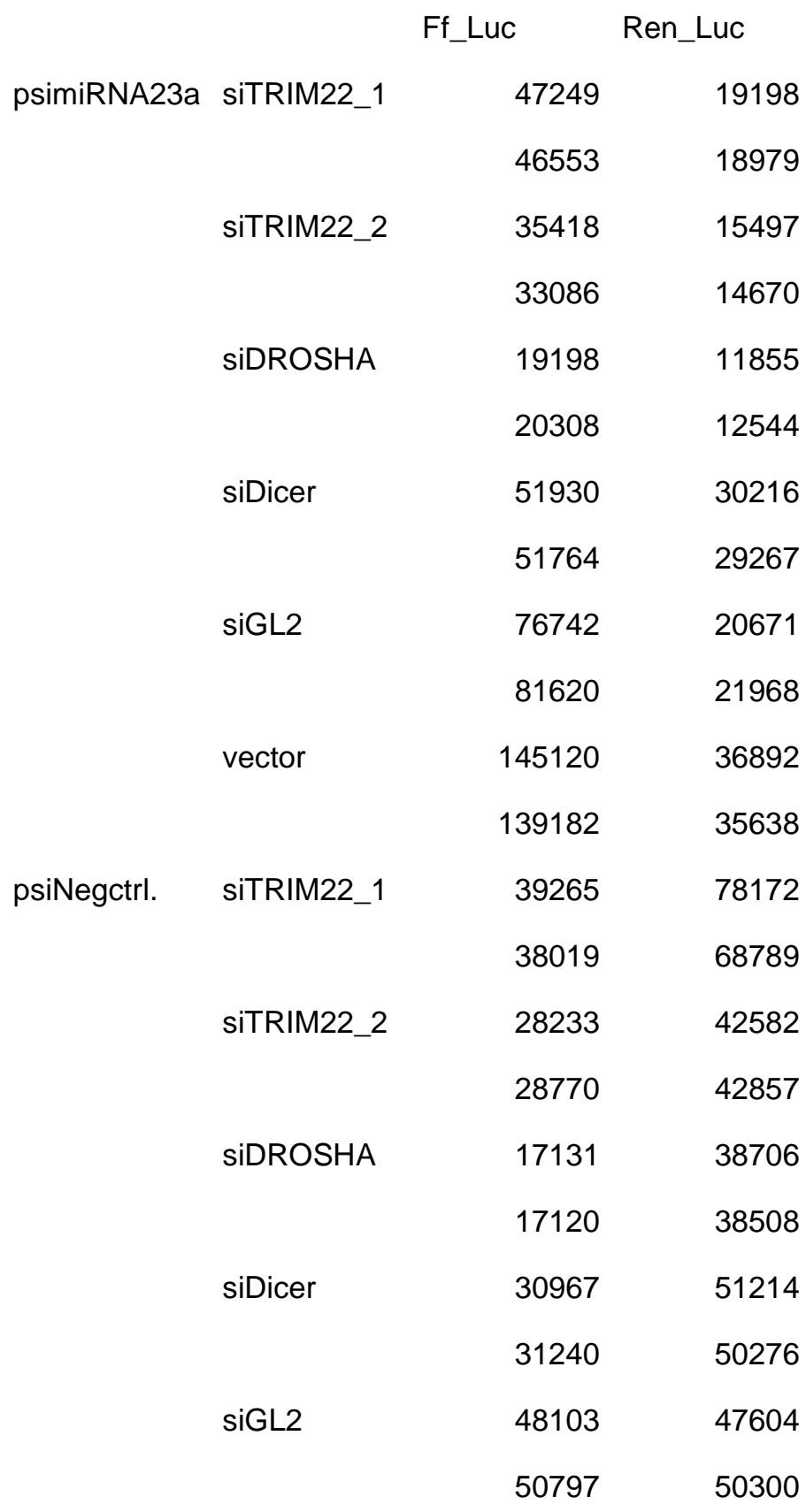

Versuch 2:

\begin{tabular}{rrrr}
\multirow{2}{*}{ psimiRNA23a } & 71389 & 15381 \\
\cline { 2 - 3 } & sitRIM22_1 & 70988 & 15753 \\
& & 61947 & 15890 \\
siTRIM22_2 & 60188 & 15296 \\
& 30908 & 10433 \\
sidROSHA & 35651 & 12417
\end{tabular}




\begin{tabular}{|c|c|c|c|}
\hline & & 62761 & 21061 \\
\hline & siDicer & 63909 & 21797 \\
\hline & & 113668 & 16349 \\
\hline & siGL2 & 112264 & 16059 \\
\hline & & 140592 & 19402 \\
\hline & vector & 129177 & 16339 \\
\hline & & 47452 & 53104 \\
\hline psiNegctrl. & siTRIM22_1 & 48501 & 53073 \\
\hline & & 41806 & 32812 \\
\hline & siTRIM22_2 & 43880 & 29061 \\
\hline & & 24054 & 24811 \\
\hline & siDROSHA & 24732 & 25001 \\
\hline & & 42723 & 44148 \\
\hline & siDicer & 44936 & 44600 \\
\hline & & 63631 & 32163 \\
\hline & siGL2 & 64108 & 33532 \\
\hline & & 101876 & 81675 \\
\hline & vector & 87299 & 63252 \\
\hline
\end{tabular}

\section{Versuch 3:}

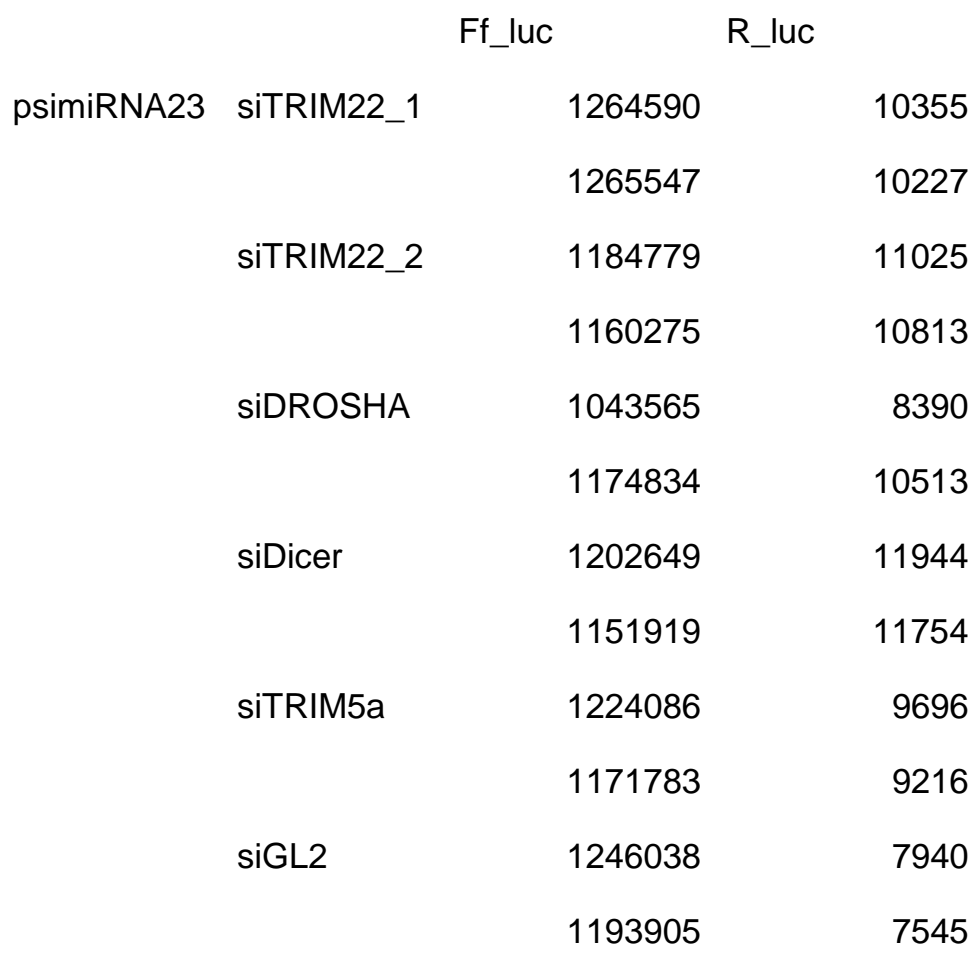




\begin{tabular}{|c|c|c|c|}
\hline psiNegctrl. & siTRIM22_1 & 470833 & 42486 \\
\hline & & 470084 & 42363 \\
\hline & siTRIM22_2 & 589748 & 46739 \\
\hline & & 594542 & 47224 \\
\hline & siDROSHA & 520763 & 40959 \\
\hline & & 492811 & 35890 \\
\hline & siDicer & 457249 & 42813 \\
\hline & & 442908 & 40121 \\
\hline & siTRIM5a & 554417 & 42485 \\
\hline & & 541131 & 41554 \\
\hline & siGL2 & 674153 & 2271 \\
\hline & & 637763 & 20416 \\
\hline
\end{tabular}

\subsection{TUNEL-Test-Rohdaten}

\begin{tabular}{lrrrrr} 
TUNEL-positiv sind: & \multicolumn{1}{c}{ siTrim1 } & siTrim2 & siGL2 & WT \\
Exp.1-\% & 27,4 & 43,07 & 9,87 & 0,91 \\
& & & & & \\
Exp.2\% & 51,63 & 53,26 & 16,75 & 0,27 \\
& & & & & \\
& siTRIM22-1 & siTRIM22-2 & siGL2 & WT & \\
Mittelwert Exp. 1 und 2 & 39,515 & 48,165 & 13,31 & 0,59 \\
STABW & 17,13319731 & 28,27097628 & 8,419360625 & 1,18 \\
& & & & & \\
Exp.1-2: & siTrim1 & siTrim2 & siGL2 & Wildtyp \\
Gesamtzellzahl & 2475 & 2058 & 3541 & 3614 \\
TUNEL-positiv & 1049 & 1065 & 423 & 24
\end{tabular}




\subsection{Quantitative-Echtzeit-PCR-Rohdaten}

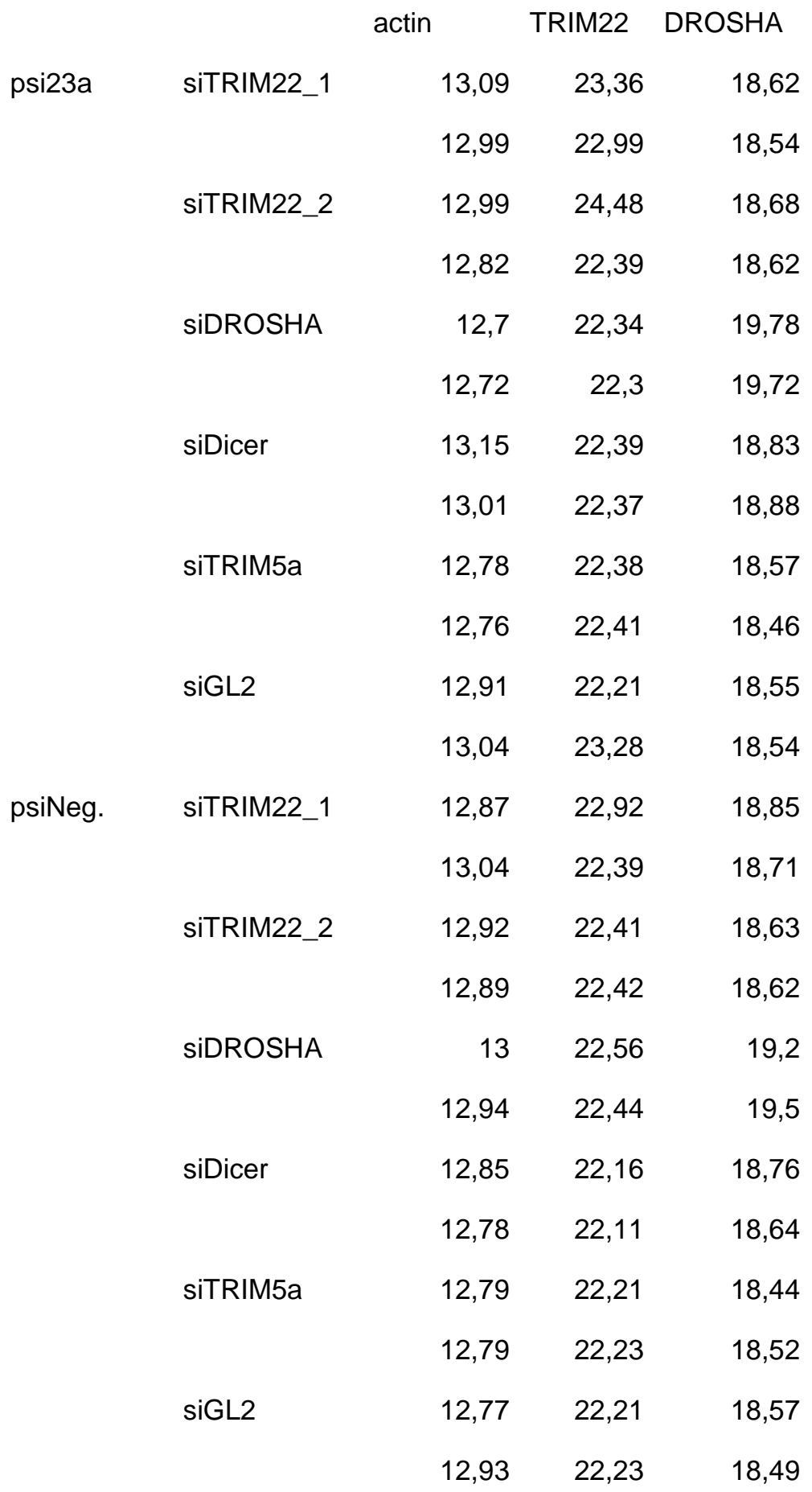

HEK-293-Zellen:

actin

TRIM22

DROSHA

no template

36,24

no template

35,97

292 siTrim22(2)

15,02

21,58

21,58

293 siDicer

14,88

21,65

19,84

293 siDicer

15,79

21,72

19,61 


$\begin{array}{lrrr}293 \text { siDROSHA } & 15,39 & 21,44 & 23,06 \\ 293 \text { siDROSHA } & 15,07 & 21,63 & 22,56 \\ 293 \text { siGL2 } & 15,73 & 21,07 & 21,07 \\ 293 \text { siGL2 } & 15,7 & 20,93 & 19,93 \\ 293 \text { siTrim22 } & 15,83 & 22,66 & 20,06 \\ 293 \text { siTrim22 } & 16,02 & 23,06 & 20 \\ 293 \text { siTrim22(1) } & 15,08 & 22,72 & 20,07 \\ 293 \text { siTrim22(1) } & 14,16 & 22,07 & 20,09 \\ 293 \text { siTrim22(2) } & 15 & 22,99 & 21,66 \\ 293 \text { siTrim5alpha } & 14,67 & 20 & 22 \\ 293 \text { siTrim5alpha } & 14,41 & 19,63 & 23,63 \\ 293 \text { Trim22 GFP } & 16,47 & 15,65 & 21,95 \\ 293 \text { Trim22 GFP } & 16,43 & 15,28 & 21,6 \\ \text { Trim22 psiempty } & 15,49 & 14,31 & 20,28 \\ \text { Trim22 psiempty } & 15,35 & 14,3 & 20,15\end{array}$




\section{Literaturverzeichnis}

Ahlquist $P$ (2002): RNA-dependent RNA polymerases, viruses, and RNA silencing. Science 296, 1270-1273.

Andersen JS, Wilkinson CJ, Mayor T, Mortensen P, Nigg EA, Mann M (2003): Proteomic characterization of the human centrosome by protein correlation profiling. Nature $\underline{426}, 570-574$.

Arriagada G, Muntean LN, Goff SP (2011): SUMO-interacting motifs of human TRIM5alpha are important for antiviral activity. PLoS. Pathog. $\underline{7}$, e1002019.

Asselin-Paturel C, Boonstra A, Dalod M, Durand I, Yessaad N, Dezutter-Dambuyant C, Vicari A, O'Garra A, Biron C, Briere F, Trinchieri G (2001): Mouse type I IFN-producing cells are immature APCs with plasmacytoid morphology. Nat. Immunol. 2 (12), 1144-1150.

Barr SD, Smiley JR, Bushman FD (2008): The interferon response inhibits HIV particle production by induction of TRIM22. PLoS. Pathog. 4, e1000007.

Barrett MT, Pritchard D, Palanca-Wessels C, Anderson J, Reid BJ, Rabinovitch PS (2003): Molecular phenotype of spontaneously arising 4N (G2-tetraploid) intermediates of neoplastic progression in Barrett's esophagus. Cancer Res. $\underline{63}, 4211-4217$.

Bartel DP, Chen CZ (2004): Micromanagers of gene expression: the potentially widespread influence of metazoan microRNAs. Nat. Rev. Genet. $\underline{5}, 396-400$.

Bernstein E, Caudy AA, Hammond SM, Hannon GJ (2001): Role for a bidentate ribonuclease in the initiation step of RNA interference. Nature 409, 363-366.

Bernstein E, Kim SY, Carmell MA, Murchison EP, Alcorn H, Li MZ, Mills AA, Elledge SJ, Anderson KV, Hannon GJ (2003): Dicer is essential for mouse development. Nat. Genet. 35, 215-217.

Biron CA, Nguyen KB, Pien GC, Cousens LP, Salazar-Mather TP (1999): Natural killer cells in antiviral defense: function and regulation by innate cytokines. Annu. Rev. Immunol. 17, 189-220.

Blumberg H, Eisen A, Sledziewski A, Bader D, Young ET (1987): Two zinc fingers of a yeast regulatory protein shown by genetic evidence to be essential for its function. Nature $\underline{328}, 443-445$.

Boehm M, Slack FJ (2006): MicroRNA control of lifespan and metabolism. Cell Cycle $\underline{5(8)}, 837-840$. 
Bornens M (2002): Centrosome composition and microtubule anchoring mechanisms. Curr. Opin. Cell Biol. 14, 25-34.

Bouazzaoui A, Kreutz M, Eisert V, Dinauer N, Heinzelmann A, Hallenberger S, Strayle J, Walker R, Rubsamen-Waigmann $\mathrm{H}$, Andreesen R, von Briesen $\mathrm{H}$ (2006): Stimulated trans-acting factor of $50 \mathrm{kDa}$ (Staf50) inhibits HIV-1 replication in human monocyte-derived macrophages. Virology $\underline{356}, 79-94$.

Brameier M, Herwig A, Reinhardt R, Walter L, Gruber J (2011): Human box C/D snoRNAs with miRNA like functions: expanding the range of regulatory RNAs. Nucleic Acids Res. 39, 675-686.

Brocker C, Thompson D, Matsumoto A, Nebert DW, Vasiliou V (2010): Evolutionary divergence and functions of the human interleukin (IL) gene family. Hum. Genomics $\underline{5}, 30-55$.

Brown RS (2005): Zinc finger proteins: getting a grip on RNA. Curr. Opin. Struct. Biol. $\underline{15}, 94-98$.

Buehrlen M, Zwaan CM, Granzen B, Lassay L, Deutz P, Vorwerk P, Staatz G, Gademann G, Christiansen H, Oldenburger F, Tamm M, Mertens R (2012): Multimodal treatment, including interferon beta, of nasopharyngeal carcinoma in children and young adults: Preliminary results from the prospective, multicenter study NPC-2003-GPOH/DCOG. Cancer

Cameron IL, Greulich RC (1963): Evidence for an essentially constant duration of DNA synthesis in renewing epithelia of the adult mouse. J. Cell Biol. 18, 3140.

Cenik ES, Zamore PD (2011): Argonaute proteins. Curr. Biol. 21, R446-449.

Coller J, Parker R (2004): Eukaryotic mRNA decapping. Annu. Rev. Biochem. $\underline{73}$, 861-890.

Compton DA (2000): Spindle assembly in animal cells. Annu. Rev. Biochem. $\underline{69}$, 95114.

Crick FH (1952): Is alpha-keratin a coiled coil? Nature 170, 882-883.

de Boer JG, Yazawa R, Davidson WS, Koop BF (2007): Bursts and horizontal evolution of DNA transposons in the speciation of pseudotetraploid salmonids. BMC Genomics $\underline{8}, 422$.

Duan Z, Gao B, Xu W, Xiong S (2008): Identification of TRIM22 as a RING finger E3 ubiquitin ligase. Biochem. Biophys. Res. Commun. 374, 502-506.

Elbashir SM, Harborth J, Lendeckel W, Yalcin A, Weber K, Tuschl T (2001): Duplexes of 21-nucleotide RNAs mediate RNA interference in cultured mammalian cells. Nature $\underline{411}$, 494-498. 
Fabian MR, Mathonnet G, Sundermeier T, Mathys H, Zipprich JT, Svitkin YV, Rivas F, Jinek M, Wohlschlegel J, Doudna JA, Chen CY, Shyu AB, Yates JR, 3rd, Hannon GJ, Filipowicz W, Duchaine TF, Sonenberg N (2009): Mammalian miRNA RISC recruits CAF1 and PABP to affect PABP-dependent deadenylation. Mol. cell $\underline{35}, 868-880$.

Fenizia C, Keele BF, Nichols D, Cornara S, Binello N, Vaccari M, Pegu P, RobertGuroff M, Ma ZM, Miller CJ, Venzon D, Hirsch V, Franchini G (2011): TRIM5alpha does not affect simian immunodeficiency virus SIV(mac251) replication in vaccinated or unvaccinated Indian rhesus macaques following intrarectal challenge exposure. J. Virol. $\underline{85}, 12399-12409$.

Freemont PS (2000): RING for destruction? Curr. Biol. 10, R84-87.

Gabler S, Schutt H, Groitl P, Wolf H, Shenk T, Dobner T (1998): E1B 55-kilodaltonassociated protein: a cellular protein with RNA-binding activity implicated in nucleocytoplasmic transport of adenovirus and cellular mRNAs. J. Virol. $\underline{72}$, 7960-7971.

Gack MU, Shin YC, Joo CH, Urano T, Liang C, Sun L, Takeuchi O, Akira S, Chen Z, Inoue S, Jung JU (2007): TRIM25 RING-finger E3 ubiquitin ligase is essential for RIG-I-mediated antiviral activity. Nature $\underline{446}$, 916-920.

Gamsjaeger R, Liew CK, Loughlin FE, Crossley M, Mackay JP (2007): Sticky fingers: zinc-fingers as protein-recognition motifs. Trends Biochem. Sci. 32, 63-70.

Gao B, Duan Z, Xu W, Xiong S (2009): Tripartite motif-containing 22 inhibits the activity of hepatitis $B$ virus core promoter, which is dependent on nuclearlocated RING domain. Hepatology $\underline{50}$, 424-433.

Glotzer M (2005): The molecular requirements for cytokinesis. Science $\underline{307}, 1735-$ 1739.

Gonzalez M, Li F (2012): DNA replication, RNAi and epigenetic inheritance. Epigenetics $\underline{7}$,

Grutter MG, Luban J (2012): TRIM5 structure, HIV-1 capsid recognition, and innate immune signaling. Curr. Opin. Virol. 2, 142-150.

Haasnoot J, Westerhout EM, Berkhout B (2007): RNA interference against viruses: strike and counterstrike. Nat. Biotechnol. 25, 1435-1443.

Hall TM (2005): Multiple modes of RNA recognition by zinc finger proteins. Curr. Opin. Struct. Biol. 15, 367-373.

Hamilton AJ, Baulcombe DC (1999): A species of small antisense RNA in posttranscriptional gene silencing in plants. Science 286, 950-952.

Hatziioannou T, Perez-Caballero D, Yang A, Cowan S, Bieniasz PD (2004): Retrovirus resistance factors Ref1 and Lv1 are species-specific variants of TRIM5alpha. Proc. Natl. Acad. Sci. U S A 101, 10774-10779. 
Herr AM: Analysen zu TRIM-Genen in Primaten, Biol. Dissertation Universität Göttingen, 2008.

Herr AM, Dressel R, Walter L (2009): Different subcellular localisations of TRIM22 suggest species-specific function. Immunogenetics $\underline{61}, 271-280$.

Hilton DJ, Richardson RT, Alexander WS, Viney EM, Willson TA, Sprigg NS, Starr R, Nicholson SE, Metcalf D, Nicola NA (1998): Twenty proteins containing a Cterminal SOCS box form five structural classes. Proc. Natl. Acad. Sci. U S A 95, 114-119.

Hirokawa N, Noda Y, Okada Y (1998): Kinesin and dynein superfamily proteins in organelle transport and cell division. Curr. Opin. Cell. Biol. 10, 60-73.

Horn EJ, Albor A, Liu Y, El-Hizawi S, Vanderbeek GE, Babcock M, Bowden GT, Hennings H, Lozano G, Weinberg WC, Kulesz-Martin M (2004): RING protein Trim32 associated with skin carcinogenesis has anti-apoptotic and E3ubiquitin ligase properties. Carcinogenesis $\underline{25}, 157-167$.

Hu X, Hipolito S, Lynn R, Abraham V, Ramos S, Wong-Staal F (2004): Relative gene-silencing efficiencies of small interfering RNAs targeting sense and antisense transcripts from the same genetic locus. Nucleic Acids Res. $\underline{32}$, 4609-4617.

Hutvagner G, McLachlan J, Pasquinelli AE, Balint E, Tuschl T, Zamore PD (2001): A cellular function for the RNA-interference enzyme Dicer in the maturation of the let-7 small temporal RNA. Science 293, 834-838.

Jackson AL, Bartz SR, Schelter J, Kobayashi SV, Burchard J, Mao M, Li B, Cavet G, Linsley PS (2003): Expression profiling reveals off-target gene regulation by RNAi. Nat. Biotechnol. 21, 635-637.

Janowski BA, Corey DR (2010): Minireview: Switching on progesterone receptor expression with duplex RNA. J. Mol. Endocrinol. 24, 2243-2252.

Kahvejian A, Svitkin YV, Sukarieh R, M'Boutchou MN, Sonenberg N (2005): Mammalian poly(A)-binding protein is a eukaryotic translation initiation factor, which acts via multiple mechanisms. Genes Dev. 19, 104-113.

Kaminskyy V, Zhivotovsky B (2010): To kill or be killed: how viruses interact with the cell death machinery. J. Intern. Med. 267, 473-482.

Karpov AV (2001): Endogenous and exogenous interferons in HIV-infection. Eur. J. Med. Res. $\underline{6}, 507-524$.

Kawamata T, Tomari Y (2010): Making RISC. Trends Biochem. Sci. 포, 368-376.

Keckesova Z, Ylinen LM, Towers GJ (2004): The human and African green monkey TRIM5alpha genes encode Ref1 and Lv1 retroviral restriction factor activities. Proc. Natl. Acad. Sci. U S A 101, 10780-10785. 
Kim AJ, Endow SA (2000): A kinesin family tree. J. Cell. Sci. 113 Pt 21, 3681-3682.

Kim DH, Saetrom P, Snove O, Jr., Rossi JJ (2008): MicroRNA-directed transcriptional gene silencing in mammalian cells. Proc. Natl. Acad. Sci. U S A $\underline{105}, 16230-16235$.

Kim VN, Nam JW (2006): Genomics of microRNA. Trends Genet. 22, 165-173.

Laemmli UK (1970): Cleavage of structural proteins during the assembly of the head of bacteriophage T4. Nature 227, 680-685.

Lagos-Quintana M, Rauhut R, Lendeckel W, Tuschl T (2001): Identification of novel genes coding for small expressed RNAs. Science 294, 853-858.

Lee Y, Ahn C, Han J, Choi H, Kim J, Yim J, Lee J, Provost P, Radmark O, Kim S, Kim VN (2003): The nuclear RNase III Drosha initiates microRNA processing. Nature $\underline{425}, 415-419$.

Lee Y, Jeon K, Lee JT, Kim S, Kim VN (2002): MicroRNA maturation: stepwise processing and subcellular localization. EMBO J. 21 , 4663-4670.

Lewis BP, Shih IH, Jones-Rhoades MW, Bartel DP, Burge CB (2003): Prediction of mammalian microRNA targets. Cell 115, 787-798.

Li X, Gold B, O'HUigin C, Diaz-Griffero F, Song B, Si Z, Li Y, Yuan W, Stremlau M, Mische C, Javanbakht H, Scally M, Winkler C, Dean M, Sodroski J (2007): Unique features of TRIM5alpha among closely related human TRIM family members. Virology $\underline{360}, 419-433$.

Lin VC, Eng AS, Hen NE, Ng EH, Chowdhury SH (2001): Effect of progesterone on the invasive properties and tumor growth of progesterone receptor-transfected breast cancer cells MDA-MB-231. Clin. Cancer Res. ㄱ, 2880-2886.

Lin VC, Ng EH, Aw SE, Tan MG, Ng EH, Chan VS, Ho GH (1999): Progestins inhibit the growth of MDA-MB-231 cells transfected with progesterone receptor complementary DNA. Clin. Cancer Res. $\underline{5}$, 395-403.

Liu J, Valencia-Sanchez MA, Hannon GJ, Parker R (2005): MicroRNA-dependent localization of targeted mRNAs to mammalian P-bodies. Nat. Cell Biol. $\underline{7}, 719$ 723.

Liu J, Zheng Q, Deng Y, Cheng CS, Kallenbach NR, Lu M (2006): A seven-helix coiled coil. Proc. Natl. Acad. Sci. U S A $\underline{103}$, 15457-15462.

Lund E, Guttinger S, Calado A, Dahlberg JE, Kutay U (2004): Nuclear export of microRNA precursors. Science $\underline{303}, 95-98$.

Martin SE, Caplen NJ (2007): Applications of RNA interference in mammalian systems. Annu. Rev. Genomics Hum. Genet. $\underline{8}, 81-108$. 
Massiah MA, Simmons BN, Short KM, Cox TC (2006): Solution structure of the RBCC/TRIM B-box1 domain of human MID1: B-box with a RING. J. Mol. Biol. $\underline{358}, 532-545$.

McIntosh JR, Koonce MP (1989): Mitosis. Science 246, 622-628.

Meister G, Landthaler M, Patkaniowska A, Dorsett Y, Teng G, Tuschl T (2004): Human Argonaute2 mediates RNA cleavage targeted by miRNAs and siRNAs. Mol. Cell $\underline{15}, 185-197$.

Meister G, Tuschl T (2004): Mechanisms of gene silencing by double-stranded RNA. Nature $431,343-349$.

Meroni G, Diez-Roux G (2005): TRIM/RBCC, a novel class of 'single protein RING finger' E3 ubiquitin ligases. Bioessays $\underline{27}, 1147-1157$.

Moore A, Donahue CJ, Bauer KD, Mather JP (1998): Simultaneous measurement of cell cycle and apoptotic cell death. Method Cell. Biol. 57, 265-278.

Morris KV (2009): RNA-directed transcriptional gene silencing and activation in human cells. Oligonucleotides $\underline{19}, 299-306$.

Motomura K, Natsume A, Kishida Y, Higashi H, Kondo Y, Nakasu Y, Abe T, Namba H, Wakai K, Wakabayashi T (2011): Benefits of interferon-beta and temozolomide combination therapy for newly diagnosed primary glioblastoma with the unmethylated MGMT promoter: A multicenter study. Cancer $\underline{117}$, 1721-1730.

Mullis KB, Faloona FA (1987): Specific synthesis of DNA in vitro via a polymerasecatalyzed chain reaction. Meth. Enzymol. 155, 335-350.

Munoz-Fontela C, Macip S, Martinez-Sobrido L, Brown L, Ashour J, Garcia-Sastre A, Lee SW, Aaronson SA (2008): Transcriptional role of p53 in interferonmediated antiviral immunity. J. Exp. Med. 205, 1929-1938.

Musacchio A (2011): Spindle assembly checkpoint: the third decade. Philos. Trans. R. Soc. Lond. B. Biol. Sci. 366, 3595-3604.

Muthukrishnan S, Both GW, Furuichi Y, Shatkin AJ (1975): 5'-Terminal 7methylguanosine in eukaryotic mRNA is required for translation. Nature $\underline{255}$, 33-37.

Nair MP, Reynolds JL, Mahajan SD, Schwartz SA, Aalinkeel R, Bindukumar B, Sykes D (2005): RNAi-directed inhibition of DC-SIGN by dendritic cells: prospects for HIV-1 therapy. Aaps J. $\underline{7}$, E572-578.

Neagu MR, Ziegler P, Pertel T, Strambio-De-Castillia C, Grutter C, Martinetti G, Mazzucchelli L, Grutter M, Manz MG, Luban J (2009): Potent inhibition of HIV1 by TRIM5-cyclophilin fusion proteins engineered from human components. J. Clin. Invest. 119, 3035-3047. 
Nicoletti I, Migliorati G, Pagliacci MC, Grignani F, Riccardi C (1991): A rapid and simple method for measuring thymocyte apoptosis by propidium iodide staining and flow cytometry. J. Immunol. Methods 139, 271-279.

Nisole S, Stoye JP, Saib A (2005): TRIM family proteins: retroviral restriction and antiviral defence. Nat. Rev. Microbiol. $\underline{3}, 799-808$.

Obad S, Brunnstrom H, Vallon-Christersson J, Borg A, Drott K, Gullberg U (2004): Staf50 is a novel p53 target gene conferring reduced clonogenic growth of leukemic U-937 cells. Oncogene $\underline{23}$, 4050-4059.

Obad S, Olofsson T, Mechti N, Gullberg U, Drott K (2007a): Expression of the IFNinducible p53-target gene TRIM22 is down-regulated during erythroid differentiation of human bone marrow. Leuk. Res. 31, 995-1001.

Obad S, Olofsson T, Mechti N, Gullberg U, Drott K (2007b): Regulation of the interferon-inducible p53 target gene TRIM22 (Staf50) in human T lymphocyte activation. J. Interferon Cytokine Res. 27, 857-864.

Olaharski AJ, Sotelo R, Solorza-Luna G, Gonsebatt ME, Guzman P, Mohar A, Eastmond DA (2006): Tetraploidy and chromosomal instability are early events during cervical carcinogenesis. Carcinogenesis 27, 337-343.

Parker R, Sheth U (2007): $\mathrm{P}$ bodies and the control of mRNA translation and degradation. Mol. Cell 25, 635-646.

Perron MJ, Stremlau M, Song B, Ulm W, Mulligan RC, Sodroski J (2004): TRIM5alpha mediates the postentry block to $\mathrm{N}$-tropic murine leukemia viruses in human cells. Proc. Natl. Acad. Sci. U S A 101, 11827-11832.

Petersson J, Ageberg M, Sanden C, Olofsson T, Gullberg U, Drott K (2012): The p53 target gene TRIM22 directly or indirectly interacts with the translation initiation factor elF4E and inhibits the binding of elF4E to elF4G. Biol. Cell 104:462-75

Petersson J, Lonnbro P, Herr AM, Morgelin M, Gullberg U, Drott K (2009): The human IFN-inducible p53 target gene TRIM22 colocalizes with the centrosome independently of cell cycle phase. Exp. Cell Res. $\underline{316}, 568-$ 79

Pillai RS (2005): MicroRNA function: multiple mechanisms for a tiny RNA? RNA $\underline{11}$, 1753-1761.

Ponting C, Schultz J, Bork P (1997): SPRY domains in ryanodine receptors (Ca(2+)release channels). Trends Biochem. Sci. 22, 193-194.

Reiter Z (1993): Interferon--a major regulator of natural killer cell-mediated cytotoxicity. J. Interferon Res. 13, 247-257.

Reymond A, Meroni G, Fantozzi A, Merla G, Cairo S, Luzi L, Riganelli D, Zanaria E, Messali S, Cainarca S, Guffanti A, Minucci S, Pelicci PG, Ballabio A (2001): 
The tripartite motif family identifies cell compartments. EMBO J. $\underline{20}, 2140-$ 2151.

Rhoades MW, Reinhart BJ, Lim LP, Burge CB, Bartel B, Bartel DP (2002): Prediction of plant microRNA targets. Cell $\underline{110}, 513-520$.

Rieseberg LH, Willis JH (2007): Plant speciation. Science 317, 910-914.

Rosenblum MG, Yung WK, Kelleher PJ, Ruzicka F, Steck PA, Borden EC (1990): Growth inhibitory effects of interferon-beta but not interferon-alpha on human glioma cells: correlation of receptor binding, 2',5'-oligoadenylate synthetase and protein kinase activity. J. Interferon Res. 10, 141-151.

Rosewicz S, Detjen K, Scholz A, von Marschall Z (2004): Interferon-alpha: regulatory effects on cell cycle and angiogenesis. Neuroendocrinology 80 Suppl 1, 85-93.

Sambrook J, Gething MJ (1989): Protein structure. Chaperones, paperones. Nature 342, 224-225.

Saurin AJ, Borden KL, Boddy MN, Freemont PS (1996): Does this have a familiar RING? Trends Biochem. Sci. 21, 208-214.

Schwarz DS, Tomari Y, Zamore PD (2004): The RNA-induced silencing complex is a Mg2+-dependent endonuclease. Curr. Biol. 14, 787-791.

Sen GL, Blau HM (2005): Argonaute 2/RISC resides in sites of mammalian mRNA decay known as cytoplasmic bodies. Nat. Cell Biol. $\underline{7}, 633-636$.

Shen J, Samul R, Silva RL, Akiyama H, Liu H, Saishin Y, Hackett SF, Zinnen S, Kossen K, Fosnaugh K, Vargeese C, Gomez A, Bouhana K, Aitchison R, Pavco P, Campochiaro PA (2006): Suppression of ocular neovascularization with siRNA targeting VEGF receptor 1. Gene Ther. 13, 225-234.

Short KM, Cox TC (2006): Subclassification of the RBCC/TRIM superfamily reveals a novel motif necessary for microtubule binding. J. Biol. Chem. 281, 8970-8980.

Siomi $\mathrm{H}$, Siomi MC (2009): On the road to reading the RNA-interference code. Nature 457 , 396-404.

Sivaramakrishnan G, Sun Y, Tan SK, Lin VC (2009): Dynamic localization of tripartite motif-containing 22 in nuclear and nucleolar bodies. Exp. Cell Res. $\underline{315}$, 15211532.

Smith JA, Martin L (1973): Do cells cycle? Proc. Natl. Acad. Sci. U S A $\underline{70}$, 12631267.

Stearns T, Evans L, Kirschner M (1991): Gamma-tubulin is a highly conserved component of the centrosome. Cell $\underline{65}, 825-836$.

Storchova Z, Kuffer C (2008): The consequences of tetraploidy and aneuploidy. J. Cell. Sci. 121, 3859-3866. 
Stremlau M, Owens CM, Perron MJ, Kiessling M, Autissier P, Sodroski J (2004): The cytoplasmic body component TRIM5alpha restricts HIV-1 infection in Old World monkeys. Nature $\underline{427}$, 848-853.

Taft RJ, Hawkins PG, Mattick JS, Morris KV (2011): The relationship between transcription initiation RNAs and CCCTC-binding factor (CTCF) localization. Epigenetics Chromatin 4, 13.

Tissot C, Mechti N (1995): Molecular cloning of a new interferon-induced factor that represses human immunodeficiency virus type 1 long terminal repeat expression. J. Biol. Chem. 270, 14891-14898.

Tomari Y, Zamore PD (2005): Perspective: machines for RNAi. Genes Dev. 19, 517529.

Towers GJ, Hatziioannou T, Cowan S, Goff SP, Luban J, Bieniasz PD (2003): Cyclophilin A modulates the sensitivity of HIV-1 to host restriction factors. Nat. Med. $\underline{9}, 1138-1143$.

Trockenbacher A, Suckow V, Foerster J, Winter J, Krauss S, Ropers HH, Schneider R, Schweiger S (2001): MID1, mutated in Opitz syndrome, encodes an ubiquitin ligase that targets phosphatase 2A for degradation. Nat. Genet. 29, 287-294.

Umbach JL, Cullen BR (2009): The role of RNAi and microRNAs in animal virus replication and antiviral immunity. Genes Dev. 23, 1151-1164.

Urano T, Saito T, Tsukui T, Fujita M, Hosoi T, Muramatsu M, Ouchi $\mathrm{Y}$, Inoue S (2002): Efp targets 14-3-3 sigma for proteolysis and promotes breast tumour growth. Nature $\underline{417}, 871-875$.

Vermeulen A, Behlen L, Reynolds A, Wolfson A, Marshall WS, Karpilow J, Khvorova A (2005): The contributions of dsRNA structure to Dicer specificity and efficiency. RNA $\underline{11}, 674-682$.

Vilcek J (2003): Boosting p53 with interferon and viruses. Nat. Immunol. ㄴ, 825-826.

Visa N, Izaurralde E, Ferreira J, Daneholt B, Mattaj IW (1996): A nuclear cap-binding complex binds Balbiani ring pre-mRNA cotranscriptionally and accompanies the ribonucleoprotein particle during nuclear export. J. Cell Biol. 133, 5-14.

Vitale I, Galluzzi L, Castedo M, Kroemer G (2011): Mitotic catastrophe: a mechanism for avoiding genomic instability. Nat. Rev. Mol. Cell Biol. 12, 385-392.

Walther TN, Wittop Koning TH, Schumperli D, Muller B (1998): A 5'-3' exonuclease activity involved in forming the $3^{\prime}$ products of histone pre-mRNA processing in vitro. RNA $\underline{4}, 1034-1046$.

Wittmann S, Wunder C, Zirn B, Furtwangler R, Wegert J, Graf N, Gessler M (2008): New prognostic markers revealed by evaluation of genes correlated with 
clinical parameters in Wilms tumors. Genes Chromosomes Cancer $\underline{47}$, 386395.

Wu RS, Bonner WM (1981): Separation of basal histone synthesis from S-phase histone synthesis in dividing cells. Cell 27, 321-330.

Yen TJ, Li G, Schaar BT, Szilak I, Cleveland DW (1992): CENP-E is a putative kinetochore motor that accumulates just before mitosis. Nature $\underline{359}, 536-539$.

Yi R, Qin Y, Macara IG, Cullen BR (2003): Exportin-5 mediates the nuclear export of pre-microRNAs and short hairpin RNAs. Genes Dev. 17, 3011-3016.

Zamore PD, Tuschl T, Sharp PA, Bartel DP (2000): RNAi: double-stranded RNA directs the ATP-dependent cleavage of mRNA at 21 to 23 nucleotide intervals. Cell 101, 25-33.

Zeng Y, Cullen BR (2005): Efficient processing of primary microRNA hairpins by Drosha requires flanking nonstructured RNA sequences. J. Biol. Chem. 280, 27595-27603.

Zhang J, Das SC, Kotalik C, Pattnaik AK, Zhang L (2004): The latent membrane protein 1 of Epstein-Barr virus establishes an antiviral state via induction of interferon-stimulated genes. J. Biol. Chem. 279 , 46335-46342.

Zirn B, Hartmann O, Samans B, Krause M, Wittmann S, Mertens F, Graf N, Eilers M, Gessler M (2006): Expression profiling of Wilms tumors reveals new candidate genes for different clinical parameters. Int. J. Cancer 118, 1954-1962. 


\section{Abbildungsverzeichnis}

Abb. 1: Struktureller Aufbau der TRIM-Proteine des 11p15-Genclusters. ................. 2

Abb. 2: FACS-Messung nach Annexin-V-Test.................................................... 5

Abb. 3: Schematische Darstellung des Zellzyklus ................................................. 7

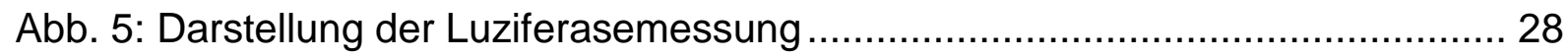

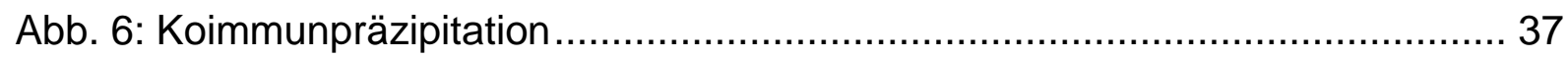

Abb. 7: Unterschiedliche subzelluläre Lokalisationen des TRIM22-GFP................ 45

Abb. 8: Verteilung des endogenen TRIM22 …................................................... 46

Abb. 9: Endogenes TRIM22 kolokalisierte mit $y$-Tubulin in HeLa-Zellen .................. 48

Abb. 10: TRIM22-GFP kolokalisierte nicht mit CENP-E .................................... 49

Abb. 11: Veränderte HeLa-Zellmorphologie durch TRIM22-GFP ........................... 51

Abb. 12: Effekt von TRIM22-GFP in HeLa-Zellen nach 72h ................................ 52

Abb. 13: Dokumentation des TRIM22-Knockdown ............................................. 54

Abb. 14: Darstellung der gestörten Mitose nach TRIM22-Knockdown .................... 55

Abb. 15: Mitose bei siGL-2-transfizierten HeLa-Zellen ....................................... 56

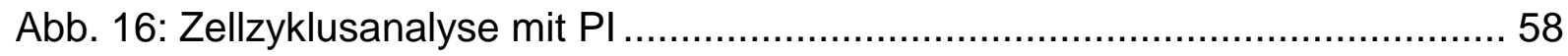

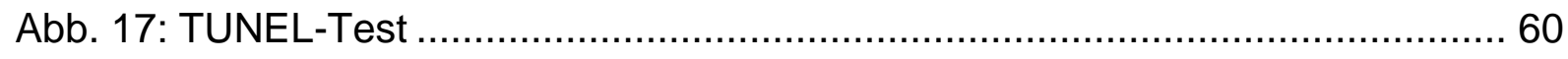

Abb. 18: Anteil apoptotischer Zellen an der Gesamtzellpopulation......................... 61

Abb. 19: IF-Mikroskopie von TRIM22 mit Komponenten der Silencing-Maschinerie 63

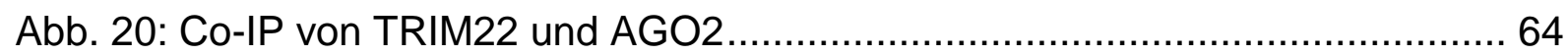

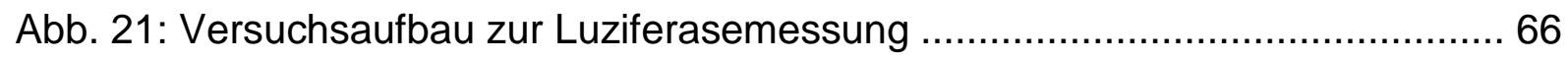

Abb. 22: Luziferasemessung: TRIM22 und Prozessierung der miRNA23a. ............. 68

Abb. 23: Zusammenfassung der drei Versuchsreihen der Luziferasemessung ........ 78

Abb. 24: Problem der dualen Transfektion ...................................................... 79

Abb. 25: Putative Funktion des TRIM22-Proteins in der miRNA-Prozessierung....... 80 


\section{Tabellenverzeichnis}

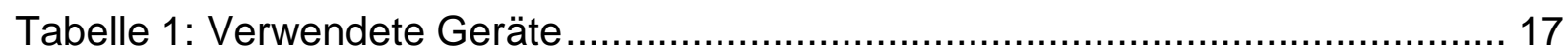

Tabelle 2: Zelllinien und Kulturmedien............................................................. 18

Tabelle 3: Standardchemikalien und Verbrauchsmaterialien .................................. 19

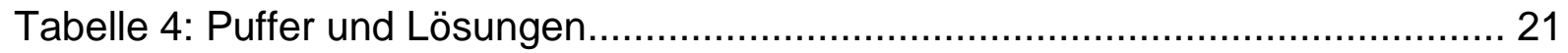

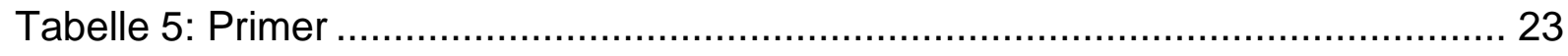

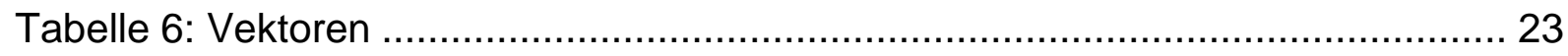

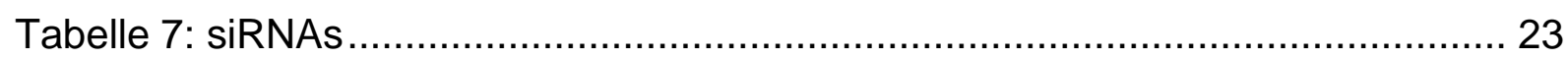

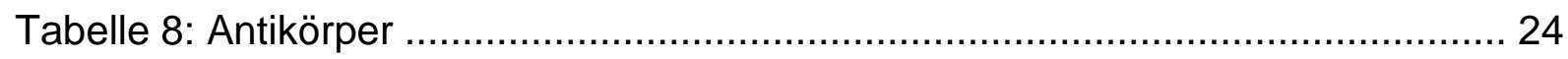

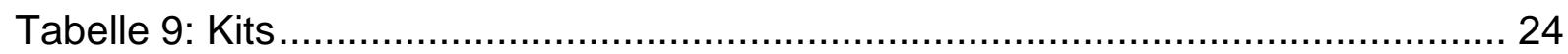

Tabelle 10: SDS-PAGE-Gelzusammensetzung.................................................. 38

Tabelle 11: Zusammenfassung der gefundenen Interaktionen durch Co-IP ............. 76 


\section{Danksagung}

Herrn Prof. Dr. rer. nat. Lutz Walter danke ich für die Vergabe des Themas, für seine ständige Diskussionsbereitschaft, für das große persönliche Engagement bei der Betreuung meiner Arbeit und das anregende Arbeitsklima in seiner Arbeitsgruppe.

Bei Herrn Dr. Jens Gruber will ich mich für brillante Denkanstöße, eine perfekte Betreuung und konstruktive Kaffeepausen bedanken.

Frau Dr. Anna Herr möchte ich für das Einarbeiten in die TRIM-Thematik und wichtige Denkanstöße danken.

Ein ganz besonderer Dank gilt Astrid Backhaus und Nicole Otto für die Hilfestellungen bei der Co-IP und den Luziferaseversuchen.

Für ihre Hilfe bei den FACS-Messungen danke ich Dr. Cornelia Rosner.

Herrn Dr. Markus Brameier, Dr. Christian Roos und Dr. Philip Kruse danke ich für die Hilfestellungen, die ich im Rahmen dieser Arbeit erhalten habe.

Für die ständige Diskussions- und Hilfsbereitschaft und die schönen und lustigen gemeinsamen Stunden im Labor danke ich Dr. Christina Albrecht, Frau Christiane Schwarz, Herrn Nico Westphal und Dr. Maike Hermes.

Frau Mechthild Pohl und allen anderen Mitarbeitern der Primatengenetik danke ich für das angenehme Arbeitsklima und die freundliche Unterstützung.

Ich danke meiner Frau Jana Deuschl und meiner Mutter Edelgard Deuschl für das Korrekturlesen der Arbeit 